NISTIR 7622

\title{
Notional Supply Chain Risk Management Practices for Federal Information Systems
}

\author{
Jon Boyens \\ Celia Paulsen \\ Nadya Bartol \\ Rama Moorthy \\ Stephanie Shankles
}

http://dx.doi.org/10.6028/NIST.IR.7622

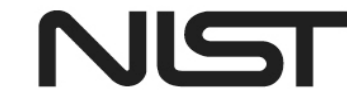

National Institute of Standards and Technology U.S. Department of Commerce 
NISTIR 7622

\title{
Notional Supply Chain Risk Management Practices for Federal Information Systems
}

\author{
Jon Boyens \\ Celia Paulsen \\ Computer Security Division \\ Information Technology Laboratory
}

Nadya Bartol

Stephany A. Shankles

Booz Allen Hamilton

Rama Moorthy

Hatha Systems

http://dx.doi.org/10.6028/NIST.IR.7622

October 2012

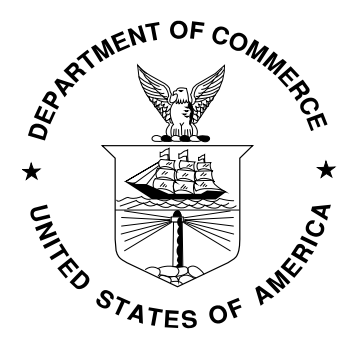

U.S. Department of Commerce Rebecca Blank, Acting Secretary

National Institute of Standards and Technology Patrick D. Gallagher, Under Secretary of Commerce for Standards and Technology and Director 


\section{Reports on Computer Systems Technology}

The Information Technology Laboratory (ITL) at the National Institute of Standards and Technology (NIST) promotes the U.S. economy and public welfare by providing technical leadership for the Nation's measurement and standards infrastructure. ITL develops tests, test methods, reference data, proof of concept implementations, and technical analyses to advance the development and productive use of information technology. ITL's responsibilities include the development of management, administrative, technical, and physical standards and guidelines for the cost-effective security and privacy of other than national security-related information in Federal information systems 


\section{NIST Interagency Reports}

NIST Interagency or Internal Reports (NISTIRs) describe research of a technical nature of interest to a specialized audience. The series include interim or final reports on work performed by NIST for outside sponsors (both government and nongovernment). NISTIRs may also report results of NIST projects of transitory or limited interest, including those that will be published subsequently in more comprehensive form. ${ }^{1}$

\footnotetext{
${ }^{1}$ http://csrc.nist.gov/publications/PubsNISTIRs.html
} 


\title{
Authority
}

This publication has been developed by NIST to further its statutory responsibilities under the Federal Information Security Management Act (FISMA), Public Law (P.L.) 107-347. NIST is responsible for developing information security standards and guidelines, including minimum requirements for Federal information systems, but such standards and guidelines shall not apply to national security systems without the express approval of appropriate Federal officials exercising policy authority over such systems. This guideline is consistent with the requirements of the Office of Management and Budget (OMB) Circular A-130, Section 8b(3), Securing Agency Information Systems, as analyzed in Circular A-130, Appendix IV: Analysis of Key Sections. Supplemental information is provided in Circular A-130, Appendix III, Security of Federal Automated Information Resources.

Nothing in this publication should be taken to contradict the standards and guidelines made mandatory and binding on Federal agencies by the Secretary of Commerce under statutory authority. Nor should these guidelines be interpreted as altering or superseding the existing authorities of the Secretary of Commerce, Director of the OMB, or any other Federal official. This publication may be used by nongovernmental organizations on a voluntary basis and is not subject to copyright in the United States. Attribution would, however, be appreciated by NIST.

\section{National Institute of Standards and Technology Interagency Report 7622 80 pages (October 2012)}

Certain commercial entities, equipment, or materials may be identified in this document in order to describe an experimental procedure or concept adequately. Such identification is not intended to imply recommendation or endorsement by NIST, nor is it intended to imply that the entities, materials, or equipment are necessarily the best available for the purpose.

There may be references in this publication to other publications currently under development by NIST in accordance with its assigned statutory responsibilities. The information in this publication, including concepts and methodologies, may be used by Federal agencies even before the completion of such companion publications. Thus, until each publication is completed, current requirements, guidelines, and procedures, where they exist, remain operative. For planning and transition purposes, Federal agencies may wish to closely follow the development of these new publications by NIST.

Organizations are encouraged to review all draft publications during public comment periods and provide feedback to NIST. All NIST publications, other than the ones noted above, are

\section{Comments on this publication may be submitted to:}

\author{
National Institute of Standards and Technology \\ Attn: Computer Security Division, Information Technology Laboratory \\ 100 Bureau Drive (Mail Stop 8930) Gaithersburg, MD 20899-8930 \\ Electronic mail: scrm-nist@nist.gov
}




\title{
Acknowledgements
}

The authors, Jon Boyens, National Institute of Standards and Technology (NIST), Celia Paulsen (NIST), Rama Moorthy (Hatha Systems), and Nadya Bartol and Stephanie Shankles (Booz Allen and Hamilton), would like to acknowledge and thank Marianne Swanson, NIST, for her leadership in initiating this project as well as in the development of the document's initial public draft. We would like to thank Dan Reddy (EMC), Edna Conway (Cisco), and Hart Rossman (SAIC) for their comments and suggestions.

We would also like to thank the members of the Comprehensive National Cybersecurity Initiative (CNCI) 11 Lifecycle Processes and Standards Working Group and their support contractors as well as members of the Information Technology (IT) Sector and Communications Sector Coordinating Councils for their review and comments on this document. Their comments and direction were instrumental in the development of this document. Additionally, we would like to thank Dr. Sandor Boyson and the University of Maryland's Supply Chain Management Center for their research on ICT SCRM, which provided valuable contributions for this document.

\begin{abstract}
This publication is intended to provide a wide array of practices that, when implemented, will help mitigate supply chain risk to federal information systems. It seeks to equip federal departments and agencies with a notional set of repeatable and commercially reasonable supply chain assurance methods and practices that offer a means to obtain an understanding of, and visibility throughout, the supply chain.
\end{abstract}

\section{Keywords}

Information and Communication Technology, ICT, Supply Chain, Risk Management, Acquire, Integrator, Supplier 


\section{Table of Contents}

Reports on Computer Systems Technology__ ii

NIST Interagency Reports ___iii

Authority _ _ iv

Acknowledgements _ $\mathrm{v}$

Abstract _ $\mathbf{v}$

Keywords _ $\mathbf{v}$

1 Introduction

1.1 Purpose _ 2

1.2 Scope 3

1.3 Background___ 4

1.4 Related Documents___ 4

1.5 Document Structure _ 5

2 Overview _ 6

2.1 Challenges _ 6

2.2 Foundational Practices

3 Implementing Supply Chain Risk Management __ 11

3.1 Roles and Responsibilities for Information and Communication Technology Supply Chain Risk Management

3.2 Information and Communication Technology Supply Chain Risk Management Implementation Process___ 14

4 Supply Chain Risk Management Practices _ 25

4.1 Uniquely Identify Supply Chain Elements, Processes, and Actors __ 28

4.2 Limit Access and Exposure within the Supply Chain _ 31

4.3 Establish and Maintain the Provenance of Elements, Processes, Tools, and Data 34

4.4 Share Information within Strict Limits __ 38

4.5 Perform Supply Chain Risk Management Awareness and Training __ 45

4.6 Use Defensive Design for Systems, Elements, and Processes ___ 47

4.7 Perform Continuous Integrator Review _ 58

4.8 Strengthen Delivery Mechanisms __ 61

4.9 Assure Sustainment Activities and Processes _ 65

4.10 Manage Disposal and Final Disposition Activities throughout the System or Element Life Cycle 
APPENDIX A GLOSSARY _ 74

APPENDIX B ACRONYMS

APPENDIX C REFERENCES___ 83

APPENDIX D UMD ICT SUPPLY CHAIN STUDY__ 86 


\section{Introduction}

The information and communications technology (ICT) supply chain is a globally distributed, interconnected set of organizations, people, processes, products, and services. It extends across the full system development life cycle including research and development (R\&D), design, development, acquisition of custom or commercial off-the-shelf (COTS) products, delivery, integration, operations, and disposal/retirement.

Federal agency information systems ${ }^{2}$ are increasingly at risk of both intentional and unintentional supply chain compromise due to the growing sophistication of ICT and the growing speed and scale of a complex, distributed global supply chain. Federal departments and agencies currently have neither a consistent nor comprehensive way of understanding the often opaque processes and practices used to create and deliver the hardware and software products and services that it procures. This lack of understanding, visibility, traceability, and control increases the challenges associated with managing the risk of exploitation through a variety of means including counterfeit materials, malicious software, or untrustworthy products. Overall, it makes it increasingly difficult for federal departments and agencies to understand their exposure and manage the associated supply chain risks. Currently, federal departments and agencies and many private sector integrators and suppliers use varied and nonstandard practices, exacerbating the challenge.

The modern ICT supply chain is subject to a variety of cyber security threats. These threats may affect the confidentiality, integrity, or availability of government information and information systems and include counterfeiting, tampering, theft, reduced or unwanted functionality, or malicious content. Vulnerabilities that can be used as the vehicles to drive these threats may be instantiated by malicious individuals and as a result of the lack of good processes and practices throughout the life cycle of a system. As ICT products or services pass through the supply chain, intentional and unintentional vulnerabilities may be inserted and transferred to federal departments or agencies. These vulnerabilities enable threat agents to insert malicious content, exfiltrate data, or take advantage of the vulnerabilities in a myriad of other ways and may result in substandard products or services, unanticipated failure rates, or compromise of federal missions and information.

A multipronged, mission-driven approach is the best way to build assurance into the ICT systems, products, and services that the federal government procures and manages. Such an approach may include: government acquisition guidelines that help integrate supply chain practices into IT acquisitions; widely adopted or international standards on supply chain practices for integrators and suppliers; a means to share specific and contextual threat information; current and new technologies and tools incorporated into supply chain practices; and increased ability of federal departments and agencies to manage supply chain risks once an information system is in place.

\footnotetext{
${ }^{2}$ A discrete set of information resources organized for the collection, processing, maintenance, use, sharing, dissemination, or disposition of information. (44 U.S.C., Sec. 3502)
} 
This document seeks to equip federal departments and agencies with a notional set of repeatable and commercially reasonable supply chain assurance methods and practices that offer a means to obtain a greater level of understanding, visibility, traceability, and control throughout the ICT supply chain than agencies have today. This understanding and visibility will improve the ability of federal departments and agencies to strategically manage the associated Information and Communication Technology (ICT) supply chain risks over the entire life cycle of ICT systems, products, and services.

Many of the ICT supply chain risk management (SCRM) activities described in this document build on existing business practices to specifically help manage supply chain risks in the evolving threat environment. These practices originate from within government and industry organizations that already use a variety of business or engineering processes from many disciplines including logistics, reliability, security, and safety. When using this document for working with mature industry organizations, government agencies should be flexible in accepting evidence of existing practices in the form that the industry already captures. This flexibility will ensure that government and industry are able to use existing artifacts collected for other disciplines to demonstrate existence of activities required to achieve supply chain assurance. It will also allow both industry and government the flexibility to improve their practices and procedures over time. Any risk management activity resulting from the application of these practices aims to improve the risk posture for the federal government.

This document organizes specific ICT SCRM practices into those targeting federal department and agency acquirers (acquirers), developers and integrators of custombuilt information systems (integrators), and COTS suppliers (including open source software) (suppliers). These practices are recommended to be used for those information systems categorized at the Federal Information Processing Standards (FIPS) 199 high-impact level. However, it is recommended that Federal agency acquirers select and tailor the acquirer practices in this document based on the suitability for a specific application or acquisition and combined impact on the performance, cost, and schedule. Federal agency acquirers may use the integrator and the supplier practices in this document as examples of reasonable expectations that can be communicated to the integrators and suppliers.

This document supports the expanded set of ICT SCRM practices in draft NIST SP 800-53 Revision 4. Because the two documents are developed in parallel, it is not possible to reconcile the specific controls and practices at this point in time. It is anticipated that the future special publication addressing ICT SCRM will be fully harmonized and consistent with draft NIST SP 800-53 Revision 4, or subsequent revisions, depending on the timing of the publication.

\subsection{Purpose}

This document provides a set of practices to help federal departments and agencies integrate ICT supply chain risk management considerations into procurement of ICT systems, products, and services. The ICT SCRM practices in this document are intended to promote a greater understanding of processes and practices used to create 
and deliver hardware and software that compose federal information systems. These practices are recommended to be used for those information systems categorized at the FIPS 199 high-impact level. ${ }^{3}$ However, agencies may choose to apply the practices recommended in this document to specific systems with a lower impact level, based on the tailoring guidance provided in draft NIST SP 800-53 Revision 4, if appropriate. ${ }^{4}$

Many of the practices in this document are based on good security practices and procedures found in NIST Special Publications (SPs) like NIST SP 800-53, Recommended Security Controls for Federal Information Systems and Organizations; the National Defense University, Software Assurance in Acquisition: Mitigating Risks to the Enterprise; and the National Defense Industrial Association (NDIA), Engineering for System Assurance, and then expanded upon to include supply chainspecific implications. Additional guidance that may have supply chain implications includes, but is not limited to, International Traffic in Arms Regulations (ITAR) and Customs-Trade Partnership Against Terrorism (CTPAT).

The practices contained in this document are built on existing practices from multiple disciplines and are intended to increase the ability of federal departments and agencies to strategically manage the associated ICT supply chain risks over the entire life cycle of products, systems, and services. The practices addressed in this document can be applied to the research and development (R\&D), design, development, acquisition of custom, government-off-the-shelf (GOTS) or COTS products, delivery, integration, operations, and disposal/retirement activities.

This document does not provide specific contract language, a detailed threat assessment, or a complete list of supply chain assurance methods and techniques that mitigate specific supply chain threats. It is our intent that public and private sector organizations apply the practices in this document and provide NIST with comments on the practicality, feasibility, cost, challenges, and successes of the guidance. NIST intends to develop a NIST Special Publication on the same topic after additional research is done.

\subsection{Scope}

This document targets all federal departments and agencies that acquire ICT products and services. It is intended to serve a diverse federal audience including mission/business owners, information system owners, acquisition staff, information system security personnel, and system engineers responsible for acquiring, delivering, and operating information systems.

This document provides guidelines for federal department and agency acquirers on developing acquisitions requirements and potential ways of monitoring whether and how well these requirements are met. The document also provides useful information

\footnotetext{
${ }^{3}$ To comply with the federal standard, organizations must first determine the security category of their information system in accordance with FIPS 199, Standards for Security Categorization of Federal Information and Information Systems, and then derive the information system impact level from the security category in accordance with FIPS 200.

${ }^{4}$ Draft NIST SP 800-53 Revision 4, Sections 2.3 and 3.2.
} 
for integrators and suppliers regarding practices that may be useful to them for addressing ICT supply chain risks in the context of federal needs.

For the purposes of ICT SCRM, only those elements ${ }^{5}$ that contain programmable logic and that are critically important to the system function should be evaluated for ICT SCRM risks (e.g., software and hardware with embedded code). Furthermore, not every element is critical, whether it is a chip, a router, or a piece of software. Agencies should conduct an analysis of mission criticality to support a risk-based decision as to whether to apply all, some, or none of the practices described in this document against elements to be acquired and any associated supply chain processes.

This document is not intended to replace existing federal government procurement policies, procedures, and practices. Rather, it aims to help integrate ICT SCRM practices proposed in this document into existing overall federal agency procurement practices. Similarly, the ICT SCRM practices provided in this document intend to incorporate the proposed practices in existing federal agency information security and logistics practices.

This document does not discuss supply chain threat scenarios. Federal departments and agencies have a diverse set of missions and operational contexts. The threats applicable to the specific federal department and agency missions are also constantly evolving. Therefore, developing specific threat scenarios may be counterproductive. Federal departments and agencies are encouraged to consult with existing threat models if the need arises.

\subsection{Background}

The President's Comprehensive National Cyber Security Initiative (CNCI) 11 is cochaired by the Department of Defense (DoD) and the Department of Homeland Security (DHS). The initiative seeks to provide federal departments and agencies with a well-understood toolkit of technical and intelligence resources to manage supply chain risk to a level commensurate with the criticality of information systems or networks. Through the work of CNCI 11, an interagency group evaluated a number of source documents and developed an initial set of supply chain assurance methods/techniques or practices that cover the system development life cycle (SDLC) as part of a governmentwide SCRM solution. The initial public draft of this document was developed using these practices as a foundation. Draft NIST SP 800-53 Revision 4, Recommended Security Controls for Federal Information Systems and Organizations, and The 25 Point Implementation Plan to Reform Federal Information Technology Management from the U.S Chief Information Officer (CIO) are also foundational to the development of this document. This report takes into consideration stakeholder comments and attempts to address many of the recommendations received while maintaining the overall purpose of the document.

\subsection{Related Documents}

\footnotetext{
${ }^{5}$ For the purposes of this document, products and product components are referred to as "elements."
} 
U.S. law and associated policy require federal departments and agencies to use international, voluntary consensus standards in their procurement and regulatory activities, except where inconsistent with law or otherwise impractical. ${ }^{6}$ The ICT SCRM approach and practices described in this document are rooted in many international standards as well as government and industry documents, which include:

- ISO/IEC 15288: 2008 Systems and software engineering - System life cycle processes;

- Draft ISO/IEC 27036 Information technology: Security techniquesInformation Security for Supplier Relationships;

- Recommended Security Controls for Federal Information Systems and Organizations, NIST SP 800-53 Revision 3 or later;

- ICT Supply Chain Threats: Frame of Reference Document, DHS;

- NDIA System Assurance Guidebook v1.0;

- The Software Supply Chain Integrity Framework (July 21, 2009) and Software Integrity Controls (June 14, 2010) from SAFECode;

- Assessing SCRM Capabilities and Perspectives of the IT Vendor Community: Toward a Cyber-Supply Chain Code of Practice. A NIST-sponsored project conducted by The Supply Chain Management Center Robert H. Smith School of Business, University of Maryland;

- Open Trusted Technology Provider Framework (O-TTPF) A White Paper by: The Open Group Trusted Technology Forum, February 2011; and

- Open Trusted Technology Provider Standard (O-TTPS) Mitigating Tainted and Counterfeit Products by: The Open Group Trusted Technology Forum. Final expected Quarter 1, 2013.

\subsection{Document Structure}

The remainder of the document is organized as follows:

- Section 2: Overview, provides a high-level discussion of ICT supply chain challenges and foundational practices.

- Section 3: Implementing ICT SCRM, provides information on how ICT SCRM considerations can be integrated into the federal acquisition life cycle.

- Section 4: Supply Chain Risk Management Practices, provides the ten practices identified for ICT SCRM throughout the system or element life cycle with specific activities tailored for suppliers, acquirers, and integrators. Activities are categorized as Programmatic Activities, General Requirements, Technical Implementation Requirements, and Verification and Validation Activities.

- Appendix A provides a glossary of terms used in this document.

- Appendix B provides acronyms and abbreviations used in this document.

- Appendix C lists references used in the development of this document.

- Appendix D summarizes the University of Maryland Supply Chain Study.

\footnotetext{
6 “National Technology Transfer and Advancement Act,” “Office of Management and Budget (OMB) Circular A-119 Revised: Federal Participation in the Development and Use of Voluntary Consensus Standards and in Conformity Assessment Activities,” and, Trade Agreements Act of 1979, as amended.
} 


\section{Overview}

This section provides an overview of challenges associated with addressing ICT SCRM and builds the foundation for implementing ICT SCRM practices within individual agencies' enterprise processes.

\subsection{Challenges}

The federal government's reliance on COTS hardware and software ${ }^{7}$ is driven by the need for cost reduction, achieving operational efficiencies, and economies of scale. Incorporating COTS hardware and software permits the federal government to leverage the pace of COTS innovation without bearing the development costs of such innovation. While the benefits are substantial, there are also consequences of such reliance that affect the federal government's ability to protect information and information systems.

The growing sophistication of today's ICT, facilitated by the speed and scale of globalization, has given rise to an increasingly complex global ICT supply chain, with logically long and geographically diverse routes, including multiple tiers of outsourcing. This leads to a significant increase in the number of individuals and organizations who "touch" a product, and may allow malicious actors (individual, organization, or nation-state), direct or indirect, to affect the management or operations of companies that may result in compromise to the information system, organization, or Nation. However, global aspects of the supply chain alone are no reason to employ special supply chain risk mitigation practices, as risks must be evaluated in their entirety.

Threats to the supply chain are constantly growing in sophistication, number, and diversity. According to an August 2009 Information Technology Sector Baseline Risk Assessment, ICT supply chain is susceptible to both intentional and unintentional threats and vulnerabilities. Intentional threats include counterfeit products and malicious software. Unintentional threats include "inadequate or poor product security and integrity practices throughout the development life cycle; unintended access to critical systems; poor procurement standards and practices; reliance on third-party providers for subcomponents; and inadequate personnel screening."

Even solely domestically developed information system elements may contain intentional and unintentional vulnerabilities that may present opportunities for supply chain-related compromises including unwanted items (e.g., counterfeits) into the supply chain. Due to the global and distributed nature of supply chains, the elements containing intentional and unintentional vulnerabilities are transferred among multiple ICT suppliers throughout the supply chain. While unintentional vulnerabilities may exist due to a variety of reasons, the fact that they are not always identified nor in

\footnotetext{
${ }^{7}$ For the purposes of this document, COTS includes open source software.

${ }^{8}$ Department of Homeland Security, Information Technology Sector Baseline Risk Assessment, August 2009.
} 
many cases resolved, and potentially inherited by the final acquirer, makes them a part of the ICT SCRM challenge.

Furthermore, acquirer, integrator, and supplier organizations generally implement quality and security through two separate enterprise operational organizations. Supply chain quality and security vulnerabilities are likely to be addressed through these separate organizations. Whether addressing intentional or unintentional vulnerabilities and related mitigations, cross-communication between these two enterprise organizations is required to holistically approach ICT SCRM.

Today's multifaceted global economy and manufacturing practices make corporate ownership and control more ambiguous when assessing supply chain vulnerabilities. For example, foreign-based companies sometimes manufacture and assemble products and components in the United States, and U.S.-based companies sometimes manufacture products and components overseas, or domestically employ foreign workers.

Though globalization and its consequences are permanent and likely to have a greater impact over time, this growing complexity reduces both the depth and breadth of visibility and traceability achievable by the federal acquirer. This lack of visibility and traceability increases the acquirer's risk of being unable to manage the risks associated with intentional and unintentional compromises which may be introduced through a variety of means, including counterfeit materials or malicious software.

Currently, federal departments and agencies as well as private sector integrators and suppliers use widely varied ICT SCRM practices. This fact is underscored by the report from the University of Maryland's Supply Chain Management Center, which indicates that there is an overall lack of emphasis on ICT SCRM from companies of all sizes (see Appendix D). As a result, the potential for intentional and unintentional compromise of federal information systems increases.

\subsection{Foundational Practices}

Successful integration of ICT SCRM into existing agency activities is a multidisciplinary enterprise process that, when performed correctly, can help manage ICT supply chain risks to federal acquirers.

Addressing the challenges associated with ICT SCRM requires integrating practices from enterprise risk management, information security, software assurance, system and software engineering, project management, quality, acquisition, and a number of other disciplines, as illustrated in Figure 1. 


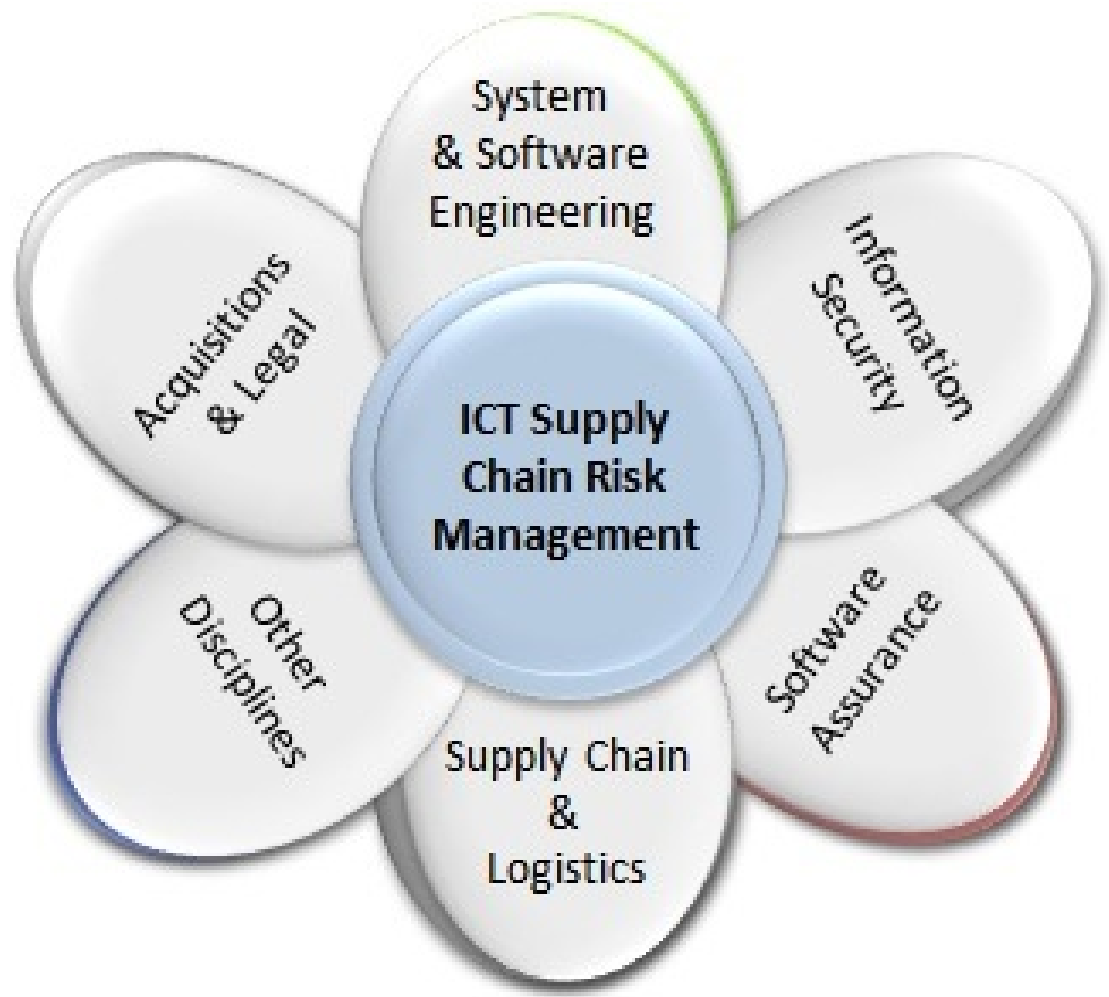

Figure 1. Components and Contributing Disciplines of ICT SCRM

To be successful, federal departments and agencies need to achieve a certain level of maturity in these multiple disciplines and ascertain that they have successfully implemented and standardized basic business practices. Basic practices include ensuring that federal department and agency acquirers understand the cost and scheduling constraints of the practices, integrating information security requirements into the acquisition language, using applicable baseline security controls as one of the sources for security requirements, ensuring a robust software quality control process, and establishing multiple delivery routes for critical system elements.

Federal departments and agencies should carefully consider using the practices described in Section 4 of this document based on their own ability to implement and make them useful, such as the maturity of federal department and agency acquisition processes, the availability of their acquisition workforce to work with integrators and suppliers, the ability of their acquisition workforce to understand and evaluate the information that they receive as a result of activities described in Section 3, as well as the feasibility of the practice given the technology environment, cost and scheduling constraints, and specific needs of the federal department or agency. Validating that the foundational practices described in this section are mature and comparable to those of the integrators and suppliers will help gain maximum value from applying the practices described in Section 4.

Furthermore, to maximize value from implementing specific ICT SCRM practices described in this document, federal departments and agencies should first assess internal existing business practices and ensure that those practices, as a foundation, are performed well. Having foundational practices in place is critical for the ability of 
federal departments and agencies to successfully and productively interact with mature integrators and suppliers who already have those practices in place and standardized.

Federal agency acquirers should ensure that they have validated existence of the following foundational practices prior to implementing the specific ICT SCRM practices contained in this document:

- Follow consistent, well-understood, well-documented, repeatable processes for system engineering, ICT security practices, and acquisition;

- Implement the appropriate tailored set of baseline security controls in NIST SP 800-53 Revision 4 or later required by the FIPS 199 impact levels;

- Perform quality assurance and quality control process and practices;

- Assign roles and responsibilities to specific individuals, including who has the required authority to take action, who has accountability for an action or result, and who should be consulted and/or informed. Ensure information system security, acquisition personnel, legal counsel, and other appropriate advisors and stakeholders are participating in decision making from system concept definition/review and are involved in, or approve of, each milestone decision through the entire system life cycle for federal systems;

- Ensure adequate resources are allocated for information system security and ICT SCRM - without funding, nothing will happen;

- Develop, implement, and test a contingency plan to include the supply chain to ensure integrity and reliability of the supply chain even during adverse events (e.g., natural disasters such as hurricanes or economic disruptions such as labor strikes). Such plans may incorporate the use of multiple suppliers or multiple supply chains, and actively manage integrators through Service-Level Agreements (SLAs) and standard operating procedures with event-triggered escalation rules; and

- Ensure that a robust incident management program is in place to successfully identify, respond to, and mitigate security incidents. This program should be capable of identifying causes of security incidents, including those originating from the supply chain.

Validating the existence of practices that contribute to ICT SCRM and building on them to integrate ICT SCRM into the agency processes requires continuous collaboration and coordination among practitioners from these multiple disciplines. These disciplines have distinct bodies of knowledge and lexicons, and practitioners working in the disciplines may not have worked together in the past and may not be familiar with each other's lexicons. Responsibilities for these disciplines and activities normally reside within different entities of a federal department/agency enterprise, necessitating collaboration across organizational boundaries. Although Figure 1 does not depict the many other disciplines that are needed, such as project management, quality assurance, and finance, these and other business functions can provide an important dimension to SCRM and should be considered when necessary.

Section 3 of this document discusses how to integrate ICT SCRM considerations into the federal department/agency acquisition life cycle. Section 4 of the document provides specific ICT SCRM practices that are tailored to address the multidisciplinary 
view by categorizing the practices under the headings of programmatic activities, general requirements, technical implementation requirements, and verification and validation requirements. These practices are for use by federal department and agency acquirers. 


\section{Implementing Supply Chain Risk Management}

Federal department and agency acquiring organizations need an integrated approach to assess and mitigate ICT supply chain risk while balancing associated costs. The development of an enterprise-wide set of policies and procedures that outlines the roles and responsibilities of all stakeholders is the first step in implementing an ICT SCRM program.

This section provides an approach for integrating ICT SCRM into federal department and agency processes enterprise-wide. This approach will help federal departments and agencies implement ICT SCRM practices and make informed decisions on the assurance of the ICT supply chain when acquiring services and operating hardware or software. Specifically, this section focuses on integrating ICT SCRM considerations into federal agency acquisition process. This section does not supersede or replace existing federal acquisition guidelines; rather, it demonstrates opportunities for integrating ICT SCRM considerations throughout existing federal acquisition processes.

As a part of implementing this approach, federal department and agency acquirers should develop procedures for determining which information systems should implement ICT SCRM mitigation strategies, guided by FIPS 199 security categorization, FIPS 200/NIST SP 800-53 security control baselines, and the phase of each individual system life cycle. Federal departments and agencies should also consult draft NIST SP 800-53 Revision 4, which provides supply chain protection controls for information systems at the high-impact level.

In the course of acquiring and using ICT products and services, federal departments and agencies may need to request information from integrators and suppliers. In the course of such interactions, departments and agencies should make an effort to minimize the impact of potentially burdening the integrators and suppliers with divergent ICT SCRM requirements and requests for information. For example, rather than issuing a separate questionnaire or survey in a special format, federal agencies should allow integrators and suppliers to reuse existing documentation that is produced by normal business activities, such as inventory or personnel management, or documents that demonstrate compliance with appropriate information security, logistics, or ICT SCRM standards. In another example, an acquirer may request assurance from integrators and suppliers that suppliers have appropriate processes to reduce counterfeits and malicious code. To reduce information requests and ensure maximum protection of integrator and supplier information, the integrator or supplier should attest to having such processes, but provide the information to the acquirer only if there is an incident.

When further evidence beyond attestation is required, integrators or suppliers may need to provide proprietary or other sensitive data to an acquirer. When requesting ICT SCRM-related data or evidence from integrators and suppliers, federal departments and agencies should ensure that integrators or suppliers are afforded sufficient opportunity to identify such data and should appropriately protect that data commensurate with the sensitivity of the data and consistent with all applicable laws and regulations. Similarly, integrators should appropriately protect supplier's data that 
will be collected and appropriately documented in contractual language that specifies how the data will be used, how long it will be kept, with whom it can be shared, or what intellectual property protections will apply.

\subsection{Roles and Responsibilities for Information and Communication Technology Supply Chain Risk Management}

Implementation of ICT SCRM will require federal department and agency acquirers to establish a coordinated team approach to assess the ICT supply chain risk and manage this risk by using technical and programmatic mitigation techniques. Supply chain activity is one of many enterprise activities and will fit under the overall governance of an agency. Specifically, supply chain risks should be considered part of what the Risk Executive Function addresses. The composition of the team, either ad hoc or formal, will enable the members to conduct a comprehensive analysis of the supply chain, communicate with external partners/stakeholders, and assist the federal acquirer in developing an ICT supply chain strategy for any given acquisition.

ICT SCRM roles and responsibilities are distributed among members of a variety of different entities within a federal department or agency, including information technology, information security, contracting, and legal. Managing the ICT supply chain is an enterprise-wide activity. Members of the ICT SCRM team should be a diverse group of people who collectively are aware of the challenges associated with the global aspects of ICT supply chain. These challenges include an understanding of how ICT products and services are procured, produced, distributed, and integrated, familiarity with methods of attack and how to prevent them, as well as legal and procurement aspects of the discipline. The strategies and mitigations proposed by the ICT SCRM team should comply with the Federal Acquisitions Regulations (FAR) as well as specific existing federal department or agency policies and procedures.

The roles and responsibilities described in this section may vary among federal department and agency acquirers. In some federal departments and agencies, a single individual may hold multiple roles. Most of these roles and responsibilities are already defined in existing NIST guidance (e.g., NIST SP 800-37). This section provides additional information specific to ICT SCRM aspects of these roles and responsibilities. ${ }^{9}$

Chief Information Officer (CIO) - The CIO is responsible for the organization's information system planning, budgeting, investment, performance, and acquisition. As such, the CIO provides advice and assistance to senior organization personnel in acquiring the most efficient and effective information system to minimize ICT supply chain risks within the organization's enterprise architecture.

Contracting Office - The Contracting Office has the authority to enter into, administer, and/or terminate contracts and make related determinations and findings. In the Contracting Office, the Contracting Officer (CO) is responsible for developing

\footnotetext{
${ }^{9}$ Descriptions of roles and responsibilities use the term "organization" to mean federal department and agency.
} 
an acquisition strategy including technical mitigations which can reduce supply chain risk. The Contracting Officer's Representative (COR) is a qualified employee appointed by the Contracting Officer to act as their technical representative in managing the technical aspects of a contract.

Legal - The Legal Office is responsible for advising the team on legal issues related to SCRM, including the acquisition process, and for approving acquisition artifacts (e.g., Request for Proposal, Quote, or Information) and contract language during procurement planning or procurement completion used to implement a supply chain risk management practice.

Risk Executive (Function) - The Risk Executive Function will work across the organization to ensure consistency in how ICT SCRM considerations are integrated into the organization's overall acquisition strategy and processes. The Risk Executive Function ensures that procurements reflect organizational risk tolerance, and that supply chain risk is considered along with other types of risks in order to ensure mission/business success.

Mission/Business Owner - The Mission/Business Owner is a high-level official ultimately responsible for the procurement, development, integration, modification, operation, and maintenance of an information system. The Mission/Business Owner may delegate execution of their responsibilities to Program Managers who work closely with the Authorizing Official (AO), Senior Information Security Officer (SISO), Information Systems Security Officer (ISSO), and the CO to ensure that supply chain risk mitigation strategies are selected, implemented, and operating as intended. The Mission/Business Owner is ultimately responsible for ensuring collaboration with various functional experts to identify and implement ICT supply chain practices that are sufficient to mitigate risks. The functional areas that may be involved include: systems engineering, system security engineering, facilities management including physical security, requirements engineering, quality assurance, reliability, compliance, manufacturing, assembly, testing, acceptance, maintenance, system and network administration, shipping and receiving, packaging and labeling, delivery, inventory management, finance, disposal, and waste management.

Senior Information Security Officer (SISO) - The Senior Information Security Officer, also known as SISO, is responsible for promulgating policies on security integration in the SDLC and the development and implementation of security policy, guidelines, and procedures pertaining to SCRM. The SISO plays a leading role in introducing an appropriately structured methodology to help identify, evaluate, and minimize supply chain risks to the organization. In addition, the SISO is responsible for analyzing and developing:

- Procedures for performing, analyzing, and utilizing integrator or supplier assessments; and

- Technical mitigation strategies derived from the integrator or supplier assessments, ensuring that assessments are performed by a third party (not necessarily an external party).

Other important roles - Finance and audit representatives are also important to ensure appropriate integration of ICT SCRM into the overall federal department and agency 
acquisition process, as well as into specific ICT SCRM acquisitions. The role of the finance representative is to ensure appropriate allocation of resources. The role of the audit representative is to ensure appropriate monitoring of performance against agreements post-implementation. In addition, federal agencies and departments may determine that other specialized roles are necessary due to the nature of an acquisition, project, or mission.

Table 1 illustrates possible roles of various ICT SCRM stakeholders with respect to SCRM Capability Implementation described in Section 3.3. This is an illustration of how different functions should work together rather than a definitive list of responsibilities or governance structure. The following terms are used in the table to articulate the level of engagements each specific role should have in the process:

- Lead - holds responsibility for decision making and execution of the activity.

- Oversee - provides senior management oversight to the activity and its execution.

- Advise - provides expert advice to the role that leads the activity.

- Approve - reviews and concurs with organization-defined sub-activities that fall within the role's expertise. This activity is mandatory.

\begin{tabular}{|l|l|l|l|l|l|l|}
\hline \multicolumn{1}{|c|}{ Process } & \multicolumn{1}{|c|}{$\begin{array}{c}\text { Risk } \\
\text { Executive } \\
\text { Function }\end{array}$} & CIO & SISO & Contracting & Legal & $\begin{array}{c}\text { Mission/Business } \\
\text { Owner }\end{array}$ \\
\hline $\begin{array}{l}\text { Plan } \\
\text { Procurement }\end{array}$ & Oversee & Oversee & Oversee & Lead & Approve & Lead \\
\hline $\begin{array}{l}\text { Define/Develop } \\
\text { Requirements }\end{array}$ & Oversee & Oversee & Oversee & Advise & Advise & Lead \\
\hline $\begin{array}{l}\text { Identify } \\
\text { Potential } \\
\text { Suppliers } \\
\text { and/or Perform } \\
\text { Market } \\
\text { Analysis }\end{array}$ & Oversee & Oversee & Oversee & Advise & Advise & Lead \\
\hline $\begin{array}{l}\text { Complete } \\
\text { Procurement }\end{array}$ & Oversee & Oversee & Approve & Lead & Approve & Lead \\
\hline $\begin{array}{l}\text { Operations and } \\
\text { Maintenance }\end{array}$ & Oversee & Oversee & Oversee & Advise & Advise & Lead \\
\hline
\end{tabular}

Table 1. ICT SCRM Stakeholders

\subsection{Information and Communication Technology Supply Chain Risk Management Implementation Process}

Reasonable risk taking is appropriate as long as risks are understood and accepted, mitigated, avoided, or transferred. This section describes the activities that take place to mitigate supply chain risk during the life cycle of the project using NIST SP 800-53.

Federal departments and agencies should ensure that the practices dedicated to mitigating supply chain risks for individual acquisitions should be commercially reasonable, and the resources used by the agency should be commensurate with the magnitude and criticality of systems and/or elements being procured. For the purposes 
of ICT SCRM, only those elements that contain programmable logic and that are critically important to the system function should be evaluated for ICT SCRM risks (e.g., software and hardware with embedded code). Furthermore, not every element is critical, whether it is a chip, a router, or a piece of software. Agencies should conduct an analysis of mission criticality to support a risk-based decision as to whether to apply all, some, or none of the practices described in this document against elements to be acquired and any associated supply chain processes. Draft NIST SP 800-53 Revision 4, SA-14 and SA-15 (enhancement 3) provide further information on determining criticality.

Prior to entering into a contract for ICT, an agency should analyze the risks, benefits, and costs associated with implementing ICT SCRM requirements. Since managing supply chain information collection, processing, and protection can result in exponential administrative costs to acquirers, integrators, and suppliers, clearly defining these requirements is critical. ICT SCRM concerns should be carefully balanced with programmatic concerns including required resources (i.e., cost, performance, and schedule), functionality, and security.

For federal systems, draft NIST SP 800-53, Revision 4 or later, should be used as the starting point for determining the set of applicable security controls for an information system (for the security control baseline). Not every information system acquisition is a candidate for assessing supply chain risk or incorporating supply chain mitigation language into procurement documents. Draft NIST SP 800-53, Revision 4, Appendix F, Security Control Catalog, requires, for those information systems categorized at the FIPS 199 high-impact level, the implementation of the security control SA-12 Supply Chain Protection.

\section{SA-12}

Control: The organization protects against supply chain threats by employing: [Assignment: organization-defined list of measures to protect against supply chain threats] as part of a comprehensive, defense-in-breadth information security strategy.

Therefore, for FIPS 199 high-impact systems, ICT SCRM should be explicitly integrated into the acquisition process to analyze potential supply chain risks, and organizations need to implement additional security controls and/or SCRM practices as needed, depicted by a solid line and in red in Figure 2.

In the case of information systems categorized at the FIPS 199 moderate- or lowimpact level, NIST SP 800-53 implementation of SA-12 is not required. For moderateimpact systems, a risk-based decision should be made by an authorizing official as to whether ICT SCRM is warranted (depicted by a dash line and in yellow in Figure 2). Low-impact systems do not require significant ICT SCRM attention, depicted in green in Figure 2.

(Note: Since information assurance (IA) controls are a living document, the most current version of SA-12 should be reviewed to make the determination.) 
Figure 2 represents the integrated ICT SCRM Implementation Process described in the following sections.

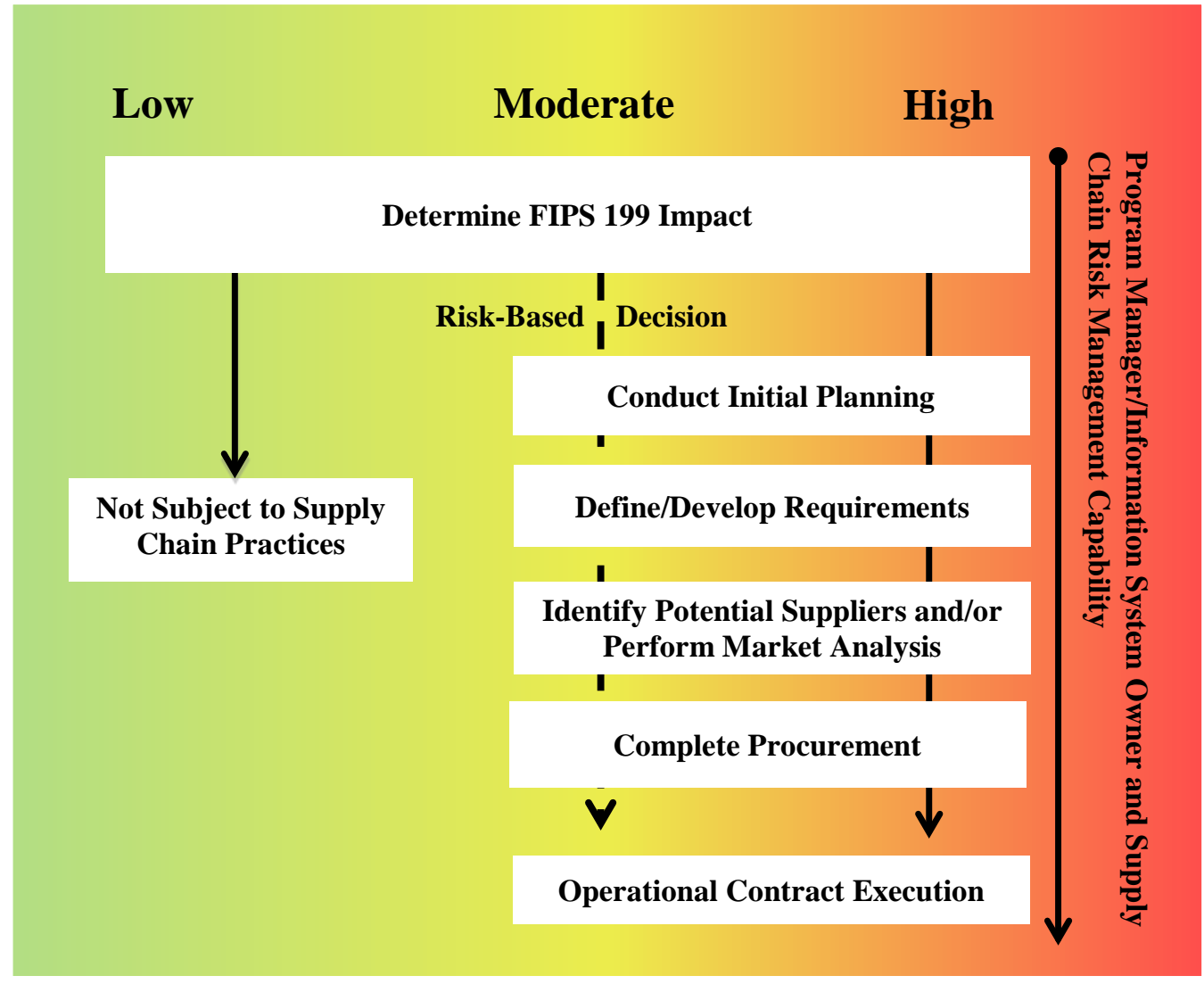

Figure 2 - ICT SCRM Implementation Process

\subsubsection{Determine Risk}

Mission/business owners, information system security personnel, stakeholder representatives, and possibly outside experts should conduct applicable risk analyses and identify applicable supply chain risk mitigations. Acquirers can use existing methodologies such as NIST SP 800-30 Revision 1 to conduct the assessment.

Because risks may be unique to each organization and are constantly evolving, this document does not provide specific threat or vulnerability information. Federal department and agency acquirers may use several methods of identifying potential risks including reviews of current and historical agency process and system documentation, interviewing of stakeholders, checklists, marketing analysis, supplierspecific risk assessment, open source information, and standard operating procedure (SOP) review. 
Federal department and agency acquirers should use appropriate techniques to manage and mitigate risk during the acquisition of information technology including but not limited to: prudent project management; use of modular contracting; thorough acquisition planning tied to budget planning by the program, finance, and contracting offices; continuous collection and evaluation of risk-based assessment data; prototyping prior to implementation; post-implementation reviews to determine actual project cost, benefits and returns; supplier certification; supplier monitoring; and focusing on risks and returns using quantifiable measures.

Section 4 of this document provides a set of practices that can be used as a source for creating ICT SCRM-related requirements.

\subsubsection{Conduct Initial Planning}

The procurement official (under the Contracting role in Section 3.1), with the assistance from the mission/business owner or their designee, information security experts, legal counsel, and other applicable members of the ICT SCRM team, should modify or develop a procurement strategy (e.g., Acquisition Plan) to best support the selected project/program. To help identify and plan for addressing ICT supply chain risk, the acquisition plan should include:

- A list of potential sources of supplies/services that could meet the need; the extent and results of market research, and the risk of using these sources to deliver the various elements of the procurement strategy;

- A description of how competition will be sought, promoted, and sustained throughout the course of the acquisition process, e.g., request for information (RFI) activities, source sought notices, market surveys;

- A description of various contracting considerations, including contract type and the use of performance-based contracts, e.g., requests for quotation (RFQ), requests for proposal (RFP), Cooperative Research and Development Agreements (CRADAs), grants, and similar documents (See Part 16 of the FAR for a description of different contract types.);

- Identification and application of relevant acquisition policies and contract clauses to ensure that needed authorities are in place and sufficient to verify the element, the element processes, and the business processes of the acquirer, integrator, and supplier; and

- Description of procurement roles and responsibilities, a roadmap for completing procurement actions and milestones, and a discussion for including special ICT SCRM considerations in the acquisition and implementation of ICT products and/or services.

Additionally, any legal issues should be disclosed, the type of contract(s) that will be in the government's best interest should be identified, and a decision made whether one or more integrators or suppliers will be required in order to meet program needs. (See Part 7.105 of the FAR for a complete list of acquisition plan of action subcomponents.)

\subsubsection{Define/Develop Requirements}


The acquirer mission/business owner or their designee, with assistance from the procurement official and other members of the SCRM team, if applicable, should define and document requirements for the procurement. During this process, mission, functionality, quality, and security requirements should be developed and documented. This process will identify the requirements for the procurement and how these requirements will apply to the specific items of supply (elements and processes).

\subsubsection{Identify Potential Integrators or Suppliers and/or Perform Market Analysis}

Once the requirements are defined, the acquirer mission/business owner should initiate a market review for potential suppliers. This effort includes a compilation of publically available financial, operational, and legal information to prepare a risk profile of a supplier to assess its current and previous performance, and identify any outstanding complaints or liabilities associated with its technical performance. It should be noted that not all circumstances warrant publication of an RFI or a Sources Sought Notice. It is up to the acquirers to select specific approaches to individual procurements.

\section{Market Analysis/Assessment}

Mission/business owners should perform market analysis using one or more of the following methods: publishing a Sources Sought Notice, publishing an RFI, or performing a market survey to obtain prices from potential integrators or suppliers.

Mission/business owners or their designees should identify known and potential sources of supply (including qualified integrators or suppliers and qualified product lists). If the potential integrators or suppliers are not known, the mission/business owner or designee should work with the contracting officer to do a market analysis to identify alternative integrators or suppliers with their respective supply chains. The market analysis should identify which companies can provide the required elements or services and suggest possible options. The various identification methods should determine if all items under the requirement could be obtained from one integrator or supplier or a number of them. Potential integrator or supplier information can also be gathered from open sources, such as the press, Internet, periodicals, and fee-based services. Mission/business owners should be aware that respondents might include integrators or suppliers not previously identified.

As part of the market analysis, federal department and agency acquirers may use due diligence questionnaires (such as the UMD Study in Appendix D) to assist in obtaining additional information about the system/element and system/element processes, as well as the integrator or supplier organizations. The purpose of these questionnaires is to gather information about the integrator or supplier's ability to address ICT SCRM concerns in addition to business and technical requirements. The responses to the due diligence questionnaires will inform acquirers of potential risks associated with the elements or services they are considering for purchase and of the suppliers ICT SCRM practices. When using the due diligence questionnaires, acquirers should request evidence or may coordinate an on-site follow-up that reviews objective evidence of the provided answers where appropriate and evaluates them for potential risks or red flags. 
These due diligence questionnaires should be used as tools and not checklists or complete listings of all possible concerns.

As a part of market analysis, an organization may choose to publish an RFI or a Sources Sought Notice to give integrators and suppliers an opportunity to tell their story based on the description in the RFI/ Sources Sought Notice.

\section{RFI}

If an agency decides to publish an RFI, this activity involves creating a plan for evaluating responses and the criteria to be used to evaluate them. The evaluation plan describes the process by which market analysis data/information should be secured and evaluated against the criteria, including the time frame for the evaluation and any measures that can be used to support the evaluation process. The results can then be used to help refine technical requirements and determine potential candidate(s) for the acquisition based on their ability to satisfy technical requirements. It is imperative that federal departments and agencies include qualified supply chain and/or information security professional(s) in the process of evaluating the ICT supply chain criteria. The evaluation may be administered through both qualitative and quantitative methods to provide a consistent methodology for refining technical requirements to be included in the future RFP.

\subsubsection{Complete Procurement}

After the completion of market analysis, the federal department and agency acquirer should develop a statement of work (SOW) or statement of objective (SOO) for the release of an RFP or RFQ. The acquirer should also develop ICT SCRM-specific evaluation criteria for evaluating responses to the RFP/RFQ. The acquirer should specify how the received data/information will be secured and evaluated against the criteria, including the time frame for the evaluation and any measures that can be used to support the evaluation process. The evaluation criteria will be used, in part, for selecting integrators and suppliers. Federal department and agency acquirers should provide appropriate protections for the proprietary and sensitive data that they receive during the RFP/RFQ process, according to applicable laws and regulations. Federal department and agencies should use the post-award due process including release of all relevant information pertaining to the reasons for award or no award.

\section{Evaluation Criteria}

ICT SCRM-focused evaluation criteria can be applied to both integrators and suppliers and can be integrated into the overall evaluation criteria for individual acquisitions.

Table 2 illustrates examples of the potential categories of ICT SCRM-focused evaluation criteria including:

\begin{tabular}{|l|l|}
\hline \multicolumn{1}{|c|}{ Category } & Description \\
\hline Organization & Key aspects of the integrator or supplier organization. \\
\hline
\end{tabular}




\begin{tabular}{|c|c|}
\hline (integrator/supplier) & $\begin{array}{l}\text { Identifying and gathering information on the integrator or } \\
\text { supplier organization is critical to managing supply chain risk. } \\
\text { Examples of such information include: } \\
\text { - Organizational History - years of operation, Central } \\
\text { Contractor Registry (CCR) registration record } \\
\text { - Foreign Interests and Influences (including ownership) } \\
\text { - Financial History and Status - Size of Organization, } \\
\text { credit rating (including Dun and Bradstreet [DUNS] } \\
\text { record) } \\
\text { - Facilities - location, history of physical security } \\
\text { violations, facilities management policies } \\
\text { - Policies for Personnel Security Review and Control } \\
\text { Integrator's ability to pass ICT SCRM requirements past } \\
\text { first tier suppliers. }\end{array}$ \\
\hline Element Processes & $\begin{array}{l}\text { Robustness and completeness of life cycle processes } \\
\text { applied to elements and services to be procured. } \\
\text { Effectively applied supply chain and ICT SCRM processes } \\
\text { decrease the likelihood of both intentional and unintentional } \\
\text { supply chain weakness that can lead to exploitable } \\
\text { vulnerabilities. Element processes that should be addressed } \\
\text { run the full element life cycle and can start at the concept } \\
\text { phase and go through to disposal. In many instances, element } \\
\text { processes are highly proprietary. Examples of these processes } \\
\text { may include: } \\
\text { - Concept and Planning } \\
\text { - Architecture and Design } \\
\text { - Development } \\
\text { - Integration/Assembly } \\
\text { - Assessment, Evaluation, and Testing (including the } \\
\text { - Manufion of the tools used in the process) } \\
\text { - Delivery } \\
\text { - Acceptance and Installation } \\
\text { - Support Services } \\
\text { - Operating Environment }\end{array}$ \\
\hline Elements & $\begin{array}{l}\text { Element's security track record. } \\
\text { Elements are subject to both intentional and unintentional } \\
\text { insertion of malicious functionality, weaknesses, and } \\
\text { counterfeits. Some key items addressed as part of the element } \\
\text { evaluation should include: } \\
\text { - Architecture/Design characteristics - including built-in } \\
\text { defenses and whether they meet functional requirements. } \\
\text { - Element history and licensing - reviewing element }\end{array}$ \\
\hline
\end{tabular}




\begin{tabular}{|l|l|}
\hline & $\begin{array}{l}\text { quality, reliability, security incidents, licensing terms, } \\
\text { indemnifications, etc. }\end{array}$ \\
- & $\begin{array}{l}\text { Publicly available record of vulnerabilities (e.g., using } \\
\text { the National Vulnerability Database) associated with the } \\
\text { element and the process for addressing incidents, root } \\
\text { cause analyses, and fixes. }\end{array}$ \\
\hline
\end{tabular}

Table 2. Potential Categories of Evaluation Criteria

Evaluation criteria should also include use of past performance ${ }^{10}$ of the integrator or supplier for indications of security consciousness in their processes and the resulting systems, elements, and services as a gauge for their supply chain assurance practices. Indicators include available information about systems, elements, and secure configurations that can be turned on by default, evidence of attempts by the integrator or supplier to reduce vulnerabilities, and what past vulnerabilities indicate about product/service strength, speed of patching, integrator or supplier pattern of addressing identified vulnerabilities, and current known yet unfixed vulnerabilities. (Note that suppliers may have legitimate reasons for not releasing information about existing but unfixed vulnerabilities.) Since past performance is no guarantee of future result, recent major changes in the integrator or supplier organization that might invalidate past performance should be examined.

\section{SOW/SOO}

The mission/business owner or designee should develop a SOW/SOO that includes a detailed description of the specific functional, technical, quality, and security requirements and qualifications. This document should include the selected ICT SCRM practices (general and technical requirements, and verification and validation activities) and NIST SP 800-53 controls relevant to an integrator and, in some instances, a supplier supporting acquirer activities. Requirements developed for market analysis and any adjustments made from the results of the RFI process should provide significant input to the RFP or RFQ.

The following should be considered when developing the SOW/SOO requirements:

- Appropriate level of risk distribution among the acquirer, integrator, and suppliers;

- Integrator’s level of responsibility for supplying assurance for systems and elements;

- Criticality analysis including:

\footnotetext{
${ }^{10}$ Effective July 1, 2009, the FAR requires federal agencies to post all contractor performance evaluations in the Past Performance Information Retrieval System (PPIRS) http://www.ppirs.gov/.
} 
o Determining from a mission criticality analysis, which system elements are critical. A system decomposition is required to identify which elements are critical for mission criticality;

o A dependency analysis to determine if any noncritical elements have a mission-critical impact on the critical elements. This will ascertain if mitigation (technology or process) is required to protect the critical components and in turn the mission; and

o Determining the appropriate level of access to the critical elements for the protection of these elements and the mission they support;

- Requirements for processes (including test and evaluation [T\&E] processes) and inclusion of these processes in contract documents;

- The methodology used by integrators to select/manage their suppliers and whether the integrator or supplier imposes similar requirements on their downstream suppliers;

- Requirements for respondents to demonstrate that they have the necessary security measures in place to manage ICT supply chain risks (e.g., attestation, provision of third-party certifications, etc.); and

- How acquirer's and integrator's or supplier's proprietary data will be used, how long it will be kept, with whom it can be shared, and what intellectual property protections will prevail.

\section{Response Review}

Once the integrator responds to the RFP/RFQ with a proposal, the acquirer will review the response. This review requires participation of multiple stakeholders who will address multiple facets of the response. The mission/business owner or designee will review adherence to procurement objectives including response to ICT SCRM evaluation criteria. Appropriate technical experts will conduct a technical review. The Contracting Officer will conduct the cost review. Other team members will review other portions of the response to ultimately determine which proposal is the most beneficial (best value) to the government.

The review team will evaluate the quality of each integrator response against predetermined, weighted evaluation factors to gauge the quality of each proposal. The review team will look for documented evidence of an integrator's claims to meet the desired ICT SCRM requirements and other indicators. Documentation can include the supplier's demonstrated record, as confirmed by references, of successful past performance of the same or substantially similar contract efforts, including quality of services or supplies, timeliness of performance, cost control, and the integrator's business relations. It can also include accepted third-party certifications.

\section{Acquisition-Specific Risk Assessment}

A risk assessment should be conducted as part of the RFP/RFQ review. The criteria for this assessment should be defined using mission, functional, quality, and security requirements. Acquirers can use existing methodologies such as NIST SP 800-30 
Revision 1 to conduct the assessment. Data to support this assessment should be collected from a variety of sources, such as:

- Integrator or supplier security track record (e.g., compilation of publicly available financial, operational, legal, and technical information);

- Software security training and awareness within the integrator or supplier organization;

- Security monitoring both of the element and element processes;

- Timeliness of vulnerability mitigation of element and element processes;

- Policies for service confidentiality;

- Policies for information sharing and access control;

- Policies for integrator or supplier information security;

- Results of independent third-party evaluations; and

- Security certifications.

Federal department and agency acquirers may consult with their counterparts in other agencies who are using the product being acquired to obtain information to support this assessment. Other items may be added to the evaluation as appropriate.

\subsubsection{Operational Contract Execution}

Once a system becomes operational, the operating environment may change. Changes include, but are not limited to, suppliers, elements, delivery processes, and business processes. These changes may alter, add, or reduce ICT supply chain risks. During operations, acquirers should continue to perform ICT SCRM, including the assessment of foundational enterprise practices. The acquirer will need to ensure that the integrator or supplier understands supply chain risk and provides information on applicable changes to the element, environment, vulnerabilities, and patches on an ongoing basis. The following activities will help the acquirer maintain supply chain oversight and improve processes for future procurements:

- Collect, analyze, record, and disseminate ICT SCRM lessons learned within the project and within the larger organization(s). This information will help enhance immediate project performance and provide input into the enterprise ICT SCRM process;

- Collect information on whether the trade-offs that were made during the procurement with regards to mitigating ICT supply chain risks substantially increased that risk;

- Identify gaps that were not addressed in past projects and how they can be filled;

- Monitor and periodically (or continuously if appropriate) reevaluate changes in the risk environment that impact the supply chain including technology innovation, operational environment, regulatory environment, etc. Respond to change where appropriate through modifying ICT SCRM requirements or if needed, modifying relationships with integrators or suppliers. Note: (1) Use 
information as available, including information from commercial sources, U.S. government agencies, and intelligence information as appropriate. (2) Respond to such changes when appropriate, e.g., by adding additional countermeasures (such as additional practices from this document) or changing to a less risky integrator or supplier;

- Integrate ICT SCRM considerations in continuous monitoring activities; and

- Collect feedback on integrator or supplier responsiveness and effectiveness at mitigating risks per acquirer requests.

The acquirer should use the practices in Section 4 to address supply chain assurance when acquiring replacement components or field additions/modifications/upgrades, particularly if they do not go through traditional acquisition processes that examine ICT supply chain risks.

Acquirers and integrators need to be aware of the time frame within which their elements and systems are expected to become obsolete and plan for replacing and upgrading these elements and systems. Systems that have a long life cycle may require a substantial number of elements that are no longer available from the original component manufacturer or through their franchised distributors. In some cases, upgrades may not be compatible with the system (backwards compatible) or supported by the original manufacturer. Acquirers and integrators should identify and plan for when elements become obsolete. 


\section{Supply Chain Risk Management Practices}

This section provides ten practices that federal department and agency acquirers (acquirers) should consider when creating the list of practices that they employ as part of their ICT SCRM strategy. Each practice is a blend of programmatic activities, validation/verification activities and requirements, as well as general and technical implementation requirements. Acquirers will implement the programmatic and validation/verification activities and will use general and technical implementation requirements for information about what may be reasonable to expect from integrators and suppliers.

The term "acquirer" is used to mean the federal department or agency acquiring the product or service. The term "integrator" is used to depict an organization that specializes in customizing (e.g., combines, adds, optimizes) elements, processes, and systems. The integrator functions can be performed by an industry partner or internal federal agency organization. The term "supplier" is used to depict an organization or individual that enters into an agreement with the acquirer or integrator for the supply of a COTS product. Examples of COTS, which may or may not be shrink-wrapped but are considered commercial, (including open source software) can encompass such elements as operating systems (OS), middleware or application layer solutions (e.g., app servers, portals, web servers), databases, routers, storage, servers, workstations, etc. COTS may include any suppliers in the supply chain and is synonymous with the terms vendor and manufacturer. For those occasions when an integrator outsources custom development to another organization, acquirers and integrators should examine both integrator and supplier practices in this document and select those that are reasonable and appropriate. The term "element" is used throughout to mean COTS and government off-the-shelf (GOTS) software, hardware, and firmware and is synonymous with components, devices, products, systems, and materials. An element is part of an information system and may be implemented by products or services. The term agreement ${ }^{11}$ refers to transaction, a contract, or any other form of documented interaction between acquirer and integrator, acquirer and supplier or integrator and supplier.

In many cases, the practices will apply to both software and hardware suppliers. Since most hardware devices contain some level of firmware or software, the document does not differentiate between hardware and software suppliers. Acquirers should use the guidance in this document to develop a strategy that best meets their needs.

The practices in this section identify essential characteristics, actions, or processes rather than specific technologies or methodologies. This is to ensure that this document can accommodate the various needs of different organizations and the rapid pace of change in ICT technology. These practices are harmonized with existing and emerging international consensus-based standards and point to those as appropriate throughout the section. Federal departments and agencies are reminded that U.S. law

\footnotetext{
${ }^{11}$ ISO/IEC 15288 defines “agreement” as mutual acknowledgement of terms and conditions under which a working relationship is conducted.
} 
and policy require them to use international, voluntary consensus standards in their procurements, except where inconsistent with law or otherwise impractical. ${ }^{12}$

The ten practices, if implemented in their entirety, cover the complete SDLC.

4.1 Uniquely Identify Supply Chain Elements, Processes, and Actors

4.2 Limit Access and Exposure within the Supply Chain

4.3 Establish and Maintain the Provenance of Elements, Processes, Tools, and Data

4.4 Share Information within Strict Limits

4.5 Perform SCRM Awareness and Training

4.6 Use Defensive Design for Systems, Elements, and Processes

4.7 Perform Continuous Integrator Review

4.8 Strengthen Delivery Mechanisms

4.9 Assure Sustainment Activities and Processes

4.10 Manage Disposal and Final Disposition Activities throughout the System or Element Life Cycle

The practices in this section are not listed sequentially, in order of importance, or aligned with system or element life cycle phases. The ten practices are descriptive and do not impose a specific approach or implementation. These practices can be applied at any point in the system or element life cycle but are not comprehensive in that they do not cover every possible practice that could be applied. As mission/business needs and new technology and standards emerge, the practices may evolve.

Several ICT SCRM practices can be simultaneously applied to an information system or the elements of an information system. In certain instances or with information systems, different practices may be applied during multiple life-cycle phases to varying degrees or to different elements (e.g., one set for the COTS supplier and another for the custom integrator). Table 3 reflects the types of actions and the descriptions an Acquirer, Integrator, and Supplier could implement for each SCRM practice selected. The federal department and agency acquirer mission/business owner or a designee, along with information security experts, should determine if the practices selected are sufficient to mitigate supply chain risks. The business owner will make the final decision as to the acceptable level of risk.

Specific threats or threat scenarios, although relevant and useful, are not discussed in this document. Such discussion would be counterproductive for two reasons: threats are constantly changing and different threats have varying impacts on federal department and agency mission functions. A comprehensive threat discussion would require individual treatment of each department/agency mission context, which is outside of scope of this document. However, federal departments and agencies are encouraged to include ICT SCRM threats in their organization's risk analysis processes.

\footnotetext{
12 “National Technology Transfer and Advancement Act,” “Office of Management and Budget (OMB) Circular A-119 Revised: Federal Participation in the Development and Use of Voluntary Consensus Standards and in Conformity Assessment Activities,” and Trade Agreements Act of 1979, as amended.
} 
Implementation of some of the practices could result in integrators or suppliers providing proprietary or other sensitive data to an acquirer. Acquirers should ensure that integrators or suppliers are afforded sufficient opportunity to identify such data and must appropriately protect that data commensurate with the sensitivity of the data and consistent with all applicable laws and regulations. Federal agencies should reference existing laws and guidelines on data classification, retention, and protection for further guidance. Similarly, integrators should appropriately protect supplier's data that will be collected. The details of this protection should be appropriately documented in contractual language that specifies how the data will be used, how long it will be kept, with whom it can be shared, or what intellectual property protections will apply.

All of the tools and mechanisms described in this section that help implement the practices should be protected throughout the system or element life cycle.

\begin{tabular}{|c|c|c|}
\hline Type of Action & Role & Description of Action \\
\hline $\begin{array}{l}\text { Programmatic } \\
\text { Activities }\end{array}$ & Acquirer & $\begin{array}{l}\text { Practices that a federal department and agency acquirer } \\
\text { will undertake within their programs, including } \\
\text { requirements to be included in contractual documents, } \\
\text { as well as internal policies and procedures. }\end{array}$ \\
\hline \multirow[t]{2}{*}{$\begin{array}{l}\text { General } \\
\text { Requirements }\end{array}$} & Integrator & $\begin{array}{l}\text { General practices that an integrator will implement } \\
\text { within programs that are either in response to } \\
\text { contractual requirements or to document existence of } \\
\text { programmatic activities that reduce ICT supply chain } \\
\text { risk. }\end{array}$ \\
\hline & Supplier & $\begin{array}{l}\text { General practices that a supplier will implement within } \\
\text { programs to document existence of programmatic } \\
\text { activities that reduce ICT supply chain risk. }\end{array}$ \\
\hline \multirow[t]{2}{*}{$\begin{array}{l}\text { Technical } \\
\text { Implementation } \\
\text { Requirements }\end{array}$} & Integrator & $\begin{array}{l}\text { Detailed technical practices that an integrator will } \\
\text { implement within programs to document technical } \\
\text { capabilities to manage ICT supply chain risk. }\end{array}$ \\
\hline & Supplier & $\begin{array}{l}\text { Detailed technical practices that a supplier will } \\
\text { implement within programs to document technical } \\
\text { capabilities to manage ICT supply chain risk. }\end{array}$ \\
\hline \multirow[t]{2}{*}{$\begin{array}{l}\text { Verification } \\
\text { and Validation } \\
\text { Activities }\end{array}$} & Acquirer & $\begin{array}{l}\text { Suggestions for how a federal agency acquirer can } \\
\text { ascertain that integrators have implemented ICT SCRM } \\
\text { in compliance with contract requirements. }\end{array}$ \\
\hline & Integrator & $\begin{array}{l}\text { Suggestions on how an integrator can demonstrate that } \\
\text { they have implemented ICT SCRM. }\end{array}$ \\
\hline
\end{tabular}




\begin{tabular}{|l|l|l|}
\hline & Supplier & $\begin{array}{l}\text { Suggestions on how a supplier can demonstrate that } \\
\text { they have implemented ICT SCRM. }\end{array}$ \\
\hline
\end{tabular}

\section{Table 3. Practice Format}

\subsection{Uniquely Identify Supply Chain Elements, Processes, and Actors}

Knowing who and what is in an enterprise's supply chain is critical to gain visibility into what is happening within it, as well as monitoring and identifying high-risk events and activities. Without reasonable visibility and traceability into supply chain, e.g., elements, processes, and actors, it is impossible to understand and therefore manage risk, and to reduce the likelihood of an adverse event. Uniquely identifying organizations, personnel, mission and element processes, communications/delivery paths and elements, as well as the components and tools used, establishes a foundational identity structure for assessment of ICT supply chain activities. For example, labeling (e.g., serial number) and tagging (e.g., radio-frequency identification [RFID] tag) software packages and modules, hardware devices, individual elements, and processes that surround them can be used for this purpose.

\subsubsection{Acquirer -Programmatic Activities}

a) Establish and retain unique identification (physical and logical) of acquirer and integrator roles, organizations, people, ideas, requirements, processes, items of supply, tools used on items of supply, T\&E procedures, delivery mechanisms, support mechanisms, and disposal/final disposition activities at the lowest practicable level.

b) Ensure that unique identifiers and methods of identification (e.g., code signing, RFID, and serial numbers) be difficult or impossible to alter and that any alterations adhere to previously set, clearly defined criteria.

c) Require that identification methods are sufficient to support provenance in the event of a supply chain issue or adverse supply chain event.

d) Establish a trusted baseline for the system/element and operational configuration based on SLAs.

e) Ensure that individuals within acquirer and integrator organizations are assigned appropriate roles throughout the system/element life cycle, regardless of personnel turnover, to ensure that the visibility of critical processes and elements is maintained.

f) For hardware, obtain detailed bill of material data highlighting the elements with embedded logic complete with element Original Equipment Manufacturer (OEM) and production location.

\subsubsection{Integrators - General Requirements}

a) Ensure that the identification method is sufficient to support system/element provenance in the event of a supply chain issue or adverse supply chain event. 
b) Ensure the implementation of unique identification requirements by developing and applying policies, procedures, and means to identify objects and activities within the supply chain at the sub-element, element, and system levels.

c) Apply unique identification requirements to design, test, and evaluation activities to include design tools (hardware and software), drawings and diagrams, and tools used to protect the design, test, and evaluation processes.

d) Require unique identifiers for critical elements in written supplier agreements.

e) Require strength of the authentication mechanism to be commensurate with the significance of the element, system, process, and /or organization to acquirer mission requirements.

f) Define, design, and implement roles to limit privilege to understand and, as needed, mitigate the risk of adverse consequences throughout the supply chain and element life cycle.

g) Establish mechanisms and processes for checking and auditing unique identifications within the acquirer and integrator environments.

h) Document that integrator personnel are assigned appropriate roles throughout the system/element life cycle, regardless of personnel turnover, to ensure that the visibility of critical processes and elements is maintained.

\subsubsection{Suppliers - General Requirements}

a) Apply unique identification requirements to delivered elements (e.g., serial numbers, date codes, license labels, etc.).

b) Ensure that identification methods are sufficient to support provenance in the event of a supply chain issue or adverse supply chain event.

c) Establish policies and procedures that require identification methods to support provenance in the event of a supply chain issue or adverse supply chain event.

d) Define, design, and implement roles that limit privilege and create redundancy throughout the element life cycle to mitigate the risk of a single role being able to, intentionally or unintentionally, create adverse consequences.

e) Require protection and safeguarding of authentication mechanisms.

\subsubsection{Integrators - Technical Implementation Requirements}

a) Implement unique identification requirements for elements and systems by applying policies, procedures, and means of identification to the supply chain.

b) Apply unique identifiers to design, test, and evaluation activities, including design tools (hardware and software), drawings and diagrams, bills of material, and tools used to protect the design, test, and evaluation processes.

c) Integrate mechanism(s) to uniquely identify system-critical hardware elements, such as a physical identifier or authenticator to the hardware. This makes unauthorized substitutions more detectable. This can include etched bar codes, holograms, or other unique identification technologies.

\subsubsection{Suppliers - Technical Implementation Requirements}

None 


\subsubsection{Acquirer - Verification and Validation Activities}

a) Assess the effectiveness of acquirer and integrator identity management and access control policies, procedures, and practices in limiting exposure of, or access to, elements or element processes.

b) Assess implementation of the acquirers' and integrators' assignment of tasks and activities to roles.

c) Employ tools and techniques to determine if authenticators are sufficiently strong to resist attacks intended to discover or compromise authenticators.

d) Perform audits on unique identification deficiencies within acquirer system/environment and report up the supply chain for corrective action.

e) Check for robustness of the acquirer and integrator infrastructure that manages both identities and labels. Assess whether identities or labels can be detected or altered (e.g., counterfeiting of credentials or spoofing of identity).

f) Examine and document weaknesses and vulnerabilities in the unique identity implementation so they may be monitored for adverse events.

g) Examine and test mechanisms for applying unique identification to discover potential deficits and/or faults in the design or implementation of such mechanisms.

\subsubsection{Integrators - Verification and Validation Requirements}

a) Assess implementation of the integrators' assignment of tasks and activities to roles.

b) Ensure that unique identifications are assigned to all actors/roles and to the tactics, techniques, procedures, and tools most associated with those actors in order to facilitate detection and tracking of threats across multiple supply chains.

c) Examine and test mechanisms for the application of unique identifications to discover potential deficits and/or faults in the acquirer system design or implementation of such mechanisms.

d) Document weaknesses or vulnerabilities in the unique identification implementation to enhance the ability of all supply chain participants to monitor the supply chain for adverse events.

e) Report deficiencies to the acquirer for corrective action to ensure that requirements for unique identification are fulfilled.

\subsubsection{Suppliers - Verification and Validation Requirements}

Report deficiencies discovered in critical elements (per acquirer/integrator) up the supply chain for corrective action to ensure that requirements for unique identification are fulfilled. 


\subsection{Limit Access and Exposure within the Supply Chain}

Elements that traverse the supply chain are subject to access by a variety of actors. It is critical to limit such access to only as much as necessary for those actors to perform their role(s) and to monitor that access for supply chain impact. Access control techniques exist that may be useful in providing needed granularity to ensure that only appropriate actors can monitor or change supply chain elements, element processes, organizations, organizational processes, information, communications, and systems covering the comprehensive supply chain.

\subsubsection{Acquirer - Programmatic Activities}

a) Establish an internal policy for the broad responsibilities of assigning access control to information, systems, supply chain elements, element processes, as well as key personnel and organizational activities as deemed necessary to protect the confidentiality, integrity, and availability of supply chain elements and processes throughout the system/element life cycle.

b) Instantiate general criteria by which access controls are to be applied, the objects of such controls, the initiating and terminating events or conditions under which such controls are applied, and specific access control mechanisms (e.g., automated, manual, or hybrid).

c) Identify the individuals (roles) and organizations with responsibility for the design, development, and implementation of access controls, to include use of information security, operations security, physical security, industrial security, and IA tactics, techniques, procedures, and tools.

d) Define requirements to include access control (both physical and logical) requirements in all written agreements with integrators including:

- Responsibilities for assigning access control among all parties;

- Mandatory, recommended, and prohibited access control methods; and

- Audit plans for access control review.

e) Define, design, specify, and require assigned roles throughout the supply chain and system or element life cycle so that no single role can, intentionally or unintentionally, create adverse consequences.

f) Evaluate all positions for opportunities to expose elements, processes, systems, or information, including requirements to potential compromise.

g) When developing system requirements, minimize exposing the uses of systems and elements, as well as the processes by which they are designed, developed, produced, tested, delivered, or supported.

h) Establish an internal policy for remote access, including allowing access to the organization's location and third-party locations, media, network, and other items to be determined.

i) Establish and document a policy describing allowed methods of remote access to elements, systems, processes, and organizations.

j) Establish and enforce requirements for personnel security reviews and assessments for acquirer personnel. These reviews and assessments should include personnel who have exposure or access to sensitive information, such as elements, element processes, business activities, or integrator or supplier intellectual property. Special attention should be paid to those personnel with 
the technical knowledge or understanding of enterprise processes that would allow them to obtain unauthorized exposure of, or access to, elements or processes that could result in compromise or loss.

\subsubsection{Integrator - General Requirements}

a) Define requirements to include access control (both physical and logical) requirements in all written agreements with acquirers and suppliers including:

a. Responsibilities for assigning access control among all parties;

b. Mandatory, recommended, and prohibited access control methods; and

c. Audit plans for access control review.

b) Review trade-offs regarding cost, schedule, and performance resulting from the application of different combinations or specific access control mechanisms.

c) Limit access to the following information (including any associated metadata): the identity of the user or developer; the functions of the system; the other systems with which it will interface; the missions the system supports; when or where the system elements will be bought/acquired; how many system instances there will be; and where the system may be deployed. The limitations on information sharing may differ for different parties and at different times (e.g., before, during, and after acquisition).

d) Conduct integrator key personnel security reviews and assessments. These reviews and assessments should include personnel who have exposure or access to elements, element processes, or business activities. Special attention should be paid to those personnel with the technical knowledge or understanding of enterprise processes that would allow them to obtain unauthorized exposure of, or access to, elements or processes that could result in compromise or loss.

\subsubsection{Supplier - General Requirements}

Use access control mechanisms that limit access to sensitive information.

\subsubsection{Integrator - Technical Implementation Requirements}

a) Develop and implement roles throughout the system life cycle to limit opportunities and means available to individuals performing these roles to expose elements, processes, systems, or information, including requirements to potential compromise.

b) Employ automated and repeatable mechanisms, when feasible, to facilitate monitoring and controlling:

a. Various access methods (physical and logical);

b. Access occurring with no manual observers and controllers; and

c. High volume of access requested in a given short period of time or simultaneously.

c) Employ automated and repeatable mechanisms, when feasible, to facilitate the maintenance and review of access records.

d) Maintain records of all physical and logical accesses and activities, both authorized and unauthorized, including by visitors and regular individuals in accordance with existing acquirer and integrator polices. 
e) Provide access control protection for both remote and mobile devices and the use of remote and mobile access points to the supply chain infrastructure.

f) Obtain chain-of-custody evidence and require tamper-evident packaging for critical hardware elements.

g) If two or more unique identities have access to an element, process, organization, information, or system, use multifactor authentication mechanisms. Two or more unique identities can include one user and one administrator when feasible.

h) Limit the use of a unique identity for multiple uses by restricting privileges and permissions (e.g., with implementation of single sign-on Personal Identity Verification).

i) Employ FIPS-validated or National Security Agency (NSA)-approved cryptography to implement digital signatures.

\subsubsection{Supplier - Technical Implementation Requirements}

Document the instantiation of audit mechanisms used to audit access control procedures (e.g., audit logs, access reports, and security incident tracking reports).

\subsubsection{Acquirer - Verification and Validation Activities}

a) Assess security risks to physical and logical access controls intended to prevent unauthorized exposure of, or access to, tools, processes, people, and systems in the supply chain that create supply chain elements or information about such elements or unauthorized introduction of counterfeit parts.

b) Perform security checks at the physical and logical boundary of the element, element processes, facilities, and system, for unauthorized access to or export of information, elements, tools, and materiel used in element processes.

c) Prevent, detect, and document any physical tampering or altering of access control mechanisms.

d) Review the integrator's processes and procedures aimed at limiting exposure of system and elements uses.

\subsubsection{Integrator - Verification and Validation Requirements}

a) Demonstrate that a mix of personnel, physical, and logical access controls are implemented which provide a level of protection commensurate with the sensitivity/criticality of the services provided or the elements procured.

b) Perform technical and procedural audits of mechanisms used to shield information related to elements, including uses, requirements, and metadata.

c) Employ Red Team approaches to identify potential pathways or opportunities for adversaries to exploit deficits or weaknesses in supply chain processes that would result in the exposure of the element or associated information including uses of element.

d) Assess the effectiveness of alternative configurations in protecting access of elements, processes, systems, and information for the purposes of confidentiality, integrity, and availability. 
e) Test internal access controls for the ability to detect anomalous behavior and facilitate timely intervention to prevent or reduce adverse consequences.

\subsubsection{Supplier - Verification and Validation Requirements}

a) Demonstrate use of access control mechanisms across the system or element life cycle and the associated supply chain.

b) Demonstrate ability to intervene in a timely manner to prevent or reduce adverse consequences within the supply chain.

\subsection{Establish and Maintain the Provenance of Elements, Processes, Tools, and Data}

All system elements originate somewhere and may be changed throughout their existence. The record of element origin along with the history of, the changes to, and the record of who made those changes is called "provenance.” Acquirers, integrators, and suppliers should maintain the provenance of elements under their control to understand where the elements have been, the change history, and who might have had an opportunity to change them.

Provenance is used when ascertaining the source of goods such as computer hardware to assess if they are genuine or counterfeit. Provenance allows for all changes from the baselines of components, component processes, information, systems, organizations, and organizational processes, to be reported to specific actors, functions, locales, or activities. Additionally, creating and maintaining provenance within the supply chain helps achieve greater traceability in case of an adverse event and is critical for understanding and mitigating risks. Doing so requires a process by which changes to objects and activities within a supply chain and the persons, organizations, or processes responsible for authorizing and performing such changes are inventoried, monitored, recorded, and reported.

Provenance can be achieved through both physical and logical techniques, such as Configuration Management (CM) for tracking changes to the elements and documenting the individuals who approved and executed these changes; robust identity management and access control to establish and record authorized or unauthorized activities or behaviors; and identification/tagging of elements, processes, roles, organizations, data, and tools.

\subsubsection{Acquirer - Programmatic Activities}

a) Establish acquirer policies requiring the provenance of acquirer and integrator tools, data, and processes used throughout the system or element life-cycle.

b) Establish policies and procedures for tracking who has access and makes changes to individual elements and element processes throughout the supply chain.

c) Establish policies to further stipulate that information related to the provenance of tools, data, and processes should be collected, processed, stored, and 
disseminated in a controlled and protected manner equal to or greater than the individual items for which provenance is maintained.

d) Establish policies to allocate responsibilities for review and approval of all changes in items subject to CM control.

e) Ensure that all change control requirements are proposed, evaluated, and justified for their impact on elements, processes, systems, missions, and exposure to supply chain risks.

f) Ensure that the organization develops, documents, and maintains under configuration control, a current baseline configuration of elements, systems, and processes (both personnel and organizational), including communicationsand connectivity-related aspects.

g) Incorporate supply chain mitigations and practices into existing organization CM policies and procedures.

h) Ensure that audit mechanisms are in place to track all changes upon approval.

i) For physical product delivery, maintain documentation of individuals who were in possession of an element at any time during purchasing, shipping, receiving, or transfer activities, including records of reviewer signatures for comparison.

\subsubsection{Integrators - General Requirements}

a) Establish formally documented roles, responsibilities, and procedures to include the management of information and documentation for establishing provenance.

b) Establish policies and procedures for tracking who has access and makes changes to individual elements and element processes throughout the supply chain.

c) Include requirements for the creation and tracking of the provenance of tools, data, and processes used throughout the system or element life cycle.

d) Document the allocation of responsibilities for the creation, maintenance, and monitoring of provenance. Subject these records to internal controls and independent audit. Require protection of such records at a level commensurate with or greater than the protection of the items, processes, or activities they describe.

e) Ensure information in the CM system is authenticated and non-repudiable (Digital signatures can be used to confirm this information.).

f) Record in CM system all changes to the element or system by processes initiated by either humans or automated systems.

g) For system, element, process, and configuration changes, where a change in element or process cannot be reversed or where non-repudiation of change is not possible, use a two-person rule for changes.

h) Employ automated mechanisms and repeatable processes to address the number and frequency of changes and to minimize human interaction to minimize error. Ensure the timely collection of change throughout the system or element life cycle.

i) Establish and implement a policy to document, monitor, and maintain valid baselines for systems and elements, including spare parts and warehoused systems/elements, throughout the life cycle. Document changes to baselines and disseminate updated baselines to appropriate supply chain participants. 
j) Define, document, approve, and enforce physical and logical access restrictions associated with changes to the elements, systems, and processes.

k) Protect information systems containing CM information against unauthorized exposure and access, including via physical and logical attacks.

l) Establish and implement a process for the CM of documentation, COTS or GOTS elements, and custom systems/elements. Perform security assessments of the CM processes and systems to attempt the detection of ongoing attacks (including the CM systems).

m) Add new elements into the CM system as configuration items (CIs) when they are introduced into the supply chain.

n) Ensure that audit mechanisms are in place to track all actual changes upon change control approval. Establish a verification process to provide additional assurance that the process of recording provenance and configuration change is working effectively, and that changes outside of these processes are prohibited by policy, with compliance enforced.

o) For physical product delivery, maintain documentation of individuals who were in possession of an element at any time during purchasing, shipping, receiving, or transfer activities, including records of reviewer signatures for comparison.

\subsubsection{Suppliers - General Requirements}

a) Provide evidence of formal processes for documenting roles, responsibilities, and procedures to include the management information and documentation for establishing provenance.

b) Provide evidence on element baselines and maintenance throughout the system or element life cycle, including as part of logistics. Establish and implement a policy to monitor and maintain a valid baseline.

c) Identify and implement appropriate levels of confidentiality, integrity, and availability including spare parts and warehoused systems/elements.

d) Ensure that the provenance of supply chain configuration items (e.g., in the CM system) is protected from unauthorized access and change.

e) Upon request, make available up-to-date product histories that document element changes including retired elements under warranty.

\subsubsection{Integrators - Technical Implementation Requirements}

a) Employ the use of mechanisms (tools and techniques) to assist in developing and maintaining the provenance of tools, data, and processes used throughout the system or element life cycle, including but not limited to use of CM or Configuration Control systems.

b) Design and implement a two-person rule for system/element/process and configuration changes, where change in an element or process cannot be reversed, or where non-repudiation of change is not possible. Identify, document, and review any exceptions from the mandatory configuration settings for individual elements, systems, and processes based on the development, operational, and delivery requirements. 
c) Employ automated mechanisms, both centrally and through a trusted distributed CM system, whereby configuration settings are applied, managed, and verified. (Note: Most automated CM systems work in both a central and distributed manner and can be set up to have a trusted distributed CM environment.)

d) Incorporate detection mechanisms for unauthorized, security-relevant configuration changes into the integrators' incident response capability to ensure that detected CM events associated with element changes are tracked, monitored, corrected, and available for historical purposes.

e) Ensure that backup information systems containing CM information implement immutable chains (e.g., digital signatures proving a sequence of events) and deploy a recovery process when a CM information system is breached or unavailable.

f) Implement accountability for all changes in configuration items by recording the identity of each individual who is making a change, when each change was made, and exactly what the change was. This information should be authenticated such that it cannot be repudiated (Digital signatures can be used to confirm this information.).

g) Document the process for ensuring traceability when moving information, elements, and processes across physical and logical boundaries including any approvals required. This may include the identification of key personnel for the handling of information.

h) Establish performance and sub-element baselines for the system and system elements. This helps to detect unauthorized tampering/modification during repairs/refurbishing by comparing the state of the returned element with the original state per element baseline.

i) Maintain chain of custody for any hardware element sent to an external provider for repair.

\subsubsection{Suppliers - Technical Implementation Requirements}

a) Establish configuration baselines for elements. This helps to detect unauthorized tampering/modification during repairs/refurbishing or unauthorized changes to audit policy or mechanisms of audit mechanisms. For example, consider using RF interrogation of ICs and compare those results to results from known trusted ICs.

b) Ensure evidence that identity management and access control provide auditability with respect to use of the CM system by supplier personnel.

\subsubsection{Acquirer - Verification and Validation Activities}

a) Verify and validate that the provenance data is appropriately protected. 
b) Document and test that the element, system, and processes (including modifications to the baseline configuration) conform to acquirer security configuration guidance - both to be deployed and already deployed.

c) Review integrators' CM processes and activities, including monitoring and auditing of the CM systems to attempt detection of ongoing attack and if separate, completion of security assessments of the CM processes and CM systems.

d) Audit integrators' ability to trace critical elements and processes throughout the supply chain.

e) Audit integrators' ability to trace any authorized and unauthorized modifications to critical elements and processes throughout the supply chain.

\subsubsection{Integrators - Verification and Validation Requirements}

a) Monitor and audit the CM systems to attempt detection of ongoing attacks.

b) Perform security assessments of the CM processes and CM systems.

c) Assess and test security measures to protect the provenance process, documentation, and system of records proposed by the security and system engineering communities.

d) Provide documentation for the methods used for countering subversion and the loss of provenance, for example, backups, immutable chains in the CM mechanism (e.g., digital signatures proving a sequence of events), or recovery processes when subversion of a CM repository is detected.

\subsubsection{Suppliers - Verification and Validation Requirements}

a) Demonstrate effective implementation of provenance processes and activities as well as CM mechanisms.

b) Demonstrate the periodic assessment and testing of security measures to protect the provenance process, documentation, and system of records proposed by the security and system engineering communities.

\subsection{Share Information within Strict Limits}

Acquirers, integrators, and suppliers need to share data and information. For the purposes of ICT SCRM, information sharing is the process by which acquirers, integrators, and suppliers (including COTS) exchange pertinent data and information. The data and information that may be shared can span the entire system or element life cycle and the entire supply chain. Content to be shared may include data and information about the use of elements, users, acquirer, integrator, or supplier organizations, as well as information regarding issues that have been identified or raised regarding specific elements. Information should be protected according to mutually agreed-upon practices. Information that could be shared may include: 
- Element design, development, test, evaluation, manufacturing, packaging for use, packaging for delivery, delivery processes, field sustainment, and depot sustainment;

- Element's development, CM, test, and operational environment information;

- The threat agents, as well as the tactics, techniques, procedures, and tools used by threat agents to attack suppliers or elements;

- Past history of element and supplier performance as well as supplier track record in successfully resolving identified issues; and

- Agreements language including contract clauses, acquisition strategies, and construction of interagency agreements.

Information sharing is difficult to scope as the activity of sharing can be one-to-one, one-to-many, or many-to-many. Information sharing is also driven by the agreement between the acquirer and the integrator and is dependent on the content of the agreement. The challenge for ICT SCRM is to ensure that information reaches specified individuals and organizations in quantity, quality, and with timeliness to perform required tasks or execute necessary functions.

Information sharing ultimately depends on the combination of attributes including the content of the information, the confidence in individuals, organizations, and systems, and their defined roles and authorities. A combination of these attributes is needed in order to implement information-sharing techniques. All parties to the agreement should ensure that the sensitive or proprietary data, including shared intellectual property, is protected appropriately.

\subsubsection{Acquirer - Programmatic Activities}

a) Establish a policy about the sharing of information throughout the life cycle of the systems/elements. Include the following topics:

a. Which information is to be shared and which information is to be withheld from sharing;

b. Those individuals and organizations eligible to receive, store, use, and retransmit information;

c. The duration of information-sharing activities, as well as the events on which information sharing will begin and will be terminated;

d. Standards and requirements for protection of data at rest and in motion;

e. Standards to be used to protect shared information against unauthorized disclosure, access, modification, dissemination, or destruction, and unauthorized use of data and information;

f. Requirements for establishing identity of participants in informationsharing arrangements;

g. The means by which information sharing is executed and the mechanisms used to provide protection of information commensurate with the importance of such information; and

h. The planning and execution of audits of information-sharing activities.

b) Enable selected authorized users to determine whether access authorizations assigned to sharing partners match the access restrictions on the information.

c) Ensure that incoming communications are originating from an authorized source and routed to an authorized destination. 
d) Validate the binding of the information-sharing party's identity to the information at the transfer/release point prior to release/transfer from one domain to another.

e) Protect requirements and supporting documentation, including acquirer, integrator, and supplier intellectual property, from exposure or access that could result in the compromise or loss the confidentiality, integrity, or availability of the requirements.

f) Develop source-selection criteria and procedures that encourage integrators to provide acquirers visibility into elements, services, and processes as part of their contracts.

g) Develop approaches that encourage integrators to gain visibility into their supply chains as deeply as possible and are reasonable. (1) Develop incentives that reward integrators for providing program-specific detailed technical information and technical data on products and services throughout the life cycle; and (2) include requirements that address the selection of open source elements.

h) Encourage and provide incentives for integrators and suppliers to deliver, for the life span of the contract, up-to-date information on changes that affect the supply chain, technology, and risk to the system and elements throughout the life cycle, such as changes in suppliers, locations, process, and technology.

i) Encourage integrators to provide technical details - both depth and breadth about the system/service, including designs (such as blueprints, schematics, bills of material, architectures, and interfaces). Such information may also be important to enable later support should the integrator stop supplying the system/service.

j) Encourage integrators to evaluate, document, and share element/element process information (including open source) that could result in weaknesses or vulnerabilities and if exploited, could result in loss or compromise.

k) Define criteria for sharing types of evidence including: measures, activities, behaviors, and test results. Criteria may include conformance with specifications and standards, compliance with statutory or regulatory requirements, and compliance with contract terms and conductions.

l) Prefer integrators and suppliers that proactively maintain transparency about themselves, their elements, and their suppliers (e.g., proactively provide all known errata for their elements and services). Please note that information published in errata may have vulnerability implications and thus should be screened before publishing.

m) Develop and employ acquisition and procurement policies, procedures, vehicles, and processes that establish restricted access to information by potential suppliers or integrators.

n) When developing requirements, minimize exposing the uses of the system and its elements, as well as the processes by which elements are designed, developed, produced, tested, delivered, or supported.

o) Based on the risk requirements of the mission and organization, consider using a centralized intermediary to acquire elements.

p) Centralize support and maintenance services to minimize direct interactions that may expose confidentiality of system uses.

q) Diversify/disperse how the product is acquired in order to make it difficult for an adversary to determine how, when, and where an element will be acquired. 
When appropriate, make the supply route less predictable through dynamic sourcing from multiple suppliers.

r) Prefer integrators who can support centralized and/or dispersed buying approaches upon request.

s) Share acquisition strategy and contract document approaches and language with other activities using or interested in common elements or suppliers.

t) Where appropriate, devise contract requirements that can be reused by other projects, and encourage the use of common requirements.

u) Provide an agreed-upon set of information security procedures to be used for information sharing across the element and system with various stakeholder communities (e.g., systems engineering, security, threat assessment, and threat response).

\subsubsection{Integrators - General Requirements}

a) Document applicable information-sharing arrangements including:

a. Description of the information to be shared;

b. The conditions under which such information will be provided to recipients;

c. The terms and conditions governing the purposes and uses to which the shared information may be applied;

d. Requests for information should protection be required of shared information, including sensitive data such as intellectual property or privacy;

e. Standards and requirements for the protection of information at rest and in motion;

f. Mechanisms by which the identity of participants in information-sharing arrangements will be established;

g. Mechanisms and methods by which the required level of information protection will be achieved;

h. Responsibilities for monitoring and oversight of information-sharing practices, procedures, techniques, and mechanisms allocated; and

i. Assignment of planning and execution of information-sharing and information-protection audits.

b) Separately document the instantiation of the techniques, procedures, and tools used to implement information-sharing agreements. Include the identity of participants in information-sharing activities, the means by which information sharing is executed, the mechanisms used to provide protection of information, commensurate with the importance or sensitivity of the information being shared, and the planned and executed audits of information-sharing activities.

c) Identify essential elements of information associated with each supply chain activity or task and the roles, processes, or organizations for whom access to such elements of information is necessary and sufficient to the successful performance of the supply chain. Such supply chain tasks could include, but are not limited to, requirements definition, acquisition and procurement planning, supply chain element creation, manufacturing, testing and evaluation, packaging for use, packaging for delivery, operational use, field and depot sustainment, and disposal and final disposition activities. 
d) Identify and assess alternative mechanisms, techniques, and procedures that could be used to facilitate the sharing of information necessary and sufficient to complete supply chain tasks. Such mechanisms could include manual, semiautomated, or fully automated systems and processes.

e) Identify tactics, techniques, procedures, and tools that could be employed to protect information-sharing mechanisms and processes against unauthorized access or unauthorized use of information included in information-sharing activities and processes.

f) Apply identity management, access controls, and CM to the informationsharing activities and processes.

g) Maintain and be prepared to share audits from various communities (systems engineering, security, threat assessment, and threat response) for further assessment, evaluation, and response.

h) Report to stakeholders the results of the audits and assessment of negotiated changes of operational and technical requirements, technical specifications, and mandatory business practices.

i) Prefer suppliers who maintain transparency about themselves, their elements, and their suppliers. For example, select suppliers who proactively provide:

a. Measures of continuous improvement in the usage of quality processes ISO/IEC 9001, ISO/IEC 27001, ISO 28000, and other certifications, which can be leveraged to help ascertain existence of responsible quality practices as they pertain to SCRM; and

b. Measures such as Common Vulnerability Scoring System (CVSS) scores for vulnerabilities and fixes that they release publicly above a particular severity level, before the product ships.

j) Protect against disclosing the uses of system, elements, or processes by which elements are designed, developed, produced, tested, delivered, or supported, or convey technological or operational advantage.

k) Report supply chain threats and incidents in operational environments to agreed-upon recipient(s) within established time frame parameters.

\subsubsection{Suppliers - General Requirements}

a) Document applicable information-sharing arrangements including:

a. The conditions under which such information will be provided to recipients;

b. The terms and conditions governing the purposes and uses to which the shared information may be applied;

c. Standards for the protection of shared information against unauthorized disclosure or uses;

d. Standards and requirements for protection of information at rest and in motion;

e. Mechanisms by which the identity of participants in informationsharing arrangements will be established;

f. Mechanisms and methods by which the required level of information protection will be achieved;

g. Responsibilities for monitoring and oversight of information-sharing practices, procedures, techniques, and mechanisms allocated; and 
h. Assignment of planning and execution of information-sharing and information-protection audits.

b) Separately document the instantiation of the techniques, procedures, and tools used to implement information-sharing agreements, and include the identity of participants in information-sharing activities, the means by which information sharing is executed, the mechanisms used to provide protection of information commensurate with the importance of or sensitivity of the information being shared, and the planned and executed audits of information-sharing activities.

c) Document various tactics, techniques, procedures, and tools that could be employed to protect information-sharing mechanisms and processes against unauthorized access or unauthorized use of information included in information-sharing activities and processes.

\subsubsection{Integrators - Technical Implementation Requirements}

a) Implement information-sharing arrangements by identifying essential elements of information to be shared as required for the completion of activities such as requirements definition, acquisition and procurement planning, supply chain element creation, manufacturing, T\&E, packaging for use, packaging for delivery, operational use, field and depot sustainment, and disposal and final disposition.

b) Identify mechanisms, techniques, and procedures that can be used to facilitate the sharing of information and match them with the content, data type, and data volume to be shared so that:

a. Only the information necessary and sufficient to complete supply chain tasks is shared; and

b. Information sharing can be used to identify and further protect elements and information that, if disclosed or accessed, could compromise the confidentiality, integrity, or availability of supply chain elements, processes, or actors within the supply chain.

c) Define technical specifications and measures derived from operational requirements to protect supply chain processes including element production, assembly, packaging, delivery, testing, and support to understand, evaluate, and minimize opportunities for unauthorized exposure of, or access to, critical elements or processes that could result in loss or compromise of confidentiality, integrity, or availability.

d) Apply identity management, access controls, and CM to the requirements process to ensure the confidentiality, integrity, and availability of requirements as well as supporting data, information, and requirements development tools.

e) Encourage suppliers to provide technical details about their elements and/or services where appropriate. Examples of information may include interface specifications, configuration details, element processes, and any known weaknesses and vulnerabilities. Such information may be important to enable follow-on support, including when an element or service is no longer available.

f) Limit disclosure of delivery process information.

g) Configure systems and elements, as well as items delivered as part of support and maintenance activities, to conceal the uses of the system/element (e.g., disable or redirect "phone home” functions). 
h) Limit disclosure of testing methods and procedures, test data, and communication routes by which such data is distributed, analyzed, and reported.

\subsubsection{Suppliers - Technical Implementation Requirements}

a) Identify mechanisms, techniques, and procedures that can be used to facilitate the sharing of information and match them with the content, data type, and data volume to be shared so that information sharing:

a. Allows only the information necessary and sufficient to complete supply chain tasks; and

b. Can be used to identify and further protect elements of information that, if disclosed or accessed, could compromise the confidentiality, integrity, or availability of supply chain elements, processes, or actors within the supply chain.

b) Document technical specifications and measures to protect supply chain processes including element production, assembly, packaging, delivery, testing, and support to understand, evaluate, and minimize opportunities for unauthorized exposure of, or access to, critical elements or processes that could result in loss or compromise of confidentiality, integrity, or availability.

c) Limit disclosure of delivery process information. Limit disclosure of testing methods and procedures, test data, and communication routes by which such data is distributed, analyzed, and reported.

\subsubsection{Acquirer - Verification and Validation Activities}

a) Assess the implementation of protection mechanisms regarding informationsharing activities through the development of combinations of information security, IA, physical security, personnel security, and operations security activities.

b) Audit results of implemented filters that constrain data structures and content to information security policy requirements when transferring information between different content or security domains

c) Verify and document the implementation of identity management, access controls, and CM to information-sharing activities as well as the confidentiality, integrity, and availability of the data and information being included in such activities.

d) Evaluate the processes by which information is shared in response to the compromise or loss of confidentiality, integrity, and availability of information, supply chain elements, or supply chain processes.

\subsubsection{Integrators - Verification and Validation Requirements}

a) Assess the implementation of information-sharing activities through the development of combinations of information security, IA, physical security, personnel security, and operations security activities.

b) Audit the effectiveness of information-sharing policies and their implementation. 
c) Monitor the information flows and interrupt the unauthorized exchange of information when such exchanges are attempted.

d) Verify the implementation of identity management, access controls, and information-sharing activities to the confidentiality, integrity, and availability data and information being included in such activities.

e) Perform periodic assessments to measure the risk to the supply chain posed by information-sharing activities including the people, organizations, information sharing-processes, and systems.

f) Verify that all supply chain participants are sharing information in response to a compromise or loss of confidentiality, integrity, and availability of information, supply chain elements, or supply chain processes.

g) Verify that information is shared on proposed measures that could be employed to prevent exposure of or access to information on elements, processes, and suppliers in the event that proposed supply chain changes are adopted.

h) Employ operational security tactics, techniques, and procedures to verify that access to information shared with potential integrators and suppliers sustains and enhances the confidentiality of element uses.

i) Configure elements before delivery to conceal the uses of the element (e.g., disable or redirect "phone home" functions).

\subsubsection{Suppliers - Verification and Validation Requirements}

a) Document the assessment and implementation of protection mechanisms regarding information-sharing activities by establishing combinations of information security, IA, physical security, personnel security, and operations security activities.

b) Audit the effectiveness of information-sharing policies and their implementation.

c) Verify and document the implementation of identity management, access controls, and CM to information-sharing activities and the confidentiality, integrity, and availability data and information being included in such activities.

d) Document the processes for sharing information in response to the compromise or loss of confidentiality, integrity, and availability of information, supply chain elements, or supply chain processes.

\subsection{Perform Supply Chain Risk Management Awareness and Training}

A strong supply chain risk mitigation strategy cannot be put in place without significant attention given to training federal department and agency acquirer personnel and integrator personnel on supply chain policy, procedures, and applicable management, operational, and technical controls and practices. NIST SP 800-50, Building an Information Technology Security Awareness and Training Program, provides guidelines for establishing and maintaining a comprehensive awareness and training program. Additionally, the ISO/IEC 27001 information security management standard and the ISO 28000:2007 supply chain process integration and certification standard provide information on developing an organization-wide program that 
includes training. This practice focuses on supply chain-specific awareness and training practices. In general, the training should include all applicable practices found in this document.

\subsubsection{Acquirer Programmatic Activities}

a) Establish organizational policy and general contractual requirements that address personnel ICT SCRM awareness and training throughout acquirer and integrator organizations.

b) Develop a comprehensive awareness and training program that implements the organization's ICT SCRM policy and procedures.

c) Require ICT SCRM awareness training for all acquirer and integrator personnel involved in requirements, acquisition, and procurement activities.

d) Train acquirer personnel to evaluate integrators based on past performance related to personnel policies, procedures, and security practices as part of source selection requirements and processes.

e) Define processes by which general supply chain information and lessons learned will be collected and shared between acquirers, integrators, and suppliers as scoped within the contract. Define how this information should be protected based on acquirer, integrator, and supplier agreements.

f) Provide training to appropriate acquirer staff on standard commercial approaches for acquiring secondary market (refurbished) items, to ensure that secondary market items are adequately supported and maintained.

g) Train system administrators and users regarding what information should be kept secure (for confidentiality, integrity, and availability) including not revealing supplier intermediaries.

\subsubsection{Integrator - General Requirements}

a) Ensure that supplier personnel awareness and training includes ICT SCRM. If appropriate, incorporate into existing training on business risk - such as protection of intellectual property. (Training may also be part of a variety of certification processes including the ISO 28000:2007 supply chain certification process or the ISO/IEC 27001 information security management system certification process.)

b) Share relevant ICT SCRM information across the life cycle, including with personnel who are assigned a new role (e.g., due to a change in the life cycle phase) and with new personnel. This includes changes of roles and personnel associated with transitioning a system to an organization operating the system and any associated suppliers.

c) Provide training to appropriate integrator staff on standard commercial approaches for acquiring secondary market (refurbished) items, to ensure that secondary market items are adequately supported and maintained. 


\subsubsection{Supplier - General Requirements}

Provide evidence of the existence of training for appropriate supplier staff on standard commercial practices for acquiring secondary market (refurbished) items, to ensure that secondary market items are adequately supported and maintained.

\subsubsection{Integrator - Technical Implementation Requirements}

Train receiving personnel (such as technical personnel, equipment specialists, and item managers) on correct processes for receiving elements/services (including spare parts), including any known anomalies in parts (which may indicate counterfeits, subversion, or quality issues).

\subsubsection{Supplier - Technical Implementation Requirements}

Establish policy and procedures that require receiving personnel (such as technical personnel, equipment specialists, and item managers) to be trained on organizational processes for receiving elements/services (including spare parts), including any known anomalies in parts (which may indicate counterfeits, subversion, or quality issues).

\subsubsection{Acquirer - Verification and Validation Activities}

a) Monitor and review contract documents to ensure that requirements for awareness and training are included and are adequate.

b) Review integrator supply chain risk awareness and training against requirements.

c) Assess integrator effectiveness of supply chain risk awareness and training.

\subsubsection{Integrator - Verification and Validation Requirements}

a) Evaluate awareness and training program for effectiveness at ensuring that integrator personnel understand ICT supply chain processes and are exhibiting appropriate behavior to address them.

b) Provide periodic documentation demonstrating the implementation and operation of a comprehensive SCRM training program to the acquirer.

c) Provide periodic updates on the status of personnel SCRM training in support of contractual requirements.

\subsubsection{Supplier - Verification and Validation Requirements}

a) Demonstrate the implementation and operation of SCRM training and awareness program within the supplier organization.

\subsection{Use Defensive Design for Systems, Elements, and Processes}


The use of design concepts is a common approach to delivering robustness in security, quality, safety, diversity, and many other disciplines that can aid in achieving ICT supply chain risk management. Design techniques apply to supply chain elements, element processes, information, systems, and organizational processes throughout the system or element life cycle. Element processes include creation, testing, manufacturing, delivery, and sustainment of the element throughout its life. Organizational and business processes include issuing requirements for acquiring, supplying, and using supply chain elements.

Defensive design techniques explicitly address contingencies in the technical, behavioral, and organizational activities that could result in adverse supply chain events. Defensive design is intended to create options that preserve the integrity of the mission function and its performance to the end user or consumer of the supply chain element should any of the contingencies or contingency elements arise. Defensive design provides flexibility to handle uncertainty and the ability to adapt to changing circumstances including environmental, malicious, or unintentional harm within the supply chain.

Element and supply chain defensive design can increase robustness against attack by reducing the likelihood or consequences of attack. Defensive design techniques include activities that consider and test supply chain elements, element processes, and organizational processes for potential failure modes and the compromise or loss of confidentiality, integrity, or availability of information. For example, during the development of requirements, defensive design considerations can explore the consequences of compromising identity. During later phases of the system or element life cycle, defensive design considerations can examine the potential consequences of compromise or loss of test data integrity, and devise a set of alternative tests or delivery processes that would offset the loss of test data confidentiality. Defensive design can also help to ensure availability of required elements and continued supply in the event of compromise to the system/element.

Defensive design can help reduce the impact of an attack on ubiquitous elements if more than one type of element is used (e.g., routers from multiple manufacturers). Defensive design also includes the review of chosen elements for achieving diversity, uses of a new design element, and a range of alternative features that could be promulgated should the compromise or loss of confidentiality be suspected or detected, providing a feedback loop for continuous improvement of supply chain elements and element processes. The implementation of any defensive design technique must consider economies of scale to manage maintenance and support costs.

\subsubsection{Acquirer - Programmatic Activities}

a) Define, design, and implement roles for individuals, organizations, elements, and element processes throughout the system or element life cycle to limit or constrain:

a. Unmonitored or uncontrolled activity across multiple elements, processes, organizations, or systems; 
b. The opportunities or means for unauthorized exposure that can lead to the compromise of elements, element processes, systems, or information; and

c. The inability to detect or monitor adverse events.

b) Define and document acquisition processes by which elements are selected for use in systems and integrate these into the organization's operational practices, acquisition strategies, and procurement activities. Specify use of genuine and tested elements. If such elements are not available, require a vetting process for use of secondary market elements.

c) Use available information about applicable threats (including threat analysis and threat assessment) to support the development of appropriate requirements.

d) Review and evaluate the system/element criteria and requirements for diversity.

e) Establish organizational policies and procedures that consider an assessment of potential supply chain risks prior to making decisions restricting or limiting diversity of elements or suppliers.

a. Such assessments should discuss the pros and cons of the exposure of elements, supplier/integrator vulnerabilities, and opportunities for exploitation based on known adversarial tactics, techniques, procedures, or tools (for example, so that they could be mitigated through diversifying elements or the supply chain).

b. Identify cases where a customized, rather than standard configuration may be more appropriate to reduce risks of compromise.

f) Establish organizational procedures that require design processes to address protective or corrective options which either avoid mission interruption or permit graceful degradation of the system should the system be attacked or compromised.

g) Require integrators and suppliers to deliver elements and element processes with commercially reasonable security configurations and designs to limit access and exposure.

h) Establish comprehensive testing policy and procedures.

i) Require that the system's operational environment protect the system both physically and logically. Include applicable system integration and custom code extension in use as part of the upgrade and maintenance efforts in system operation requirements.

j) Develop and implement an approach for handling and processing reported supply chain anomalies. Require the separation of duties for people and organizations as well as the separation of functions for supply chain elements and element processes.

k) Require redundancy and diversity throughout the supply chain and document the benefits, risks, costs, and contingency plans to respond to supply chain risks resulting in decisions to reduce diversity and redundancy or alternatives in availability of supply chain elements or element processes.

l) Use threat assessment techniques and information to determine if the proposed design alternatives meet defensive design criteria.

m) Use threat analysis techniques (such as threat modeling) to examine the element's design vulnerabilities.

n) Model, simulate, test, and evaluate the supply chain risks prior to decisions to limit the diversity of system/elements or suppliers. 
o) Avoid use of secondary market elements unless no other sources exist. Should a decision be made to keep or use secondary market elements, after careful consideration, define and document the processes for how to procure, integrate, and maintain them.

p) Establish processes for making decisions regarding keeping or disposing of counterfeit elements for those cases when secondary market elements are found to be counterfeit or tampered with in the supply chain.

\subsubsection{Integrators - General Requirements}

a) Incorporate defensive design criteria in all technical requirements. These requirements should result in design options for elements, systems, and/or processes that protect mission capabilities, system performance, or element confidentiality, integrity, and availability.

b) Establish and implement processes by which elements are selected for use in systems. Specify use of genuine and tested elements.

c) Define the system/element requirements to allow for diversity in element supply.

d) Document evidence of separation of duties applied to limit opportunities and means to cause adverse consequences, across the supply chain and the element life cycle. Ensure there is no "single person point of failure" for key positions (including operations and maintenance) to reduce program impact if any particular key person departs.

e) Define and/or use standards-based technical interfaces and process requirements to provide options for the modification of processes or modification/replacement of elements should a supply chain compromise occur.

f) Develop processes to utilize, where appropriate, practices to institute original equipment manufacturer (OEM) product and software validation tools that are noninvasive and could detect counterfeits elements or product intrusions.

g) Establish an adequate supply of trusted spare and maintenance parts for use well beyond the life span of the system.

h) For critical elements/services, determine the specific source of the element/service, not merely a corporate or organizational identity.

i) Ensure that practices (including product and personnel practices) have been put in place in the supplier organizational entity to deliver elements/services with necessary confidentiality, integrity, and availability.

j) For critical elements, consider using preapproved sources (e.g., trusted foundry/trusted integrated circuits for elements containing integrated circuits).

k) Conduct an assessment of potential supply chain risks prior to making decisions restricting or limiting diversity of elements or suppliers, including legacy suppliers. Assessments should:

a. Discuss pros and cons of exposure of suppliers or elements deficits, weaknesses, faults, vulnerabilities, and opportunities for exploitation based on known adversarial tactics, techniques, procedures, or tools, so that they could be mitigated through diversifying elements or the supply chain; 
b. Identify cases where a standard configuration may reduce costs, but can increase risks due to known adversarial tactics, techniques, and procedures; and

c. Document risk-based decisions, taking above concerns into consideration.

l) Consider using more than one implementation or configuration of both the supply chain and the system/element.

m) Perform assessments of alternative implementations of required functionality in elements to assess deficits, weaknesses, faults, or vulnerabilities. Document relative strengths and weaknesses of alternative elements, element designs, and element processes.

n) Ensure that elements are assigned varying degrees of criticality depending on the purpose and use of each element.

o) Ensure the continued availability of required elements and continued supply in the event of compromise to the system/element through diversity of supply (especially on commodity functions).

p) Ensure the removal or the turning off of any unnecessary functions that are prevalent in COTS or, in some cases, GOTS. This would include implementations that may be designed to support multiple applications or purposes. If left active, these functions may permit unauthorized access or exposure of the system or perform a function that reduces the availability of other functions.

q) Prefer elements that use widely used and/or international standards, making it more feasible to replace them.

r) Implement and maintain mechanisms to deliver appropriate privileges, separation of duties, provenance, and protection of sensitive data related to elements or systems during the development process. This includes when collaboration is required among acquirers, integrators, and suppliers.

s) Perform manual review of elements, processes, and system(s) to identify and remediate any weaknesses and vulnerabilities including peer reviews (e.g., walk-throughs and inspections) and comprehensive or sampled reviews. Employ independent internal or external reviewers.

t) Use two-person control when performing custom development and integration of critical elements and performing critical processes, such as paired development processes.

u) When counterfeit or secondary market elements are found in the supply chain, notify the acquirer immediately. Work with the acquirer to decide whether to keep or dispose of these elements, and should a decision be made to use them, how to integrate them.

v) Identify critical elements by examining the composition of the system elements to ensure that their combination will not compromise the defenses. Combining two elements, each of which is individually secure from attack, may result in a new vulnerability.

\subsubsection{Suppliers - General Requirements}

a) Document the uses of processes by which elements are selected for use in systems. Specify the use of genuine and tested elements. 
b) Report to the acquirer any element maintenance changes, standard interface changes, patches, and upgrades with any associated vulnerabilities. Leverage industry best practice for security patches to include a list of what issues are "covered" in the patches (i.e., the nature of the issues, a severity rating such as CVSS, etc.).

c) Deliver, where appropriate, sufficiently robust elements that do not degrade in performance, even when out-of-bounds inputs are provided (where practicable).

d) If available, provide assessment results of potential failure modes and effects on various proposed element designs based on the application of observed adversary tactics, techniques, procedures, and tools.

e) Establish reviews as a practice (e.g., manual or using automated tools) to be employed as appropriate into the element life cycle, to identify and remediate any weaknesses and vulnerabilities; include peer reviews (e.g., walk-throughs and inspections) and comprehensive or sampled reviews.

f) Establish processes that address code changes that are authorized, validated, and tested (to ensure that they do not introduce regressions or break other functionality).

g) Notify the acquirer and the integrator when counterfeit products are found in the supply chain.

h) Ensure the use of processes that limit entrance of counterfeit items into the supply chain and when entered/breached, the processes for corrective action.

\subsubsection{Integrators - Technical Implementation Requirements}

a) Use existing resources such as market/technical analysis results, prequalified product lists (e.g., available from General Services Administration [GSA], DHS, or internal integrator list) for identifying candidate elements. If applicable, require elements to have certifications and validations such as Common Criteria, FIPS 140-2 validation, and Federal Desktop Core Configuration (FDCC)/ United States Government Configuration Baseline (USGCB).

b) Consider using more than one implementation of the supply chain or more than one implementation or configuration of the element.

c) Consider using paired development/manufacturing for systems and elements as it provides checks and balances for both intentional and unintentional insertions of malware and also provides a way to monitor the quality of development/manufacturing.

d) Identify and document diversity of suppliers to facilitate a change if the original supplier becomes unavailable.

e) Review elements to determine if source information matches are found on the approved products lists, and whether ownership has changed since its approval.

f) Consider placing elements in escrow and not (fully) paying for those elements until verification of authenticity and acceptance testing of element is complete.

g) If secondary market items have entered the supply chain, take actions to reduce the potential for subversion including additional verification, searching for 
malware, verifying firmware patches, comparison with known good products, and establishing larger stockpiles of spares.

h) Include protection for data at rest and in motion including, but not limited to, the use of various forms of encryption.

i) Assess the design and implementation of identity management, access controls, and process monitoring mechanisms to facilitate timely detection and classification of anomalous behaviors that may result in adverse consequences through observation of tasks and activities.

j) Use robust programming languages that do not have inherent security flaws for the development of operational requirements and technical specifications for custom-built products.

a. Implement hardware and software design using programming languages that avoid inherently insecure coding constructs to reduce the likelihood of weaknesses and supply chain-related compromise.

b. Design countermeasures and mitigations against potential exploitations of programming language weaknesses and vulnerabilities in system and elements.

k) Use structured and standardized approaches to reduce the complexity of the design, production, and implementation of both the system and the environment.

l) Identify and implement interface standards wherever practical to promote system and element sustainability and element reusability.

m) Use industry best practices, such as Defense Information Systems Agency (DISA) Security Technical Implementation Guides (STIGs), NSA Systems and Network Analysis Center (SNAC) guides, and NIST Special Publications and configuration checklists, to define secure configuration requirements and to configure elements to increase security and limit unnecessary functionality.

n) Determine the acceptability of, and document the presence of, abused behaviors or design deficits or weaknesses of the acquirer system that could become vulnerabilities if exploited (e.g., "call home” functionality, default passwords that do not require change before use).

o) Isolate system elements using techniques such as virtual machines, quarantines, jails, sandboxes, and one-way gateways to reduce the damage one element can do to another.

p) Include the ability to configure system or element isolation, even if this reduces system capability.

q) Limit the number, size, and privileges of critical elements.

r) Design elements to withstand out-of-bounds inputs (e.g., excessive voltages, numbers out of range, and so on), so that they are harder to disable.

s) Include fail-over/redundant systems or system elements when possible and appropriate.

t) Use FIPS 140-2-validated cryptographic modules at rest and in motion and anti-tamper (including tamper-resistant and tamper-evident) mechanisms to 
counter theft and subversion (including auto-destruction if tampering is detected).

u) Enable optional compiler warnings (where practical) early in the code development process to identify weaknesses and reduce false alarms. Compilers used in software development include some static analysis capabilities, but remediating the software can become difficult if the warnings are not enabled early. Flags will almost certainly increase false alarms during the phase they are used; however, the benefits outweigh having to address false positives.

v) Disable, remove, or require suppliers to disable or remove, unused functions of a system element, such as "extras" or extensibility functions such as plug-ins. Note that some of these “extras” may be useful to a system's mission, and are therefore not unused functions.

w) Develop bounding cases for design or operation for both elements and element processes to identify potential compromise or loss of confidentiality, integrity, or availability that would impact cost, schedule, or performance of those elements and element processes, as well as missions that they support throughout each system or element life cycle phase.

- Consider a broad range of contingencies (hazards) including natural events, unintentional actions by individuals or organizations, or intentional actions by individuals and organizations that might impact mission accomplishment.

x) Identify cases where a customized, rather than standard configuration may be more appropriate to reduce risks of compromise.

y) Prepare personnel participating in manual reviews by reporting or demonstrating known adversary tactics, techniques, procedures, and tools for exploiting weaknesses or deficits in systems/elements, assemblies, information systems, or processes.

z) Use a variety of testing techniques including fuzz testing, static analysis testing, dynamic testing, and penetration testing to identify architecture, design, and implementation weaknesses, search for common security weaknesses and vulnerabilities, search for virus/malware signatures, identify failures to comply with standards and requirements including process requirements, and identify areas in need of in-depth testing.

a. Test for compliance on both ends of interfaces. The use of standardized interfaces may facilitate the expanded use of test suites and potentially increase the breadth of testing.

b. Where practical, test and deliver the system with debug options off, or make the debug capabilities inaccessible to unauthorized users. While “debug” options may be useful during development, it is recommended to turn this function off and remove all relevant information from the executable system, to avoid exposure of system information that could lead to compromise. 
c. Use both negative and positive tests to verify that the system/element/process does not do what it should not do, as well as that it does what it is supposed to do.

d. Monitor for unexpected or undesirable behavior during testing, such as network behavior (e.g., a surprise "call home” or opening of network port), file system behavior (e.g., reading or writing information to unexpected files/directories), race conditions, and deadlocks.

e. Protect test cases and test results from unauthorized access by using encryption, signatures, and other methods. For example, for software, ensure that test cases and test results are signed to demonstrate absence of tampering.

\subsubsection{Suppliers - Technical Implementation Requirements}

a) Document various defensive design techniques used on the logical and physical design, manufacturing, and supply chain environment.

b) Document the variety of testing techniques used to verify whether the element can be trusted.

c) Provide elements "secured by default" at a level appropriate to the requirements of the acquirer or integrator (e.g., configuration guides).

d) Deliver elements in a manner that facilitates proof of authenticity verification by the acquirer.

e) Verify and document the use of both negative and positive tests to ascertain that the system/element/process does what it is supposed to do and does not do what it should not do.

f) Monitor for unexpected or undesirable behavior during test, such as network behavior (e.g., a surprise "call home” or opening of network port), file system behavior (e.g., reading or writing information to unexpected files/directories), race conditions, and deadlocks.

g) Establish a trusted baseline for the element and operational configuration. Use this baseline to identify unauthorized changes or tampering.

h) Use existing vulnerability and incident management capabilities to identify potential supply chain vulnerabilities.

\subsubsection{Acquirer - Verification and Validation Activities}

a) Review integrators' quality assurance processes to ensure compliance with requirements, federal procurement policy, and FAR.

b) Examine the element to ensure that it is as specified in requirements and that it is new, genuine, tested, and that all associated licenses (including support agreements) are valid.

c) Assess proposed or implemented acquirer system design, development, test, evaluation, assembly, manufacture, packaging, delivery, and sustainment processes for weaknesses (deficits) or faults (vulnerabilities) to determine their robustness and potential for compromise of confidentiality, integrity, or 
availability of elements and element processes, systems, information, and organizations.

d) Monitor, evaluate, test, and Red/Blue Team software and hardware implementation of designs for weaknesses and vulnerabilities; provide feedback to integrators and suppliers on findings, and work with them as they develop solutions and mitigating strategies.

e) Consider use of third parties to evaluate and test elements when those capabilities do not exist in-house.

f) Perform audits of defensive design practice requirements throughout the system or element life cycle.

g) Review test and evaluation results remediation throughout the life cycle to ensure compliance with configuration requirements as defined within the program.

h) Review and evaluate the application of criteria and decision outcomes for diversity choices against contractual requirements.

i) If counterfeit elements have entered the supply chain, take action to remove these items from inventory and any system where they have been installed as quickly as possible.

j) Monitor and audit systems and operations to reduce the risk of unauthorized removal, replacement, and/or modification of elements. Modification review may include applicable system integration and custom code extension activities as part of the upgrade and maintenance efforts for system operations.

k) Periodically audit integrator system activities for compliance with requirements/Service-Level Agreement (SLA) and to detect potential supply chain issues. This may include the review of any reports providing a summary of any detection of malicious functionality, known vulnerabilities, or changes in suppliers or supplier venue.

l) Perform assessments of potential failure modes and effects on various proposed element designs based on the application of hypothesized or observed tactics, techniques, procedures, and tools of threat sources.

m) Assess the effectiveness of alternative configurations in protecting the confidentiality, integrity, or availability of elements, processes, systems, and information against potential or observed threat sources.

n) Assess the effectiveness of physical and industrial security, information security, and IA tactics, techniques, and procedures to support design, definition, and implementation of roles to reduce opportunities for adverse consequences.

o) Assess the introduction of deficits, weaknesses, vulnerabilities, faults in, and opportunities for potential exposure of or access to elements or element processes as a result of different implementations of standards.

\subsubsection{Integrators - Verification and Validation Requirements}

a) Examine the element to ensure that it is new, that it was specified in the requirements, and that all associated licenses are valid. 
b) Identify past vulnerabilities in elements and element processes to determine if they have been addressed and what they indicate about the strength of the elements' security.

c) Implement a third-party assessment process for acceptance testing to ensure elements are genuine.

d) Verify that the element's performance does not degrade or cause system failure even when out-of-bounds inputs are provided (where practicable).

e) Perform assessments of potential failure modes and effects on various proposed element designs based on the application of hypothesized or observed adversary tactics, techniques, procedures, and tools.

f) Assess opportunities for the introduction of weaknesses and vulnerabilities in systems and elements as a result of different implementations of standards.

g) Assess the proposed use of government or military standards to guard against the unnecessary exclusion of other standards that unduly restrict choices of potential elements or suppliers.

h) Assess the effectiveness of alternative configurations in protecting the confidentiality, integrity, or availability of elements, processes, systems, and information against known vulnerabilities.

i) Monitor and assess the implementation of systems and the results of manual review requirements to ensure compliance with laws, regulations, policies, and conformance to contract specifications or standards. Include an assessment of testing results (from all types of testing) to identify additional vulnerabilities, and report results of such assessments.

j) Model, simulate, test, and evaluate supply chain risks prior to decisions to limit the diversity of system/elements or suppliers.

k) Consider documenting alternative implementations of supplied elements including relative strengths and weaknesses of alternative elements, element designs, and element processes (including supplier business practices), as well as deficits, weaknesses, faults, or vulnerabilities.

l) For COTS, provide integrator assessments results of supplier technologies to the suppliers, when appropriate, to ensure transparency and promote technology improvements.

\subsubsection{Suppliers - Verification and Validation Requirements}

a) Implement appropriate system and organizational certification requirements to provide rigor in the process to demonstrate a quality assurance mechanism's facet of defensive design. A management system certification, such as ISO 9001, ISO/IEC 27001, or ISO 28000, may provide evidence of quality assurance, security, and supply chain management processes.

b) Confirm (manually and/or automatically) that the operational configuration profile is correct. Report findings if actual operations differ from the expected (or baseline) operational profile. Such profiles should consider time of use, information being used (e.g., directories), applications, equipment, and connections used. 


\subsection{Perform Continuous Integrator Review}

Continuous integrator review is an essential practice used to ascertain that defensive measures have been deployed. It includes testing, monitoring, auditing, assessments, and any other means by which the acquirer observes integrator practices. The purpose of continuous integrator review is to validate compliance with requirements, ascertain that the system behaves in a predictable manner under stress, and detect and classify weaknesses and vulnerabilities of elements, processes, systems, and any associated metadata.

Federal department and agency acquirers should use the continuous integrator review to help determine if integrators are fulfilling the requirements defined in the agreement and whether any remedial actions are required based on the environment and use. Continuous integrator review should be conducted in multiple contexts including the selection of COTS elements, integrating COTS and GOTS into larger systems, and accepting the delivery of COTS, GOTS, and custom or open source elements. This may be done at different points during the system or element life cycle including development, operations, sustainment, and disposal.

This practice focuses on the integrator rather than on the supplier. The relationship between the integrator and the acquirer requires a great deal of transparency and traceability as the integrator is likely to have access to acquirer's systems, facilities, people, and processes. The integrator is also likely to use their own infrastructure to develop, integrate, or maintain the acquirer's systems and provide a combination of service and element under an agreement. By definition, this relationship has a great number of dependencies, including a substantial amount of bidirectional information and data exchange.

In contrast, the relationship between the acquirer and the supplier involves less collaboration and sharing of information and infrastructure. Therefore, acquirers have some limitations in their ability to review supplier processes. However, integrators are encouraged to review their own relationships with individual suppliers and apply those practices as appropriate, especially in the case of suppliers being custom development houses.

\subsubsection{Acquirer - Programmatic Activities}

a) Establish a comprehensive integrator review policy and procedures that span the system or element life cycle and use multiple methods, including testing, monitoring, assessment, and auditing.

b) Require, where applicable, periodic independent third-party audits of integrator systems.

c) Define specific types of continuous integrator review to be required in procurements.

d) Examine the hiring and personnel policies and practices of integrators to assess the strengths or weaknesses of the personnel security policies and procedures.

e) Require that the integrators' personnel security policies and practices meet the minimum required by the acquirer. 
f) Require the review of operational and technical requirements and mandatory business practices (processes and rules). Include reviews where applicable, including during all milestone or "make versus buy" decisions, design reviews, reviews of acquisition and procurement plans, and reviews of vulnerabilities in elements and processes. When requirements result in proposed changes in the supply chain, evaluate these changes for increased opportunities of adversary exposure of, or access to, elements, element processes, or supplier business processes.

g) Evaluate changes in the supply chain environment or the context of system/element use, under which additional protective measures might be required in order to assure or enhance the current level of confidence in the confidentiality, integrity, and availability of elements.

h) Define criteria and thresholds for identifying and tracking critical elements that require modification or replacement throughout the supply chain. These thresholds should be set well before an element's expected retirement from service and based, for example, on mean-time-between-failures (MTBF) for hardware and the number of releases for software.

i) Require the integrator to monitor supplier activities, with notification to supplier, to detect and assess threats or attempts to gain, or exploit exposure of, access to elements, supply chain processes, or supply chain actors.

j) Require that reviewers are qualified to identify weaknesses and vulnerabilities in the supply chain or integrator SCRM processes and procedures.

k) Continuously monitor acquirers' and integrators' internal controls over the allocation of tasks and activities to roles.

l) Test acquirers' and integrators' internal controls for their effectiveness in detecting anomalous behavior and timely intervention to prevent or reduce adverse consequences.

m) Assess the effectiveness of protective measures against threat sources' ability to gain access to the processes, system, or elements. Measures of protective effectiveness include time delay, required level of effort by the adversary, or ease of detection.

n) Require implementation of static and dynamic analysis for selected elements and processes (e.g., automated manufacturing/test processes and delivery mechanisms).

o) Require that penetration testing be a realistic simulation of the active adversary’s known adversary tactics, techniques, procedures, and tools. State the conditions and criteria throughout the life cycle for physical and logical penetration testing of systems, elements, or processes.

p) When practical for evaluating potential critical system elements, prefer integrators and suppliers that have incorporated static and dynamic analysis as best practices into their system or element life cycle process before: 1) making a make-buy decision; 2) selecting COTS, GOTS, custom, or open source elements; and 3) accepting COTS, GOTS, custom, or open source elements into the system.

\subsubsection{Integrators - General Requirements}

a) Continuously monitor internal controls in addressing the allocation of tasks and activities to roles. 
b) Test internal controls for their ability to detect anomalous behavior and facilitate timely intervention to prevent or reduce adverse consequences.

c) Assess the effectiveness of protective measures against threat sources' to gain access to processes, systems, or elements. Measures of protective effectiveness include time delay, required level of effort by the adversary, or ease of detection.

d) Perform manual reviews of the elements, processes, and systems to identify and remediate any weaknesses and vulnerabilities, including peer reviews (e.g., walk-throughs and inspections) and comprehensive or sampled reviews.

(Employ independent internal or external reviewers: external reviewers may be able to spot issues that people too close to the system cannot, and may have expertise that internal reviewers lack; internal reviewers may know key information that external reviewers do not.)

e) Apply various testing and analysis tools to potential system elements before: 1) making a make-buy decision; 2) selecting COTS, GOTS, custom, or opensource elements; and 3) accepting COTS, GOTS, custom, or open source elements into the system.

f) Verify that processes addressing code change incorporation are authorized, validated, and tested (to ensure they do not introduce new vulnerabilities, regressions, or break other functionality).

g) Determine the conditions and criteria throughout the life cycle for physical and logical testing of systems, elements, or processes.

h) Identify and track critical processes and elements throughout the supply chain that require modification or replacement well before an element's expected retirement from service, based, for example, on MTBF for hardware and based on the number of releases for software.

i) Determine and document hardware failure rates and periodically verify these rates.

j) Determine and document critical software patches or the extent of releases that would leave software vulnerable.

\subsubsection{Suppliers - General Requirements}

None

\subsubsection{Integrators - Technical Implementation Requirements}

None

\subsubsection{Suppliers - Technical Implementation Requirements}

None

\subsubsection{Acquirers - Verification and Validation}

a) Review and verify that the integrator's security policies, procedures, and activities are executed throughout the system/service life cycle. The purpose is to identify supply chain process weaknesses or vulnerabilities that, if exploited, 
could result in the loss or compromise of confidentiality, integrity, or availability.

b) Review the integrators' processes and procedures aimed at limiting exposure of system and element uses.

c) Ensure that the integrator assess known adversary tactics, techniques, and procedures; tools against physical, information security and IA; and personnel security practices employed to protect the supply chain environment.

d) Perform/outsource acceptance testing to ensure compliance with performance specifications.

e) Incorporate testing results (from all types of testing) into the oversight of other supply chain practices.

f) Monitor and assess the implementation and results of manual review requirements to ensure compliance with laws, regulations, and policies as well as conformance to contract specifications or standards.

g) Monitor and assess the implementation and results of applying various testing techniques (for example, penetration testing or baseline testing before accepting the system).

\subsubsection{Integrators - Verification and Validation Requirements}

a) Monitor supplier activities, as appropriate, to detect and assess threats or attempts to gain or exploit exposure of or access to elements, supply chain processes, or supply chain actors.

b) Monitor and assess the implementation of systems and the results of manual review requirements to ensure compliance with laws, regulations, and policies, as well as to ensure conformance to contract specifications or standards.

c) Assess testing results (from all types of testing) to identify additional vulnerabilities and report results of such assessments to the acquirer.

d) Perform technical and procedural audits of mechanisms used to shield the uses of the element.

\subsubsection{Suppliers - Verification and Validation Requirements}

None

\subsection{Strengthen Delivery Mechanisms}

Delivery, including inventory management, is an essential function within the supply chain, which has a great potential for being compromised. In today's ICT environment, delivery can be both physical (e.g., of hardware) or logical (e.g., software modules and patches). Delivery may happen at any point across a system or element life cycle, among multiple parties and multiple links of a given supply chain, and includes acquirers, multiple integrators, and multiple suppliers.

Because delivery may be compromised anywhere along the supply chain and system or element life cycle, federal department and agency acquirers should ensure 
protection of both physical and logical element delivery mechanisms to adequately protect the confidentiality, integrity, or availability of systems and elements delivered through the supply chain. This practice addresses the steps needed to strengthen the delivery mechanisms to ensure that opportunities are not provided for unauthorized access or exposure to the element, processes, and system, as well as information about their uses, which can result in unauthorized modification (including substitution and subversion) or redirection by active adversaries to an alternate location.

\subsubsection{Acquirer - Programmatic Activities}

a) Require that systems and elements are incorporated into the organization's inventory management system.

b) Establish policies and processes for logical delivery of software to ensure that it originated from a legitimate source and has not been tampered with en route.

c) Examine organization's inventory management policies and processes to ensure that they include:

a. How to request replacements;

b. Appropriate stocking, including the location and protection of spares;

c. Chain-of-custody policies to define who delivered the inventory, from what location, on which carrier, who handled it along the way, who the inventory should go to, when it arrived, who handled it, where it is located, and if the received inventory is reconciled to what was ordered; and

d. Inventory counting and accounting policies.

d) Determine which system and system element replacements will be needed, when, where, and how quickly. Some critical element spares may need to be stored near or with systems so that they can be rapidly replaced. For organizations using just-in-time delivery, ensure that the system/element will be delivered in time even in a stressed/emergency environment.

e) Require education and training for personnel inventory management policies and processes.

f) Maintain a level of physical and/or logical access control (i.e., locking file cabinets on the integrator premises), where relevant, for all purchase order/delivery authorizations for physical product delivery.

g) Ensure the physical security of inventory, including personnel security checks, access controls, and monitoring.

\subsubsection{Integrators - General Requirements}

a) Establish processes to assure that the system or element will be delivered when needed:

a. Modify the delivery path so that it is difficult to prevent delivery (e.g., via sabotage); and

b. Define multiple vetted delivery paths, in case a delivery path is unavailable or compromised.

b) Establish minimum baselines for supply chain delivery, processes, and mechanisms.

c) Where appropriate, use trusted contacts and ship via a protected carrier (such as U.S. registered mail, using cleared/official couriers, or a diplomatic pouch). Protect the system and element while storing before use (including spares). 
d) Design delivery mechanisms to avoid exposure or access to the system and element delivery processes, and use of the element during the delivery process.

e) Implement delivery processes for the intended logical and physical transfer and receipt of elements to be done by authorized personnel.

f) Ensure education and training for personnel inventory management policies and processes.

g) Use nondestructive techniques or mechanisms to determine if there is any unauthorized access throughout the physical delivery process.

h) Maintain a level of physical and/or logical access control (i.e., locking file cabinets on the integrator premises), where relevant, for all purchase order/delivery authorizations for physical product delivery.

\subsubsection{Suppliers - General Requirements}

a) Establish a minimum baseline for supply chain delivery, processes, and mechanisms. Where appropriate, use trusted contacts and ship via a protected carrier (such as U.S. registered mail, using cleared/official couriers, or a diplomatic pouch). Protect the system and element while storing before use (including spares).

b) Implement delivery processes for the intended logical and physical transfer and receipt of elements to be done by authorized personnel.

c) Provide documentation of any nondestructive techniques or mechanisms to determine if there is any unauthorized access throughout the delivery process.

\subsubsection{Integrators - Technical Implementation Requirements}

a) Use and check difficult-to-forge marks (such as digital signatures and hologram, DNA, and nano tags) for all critical elements.

b) Use anti-tamper mechanisms for prevention and discovery, including tamperresistant and tamper-evident packaging (e.g., tamper tape or seals). These must be difficult to remove and replace without leaving evidence of such activity.

c) Stipulate assurance levels and monitor logical delivery of products and services, requiring downloading from approved, verification-enhanced sites. Consider encrypting elements (software, software patches, etc.) at rest and in motion throughout delivery. Mechanisms that use cryptographic algorithms must be compliant with NIST FIPS 140-2.

d) Include in inventory management policies and processes on how to request replacements; appropriate stocking (including the location and protection of spares); chain-of-custody policies (to know who the inventory should go to, when it arrives, who handled it, where it is located, and if the received inventory is reconciled with what was ordered); and inventory counting and accounting policies.

e) Consider using multiple sources and compare them, to see if the elements have unexplained differences (e.g., in appearance, performance, or software hash codes).

f) Document and address or resolve potential attacks on delivery mechanisms to estimate and evaluate potential loss or compromise of confidentiality, integrity, or availability of elements. 
g) Use quarantine mechanisms (e.g., proxy servers) to screen code from multiple external sources prior to inclusion into acquirer or integrator systems.

\subsubsection{Suppliers - Technical Implementation Requirements}

a) Use and check difficult-to-forge marks (such as digital signatures or hologram, DNA, and nano tags) for all critical elements.

b) Document any anti-tamper mechanisms used for prevention and discovery, including tamper-resistant and tamper-evident packaging (e.g., tamper tape or seals). These must be difficult to remove or replace undetected.

c) Document and monitor the logical delivery of elements, requiring downloading from approved, verification-enhanced sites. Consider encrypting elements (software, software patches, etc.) at rest and in motion throughout delivery. For mechanisms that use cryptographic algorithms, consider compliance with NIST FIPS 140-2.

d) Document and resolve potential attacks on delivery mechanisms to estimate and evaluate potential loss or compromise of confidentiality, integrity, or availability of elements.

e) Obtain chain of custody for all critical hardware and require tamper-evident packaging.

\subsubsection{Acquirer - Verification and Validation Activities}

a) Verify that the integrator has documented processes for the hardening of delivery mechanisms when required, including use of protective physical and logical packaging approaches for systems, elements, and associated technical or business process information, and protection of element processes throughout the system and element life cycle.

b) Review and make recommendations regarding the training of integrator personnel in methods and performance of tasks to harden supply chain delivery mechanisms.

c) Verify that the delivery processes ensure that only authorized personnel will do the intended transfer and receipt of elements and services. ${ }^{13}$

d) Verify that the integrator has realistic continuity plans to ensure that systems and elements will be available even in a stressed/emergency environment.

e) Verify that the integrator and supplier have processes that detect significant differences in elements being delivered (e.g., to detect inconsistency with specification, potential counterfeits, etc.).

f) Verify that the integrator has processes that detect significant differences in elements.

g) Perform evaluations of integrator delivery mechanisms for compliance with the processes and procedures implemented to protect the element during production, delivery, and support activities.

${ }^{13}$ ANSI/NASPO-SA-2008 
h) Perform periodic evaluations of personnel to ensure compliance with inventory management policies and processes.

\subsubsection{Integrators - Verification and Validation Requirements}

a) Use modeling, simulation, tests, exercises, drills, war games, or Red/Blue Team exercises to assess supply chain delivery processes to ascertain the susceptibility and vulnerability of elements to sabotage, subversion, or compromise during delivery.

b) Perform physical and information security reviews of supply chain mechanisms used by suppliers to assess the effectiveness of measures intended to reduce opportunities for exposure of, or access to, elements, processes, or information regarding elements or processes.

\subsubsection{Suppliers - Verification and Validation Requirements}

None

\subsection{Assure Sustainment Activities and Processes}

The sustainment process begins when an element or a system becomes operational, and ends when it enters the disposal process. This includes system maintenance, upgrade, patching, element replacement (e.g., spare part, alternate supply) and other activities that keep the system or element operational. Any change to the elements, system, or process can introduce opportunities for subversion throughout the supply chain. These changes can occur during any stage of the system or element life cycle.

The sustainment processes should limit opportunities and means for compromise of the confidentiality, availability, and integrity of elements and operational processes. Federal department and agency acquirers should include the implications of those types of changes as well as protecting, monitoring, and auditing the elements and element processes during operation in the agreements with their integrators. Please note that, for this practice, an integrator is the party that is responsible for sustainment.

This practice applies to both the bounded operational systems within the acquirers' environment, which may require multitiered integrator operational support, as well as the outsourced operational information systems, which are used remotely by the acquirer.

A number of security controls contained within draft NIST SP 800-53 Revision 4 or later, including maintenance and personnel security controls, provide a baseline of assurances that organizations should employ. The practices described below build on those security controls, particularly those that address FIPS199 high-impact systems.

\subsubsection{Acquirer - Programmatic Activities}


a) Include procurement clauses in formal service and maintenance agreements that reduce supply chain risk.

b) When acquiring OEM elements, including refurbished elements, establish a contractual relationship with the originator or original manufacturer that provides vetted, competent support where possible.

c) Where possible (including rapid acquisition), purchase only elements and services previously screened by integrator for supply chain risks (including counterfeits, secondary market elements, and subversion).

d) Consider advance purchase and inventory of spare parts while they are widely available and verifiable and can be installed by trained and knowledgeable authorized service personnel.

e) Consider supply chain risks when acquiring replacement elements or field additions/modifications/upgrades, particularly if they do not go through traditional acquisition processes that examine supply chain risks.

f) For critical elements, perform a more rigorous SCRM review throughout the purchasing process.

g) Prefer formalized service/maintenance agreement(s) that include:

a. Use of specified or qualified spare parts suppliers;

b. Provide a complete record of changes performed during maintenance (e.g., audit trail or change log); and

c. Review changes made during maintenance.

h) Establish and implement agreements for competent and suitable support including refurbished and/or salvaged elements, when acquiring elements. Consider requiring the OEM to certify the equipment as suitable.

i) Identify methods of verifying that service personnel are authenticated and authorized to perform the service work needed at the time.

j) Require that the system's operational environment will protect the system physically and logically.

k) Require continuous monitoring activities on the operational system as outlined in NIST SP 800-37 and NIST SP-137.

l) Include supply chain considerations and requirements in contracts for operational systems and outsourced services.

m) Require, where applicable, periodic independent third-party audits of elements and systems.

n) Include applicable system integration and custom code extension activities as part of the upgrade and maintenance efforts in a system's operational requirements and ensure that they are subject to the same rigorous set of testing as originally required.

o) Develop and implement an approach for handling and processing reported supply chain anomalies.

p) Require the supplier to identify the expected life span of the element to help the acquirer plan for any migration that might be required in support of continued system and mission operations.

q) Software is often not under warranty. Some software integrators may be willing to provide service and maintenance agreements such as SLAs, limited warranties, or a maintenance contract. Consider establishing such service agreements for critical software systems. For example, such agreements could include language that the integrator: 
a. Check for preexisting malware (e.g., using a virus checker or static analyzer tools) before accepting delivery. Where practical, perform checks after delivery of patches or later revisions/updates, and/or perform periodic checks.

b. If using third-party or open source software, update the software if vulnerabilities in that software are publicly disclosed and patches/updates are available.

r) Require training on the OEM's procedures for acquiring secondary market (refurbished) items.

s) Require establishment of a process for managing supply chain vulnerabilities, including detecting, tracking/logging, selecting a response, performing the response, and documenting the response. This provides a feedback loop for continuous improvement of supply chain elements and element processes and corrective action handling for any vulnerability or other issues that require addressing. Similarly, a standardized due process procedure may be needed to ensure that integrators, suppliers, element and sub-suppliers have the opportunity to address and/or appeal any actions that acquirers may seek to impose.

t) Develop organizational policy and procedures that require that any counterfeit parts detected will be seized, destroyed, or preserved for law enforcement evidentiary purposes (not returned to the source/supply chain); otherwise, such items may be used to develop future counterfeit elements. If appropriate, share the counterfeit elements with the authentic supplier for further analysis.

u) Examine organization and process certifications. Determine if the supplier is an authorized distributor/reseller/maintainer by the OEM to help determine risk (e.g., recipient may lose integrity/availability if it will not be serviced later, and if subverted, may lose confidentiality). This includes secondary market, potentially counterfeit, and subverted elements.

v) Establish a formal written policy on software update and patch management. It should articulate the conditions under which updates and patches will be evaluated and administered, such as a change in supplier and the anticipated impact on elements, processes, and uses.

w) Where relevant, designate and document personnel for physical product purchasing and delivery.

$\mathrm{x}$ ) Implement written and repeatable processes for the purchasing, receipt, and delivery of materials for physical element delivery.

y) Request evidence of the implementation of written, repeatable processes for the purchasing, receipt, and delivery of materials for physical element delivery.

z) Use two-person/party review of all orders and shipments, including the comparison of deliverables and receivables to requisition/purchase orders for accuracy of physical product delivery (for example, selection of two individuals from separate departments or duty areas).

\subsubsection{Integrators - General Requirements}

a) Avoid introducing new actors in maintenance activities where possible (e.g., keep original manufacturers and/or OEM-authorized suppliers). If new actors need to be added, implement a vetting process for them. Notify the acquirer of any major changes in a maintenance organization's structure or process (e.g., 
physical move to a different location, change in ownership, outsourcing, and/or changes in personnel).

b) Notify acquirer of any changes in an element's life span, including end of life, to enable the acquirer to plan for any migration that might be required in support of continued system and mission operations.

c) Establish a process for managing supply chain vulnerabilities including detecting, tracking/logging, selecting a response, performing the response, and documenting the response. This provides a feedback loop for continuous improvement of supply chain elements and element processes.

d) Implement policies on element software update and patch management. These should articulate the conditions and sources under which updates and patches are delivered or made available to customers.

e) Document the existence of a process to detect counterfeit parts in the supply chain. If counterfeit market parts are detected, require that they are seized, destroyed, or preserved for law enforcement evidentiary purposes (not returned to the source/supply chain). Work with the acquirer to ensure that counterfeit and subverted elements are subjected to forensic analysis.

f) Establish formalized service/maintenance agreement(s) that include:

a. Maintenance personnel should meet predefined criteria; and

b. Report major changes in a maintenance organization's structure (e.g., physical move to a different location/offshoring, change in ownership, outsourcing, and changes in personnel).

g) Repair any identified problem if it is a common and widely known security weakness or with significant operational impact. (Examples of such weaknesses may include Open Web Application Security Project [OWASP] top ten [OWASP 2010] or the Common Weakness Enumeration [CWE 2008].)

\subsubsection{Suppliers - General Requirements}

None

\subsubsection{Integrators - Technical Implementation Requirements}

a) Establish a trusted baseline for the system/element and operational configuration based on SLAs. Use this baseline to identify unauthorized changes or tampering.

b) Protect system elements from tampering by using a variety of methods. Methods can include robust configuration management, limited privileges, checking cryptographic hashes, and applying anti-tamper techniques. Use existing vulnerability and incident management capabilities to identify potential supply chain vulnerabilities. This provides a feedback loop for continuous improvement of supply chain elements and element processes.

c) Provide maintenance personnel capable of meeting the terms of the contract.

d) Ensure that remote maintenance is used only for approved purposes.

e) Disclose to the acquirer under suitable contractual protections, as appropriate, the processes for vulnerability detection including determining root cause and 
context, determining severity (where feasible), logging, ranking (assigning severity ratings), and triaging security bugs.

f) Disclose policies on patching and notification, including the criteria for issuances of fix issues (e.g., above a particular CVSS score) prior to product shipment.

g) Provide trustworthy patch and update processes including the authentication of the patch and/or update source (e.g., digitally signed patches).

h) Perform forensic analysis on failed elements and processes to determine the cause of failure. Isolate and diagnose the elements of the component that are not performing properly and assess the origin and mechanisms of the failure. Assess the impact of the failure, ways to detect failures, and mitigating actions (include ways to detect and prevent future occurrences).

\subsubsection{Supplier - Technical Implementation Requirements}

None

\subsubsection{Acquirer - Verification and Validation Activities}

a) Conduct a manual review and inspection, as well as acceptance testing, for refurbished or secondary market elements permitted for use. This review and inspection should be conducted during initial procurement and continued throughout operations and sustainment.

b) Conduct inspection and acceptance testing of incoming items to detect evidence of tampering for physical product delivery.

c) Review the suppliers' service and maintenance programs and procedures for compliance with contractual requirements.

d) Evaluate changes in maintenance agreements (e.g., physical move to a different location/offshoring, change in ownership, outsourcing, and changes in personnel) and manage risks associated with them.

e) Monitor and audit the systems and operations to reduce the risk of unauthorized element(s) removal, replacement, and/or modification. Modification review may include applicable system integration and custom code extension activities as part of the upgrade and maintenance efforts for system operations.

f) Monitor the suppliers of elements of the same family (e.g., similar commoditized elements) to learn of newly discovered vulnerabilities. Provide feedback on relevant, element-specific vulnerabilities to the OEM/supplier for continuous improvement of supply chain elements and element processes.

g) Verify the digital signatures to ensure that patches are not tampered with during delivery and are applied to the system in the same state as they were when they were produced.

h) Verify that the delivery mechanism is defined (for example, define the strength of authentication and the encryption mechanism).

i) Verify the authenticity of patches including nonscheduled or out-of-sequence patches. 
j) Verify that the integrators and suppliers have a protected and access-controlled supply chain risk incident report repository.

\subsubsection{Integrators - Verification and Validation Requirements}

a) Use multiple and complementary monitoring and auditing approaches and leverage existing data to analyze for supply chain risk during sustainment.

a) Conduct additional manual review and inspection, as well as acceptance testing, when refurbished or secondary market items are permitted for use during initial procurement and continuing through operations and sustainment.

b) Evaluate the changes in maintenance agreements (e.g., physical move to different location/offshoring, changes in ownership, outsourcing, and change in key personnel) and manage risks associated with them.

b) Identify identical elements coming in from different suppliers as required. For example, if specific orders need to be isolated, the elements from that order can be identified and processed appropriately.

c) Notify the acquirer and integrator of newly discovered vulnerabilities for continuous improvement of supply chain elements and element processes.

d) Verify that each patch is either digitally signed or, at minimum, has a checksum before it is made available to customers.

c) Periodically audit system activities for compliance with requirements/SLA and to detect potential supply chain issues. This may include the review of any reports providing a summary of any detection of malicious functionality, known vulnerabilities, or changes in suppliers or supplier venue - providing a feedback loop for continuous improvement of supply chain elements and element processes.

d) Periodically monitor suppliers' general profile for changes in ownership, credit rating, or other factors that can affect the supplier's risk profile.

\subsubsection{Supplier - Verification and Validation Activities}

None

\subsection{Manage Disposal and Final Disposition Activities throughout the System or Element Life Cycle}

Elements, information, and data can be disposed of at any time across the system and element life cycle (not only in the disposal or retirement phase of the system or element life cycle). For example, disposal can occur during R\&D, design, prototyping, or operations/maintenance and include methods such as disk cleaning, removal of cryptographic keys, partial reuse of components, etc.

This practice addresses the disposal of elements, tools, and documentation. Poor disposal procedures can lead to unauthorized access to systems and elements, but disposal is often performed by actors who may not be aware of supply chain threats or procedures. Opportunities for compromise during disposal affect physical (paper documents) and logical (magnetic) media, as well as the disposal processes 
themselves. Acquirers frequently neglect to define rules for disposal, increasing the chances that the systems and elements acquired will be compromised.

NIST SP 800-88, Guidelines for Media Sanitization, assists organizations in implementing a media sanitization program with proper and applicable techniques and controls for sanitization and disposal decisions. This practice builds on the guidance provided in that document and provides additional guidance regarding properly addressing supply chain assurance during disposal.

\subsubsection{Acquirer - Programmatic Activities}

a) Ensure that disposal requirements are included in contract documents.

b) Negotiate and define disposal practices with suppliers/integrators to align planning and procedures during the system and associated elements' lifetime, including authorized service personnel's access to authentic parts and the handling of damaged or retired elements, a listing of parts, and the data retention (if any) capability of each.

c) Establish organizational policies and procedures that :

a. Encourage the selection of elements that can be disposed in a way that does not expose protected information. For example, select elements that permit offloading of data prior to disposal or elements that are easy to wipe clean prior to disposal;

b. Require the use of trusted disposers, as appropriate (in some cases, they may need to be cleared);

c. Require procedures for the secure and permanent destruction of elements, as appropriate; and

d. Destroy any counterfeit market parts detected that do not have forensic or evidentiary value by reputable disposers that have been validated by authentic original suppliers or trained law enforcement authorities.

d) When required for forensic investigations or later comparison for detection of counterfeit elements, surrender elements for disposal to a dedicated repository.

e) Establish the end-of-life support process for systems and elements.

\subsubsection{Integrators - General Requirements}

a) Train all personnel involved in the disposal process on supply chain risk and internal procedures.

b) Encourage the selection of elements that can be disposed of in a way that does not expose protected information (for example, elements that permit offloading of data prior to disposal or elements that are easy to wipe clean prior to disposal).

c) Prohibit the transmission or distribution of acquirer's, integrator's, or supplier's sensitive data or sensitive elements to unauthorized or unspecified parties during disposal activities. 
d) When required for forensic investigation or for later comparison for detection of counterfeit elements, surrender elements for disposal to a dedicated repository.

e) Require the use of trusted disposers, as appropriate (in some cases, they may need to be cleared).

f) Implement procedures for the secure and permanent destruction of elements.

g) Engage trained disposal service personnel and set expectations for the procedures that conform to the acquirer's disposal policy.

\subsubsection{Suppliers - General Requirements}

a) Establish relationships with trusted disposers who have documented an effective disposal process.

b) Implement processes and procedures for the secure and permanent destruction of elements, as appropriate.

\subsubsection{Integrators - Technical Implementation Requirements}

a) Ensure that scrap materials, out-of-specification elements, or suspect or confirmed defective, counterfeit, or tampered elements are controlled, preserved for appropriate evidentiary or forensic purposes, and disposed of properly.

b) Identify all elements and sub-elements that need to be specially disposed of (including Hazardous Materials [HAZMAT]/explosive ordinance/environment impact, confidential equipment, etc.).

c) Carefully move, save, remove, and/or destroy data so that it does not harm, lose, or corrupt required information and does not expose acquirer's sensitive information.

d) Maintain a system to inventory and record disposal of controlled items.

e) Describe the organizational capabilities for disposal of elements/systems in support of the acquirer's policy, either in an RFI response or in general program support documentation.

\subsubsection{Suppliers - Technical Implementation Requirements}

a) Manage and properly dispose of all scrap materials, out-of-specification elements, or suspected or confirmed defective, counterfeit, or tampered elements.

b) Establish processes used to identify all elements/sub-elements that need to be specially disposed of (including HAZMAT/explosive ordinance/environment impact, confidential equipment, etc.). 
c) Document the process used to carefully move or save data so that it does not harm, lose, or corrupt required information and does not expose acquirer's sensitive information.

d) Describe technical limitations related to disposal activities (e.g., degaussed media cannot be reused and will void warranties).

\subsubsection{Acquirer - Verification and Validation Activities}

a) Assess the integrators' and suppliers' capability to meet the disposal requirements.

b) Periodically review the acquirer's organizational disposal process.

c) Ensure the adequacy of the destruction method for controlled items.

\subsubsection{Integrators - Verification and Validation Requirements}

a) Ensure the adequacy of the destruction method for controlled items (e.g., NIST 800-80 controls for removable media).

b) Verify suppliers' security procedures to govern the transfer of elements and acquirer's sensitive information.

c) Ensure that items subject to controlled disposal are accurately identified, marked, and recorded for traceability.

\subsubsection{Suppliers - Verification and Validation Requirements}

a) Regularly review the disposal process.

b) Verify and validate the identification and tracking of items subject to preservation for forensics and evidentiary purposes and/or controlled disposal. 


\section{APPENDIX A GLOSSARY}

\begin{tabular}{|c|c|c|}
\hline Term & Definition & Source \\
\hline Access & Ability to make use of any information system resource. & NISTIR 7298 \\
\hline Acquirer & Stakeholder that acquires or procures a product or service. & $\begin{array}{l}\text { ISO/IEC } \\
\text { 15288, adapted }\end{array}$ \\
\hline Acquisition & $\begin{array}{l}\text { Includes all stages of the process of acquiring product or } \\
\text { service, beginning with the process for determining the need for } \\
\text { the product or service and ending with contract completion and } \\
\text { closeout. }\end{array}$ & $\begin{array}{l}\text { NIST SP 800- } \\
64 \text {, adapted }\end{array}$ \\
\hline $\begin{array}{l}\text { Authorizing } \\
\text { Official (AO) }\end{array}$ & $\begin{array}{l}\text { Senior federal official or executive with the authority to } \\
\text { formally assume responsibility for operating an information } \\
\text { system at an acceptable level of risk to organizational } \\
\text { operations (including mission, functions, image, or reputation), } \\
\text { organizational assets, individuals, other organizations, and the } \\
\text { Nation. }\end{array}$ & CNSSI-4009 \\
\hline Baseline & $\begin{array}{l}\text { Hardware, software, databases, and relevant documentation for } \\
\text { an information system at a given point in time. }\end{array}$ & CNSSI-4009 \\
\hline $\begin{array}{l}\text { Commercial off- } \\
\text { the-shelf (COTS) }\end{array}$ & $\begin{array}{l}\text { Software and hardware that already exists and is available from } \\
\text { commercial sources. It is also referred to as off-the-shelf. }\end{array}$ & $\begin{array}{l}\text { NIST SP 800- } \\
64\end{array}$ \\
\hline Contract & $\begin{array}{l}\text { A mutually binding legal relationship obligating the seller to } \\
\text { furnish the supplies or services (including construction) and the } \\
\text { buyer to pay for them. It includes all types of commitments that } \\
\text { obligate the Government to an expenditure of appropriated } \\
\text { funds and that, except as otherwise authorized, are in writing. } \\
\text { In addition to bilateral instruments, contracts include (but are } \\
\text { not limited to) awards and notices of awards; job orders or task } \\
\text { letters issued under basic ordering agreements; letter contracts; } \\
\text { orders, such as purchase orders, under which the contract } \\
\text { becomes effective by written acceptance or performance; and } \\
\text { bilateral contract modifications. Contracts do not include grants } \\
\text { and cooperative agreements covered by } 31 \text { U.S.C. 6301, et seq. }\end{array}$ & 48 CFR \\
\hline $\begin{array}{l}\text { Contract } \\
\text { administration } \\
\text { office }\end{array}$ & $\begin{array}{l}\text { An office that performs- (1) Assigned post-award functions } \\
\text { related to the administration of contracts; and (2) Assigned pre- } \\
\text { award functions. }\end{array}$ & 48 CFR \\
\hline $\begin{array}{l}\text { Contracting } \\
\text { office }\end{array}$ & $\begin{array}{l}\text { An office that awards or executes a contract for supplies or } \\
\text { services and performs post-award functions not assigned to a } \\
\text { contract administration office (except as defined in } 48 \text { CFR). }\end{array}$ & $48 \mathrm{CFR}$ \\
\hline $\begin{array}{l}\text { Contracting } \\
\text { Officer (CO) }\end{array}$ & $\begin{array}{l}\text { An individual who has the authority to enter into, administer, or } \\
\text { terminate contracts and make related determinations and } \\
\text { findings. }\end{array}$ & $\begin{array}{l}\text { Federal } \\
\text { Acquisition } \\
\text { Regulation }\end{array}$ \\
\hline $\begin{array}{l}\text { Critical } \\
\text { Component }\end{array}$ & $\begin{array}{l}\text { A system element that, if compromised, damaged, or failed, } \\
\text { could cause a mission or business failure. }\end{array}$ & \\
\hline $\begin{array}{l}\text { Defense-in- } \\
\text { Breadth - }\end{array}$ & $\begin{array}{l}\text { A planned, systematic set of multidisciplinary activities that } \\
\text { seek to identify, manage, and reduce risk of exploitable } \\
\text { vulnerabilities at every stage of the system, network, or sub- } \\
\text { component life cycle (system, network, or product design and } \\
\text { development; manufacturing; packaging; assembly; system } \\
\text { integration; distribution; operations; maintenance; and } \\
\text { retirement). }\end{array}$ & CNSSI-4009 \\
\hline
\end{tabular}




\begin{tabular}{|c|c|c|}
\hline Defense-in-Depth & $\begin{array}{l}\text { Information security strategy integrating people, technology, } \\
\text { and operations capabilities to establish variable barriers across } \\
\text { multiple layers and dimensions of the organization. }\end{array}$ & $\begin{array}{l}\text { CNSSI-4009; } \\
\text { NIST SP 800- } \\
53\end{array}$ \\
\hline Defensive Design & $\begin{array}{l}\text { Design techniques which explicitly protect supply chain } \\
\text { elements from future attacks or adverse events. Defensive } \\
\text { design addresses the technical, behavioral, and organizational } \\
\text { activities. It is intended to create options that preserve the } \\
\text { integrity of the mission and system function and its } \\
\text { performance to the end user or consumer of the supply chain } \\
\text { element. }\end{array}$ & \\
\hline Degradation & $\begin{array}{l}\text { A decline in quality or performance; the process by which the } \\
\text { decline is brought about. }\end{array}$ & \\
\hline Element & $\begin{array}{l}\text { ICT system element member of a set of elements that } \\
\text { constitutes a system. }\end{array}$ & $\begin{array}{l}\text { ISO/IEC } \\
15288, \\
\text { adapted }\end{array}$ \\
\hline $\begin{array}{l}\text { Element } \\
\text { Processes }\end{array}$ & $\begin{array}{l}\text { A series of operations performed in the making or treatment of } \\
\text { an element; performing operations on elements/data. }\end{array}$ & \\
\hline $\begin{array}{l}\text { Federal } \\
\text { Acquisition } \\
\text { Regulation } \\
\text { (FAR) }\end{array}$ & $\begin{array}{l}\text { The Federal Acquisition Regulations System is established for } \\
\text { the codification and publication of uniform policies and } \\
\text { procedures for acquisition by all executive agencies. }\end{array}$ & 48 CFR \\
\hline $\begin{array}{l}\text { Federal } \\
\text { Information } \\
\text { Processing } \\
\text { Standards } \\
\text { (FIPS) }\end{array}$ & $\begin{array}{l}\text { A standard for adoption and use by federal departments and } \\
\text { agencies that has been developed within the Information } \\
\text { Technology Laboratory and published by the National Institute } \\
\text { of Standards and Technology, a part of the U.S. Department of } \\
\text { Commerce. A FIPS covers some topic in information } \\
\text { technology in order to achieve a common level of quality or } \\
\text { some level of interoperability. }\end{array}$ & $\begin{array}{l}\text { NIST SP 800- } \\
64\end{array}$ \\
\hline High Impact & $\begin{array}{l}\text { The loss of confidentiality, integrity, or availability that could } \\
\text { be expected to have a severe or catastrophic adverse effect on } \\
\text { organizational operations, organizational assets, individuals, } \\
\text { other organizations, or the national security interests of the } \\
\text { United States; (i.e., 1) causes a severe degradation in mission } \\
\text { capability to an extent and duration that the organization is able } \\
\text { to perform its primary functions, but the effectiveness of the } \\
\text { functions is significantly reduced; 2) results in major damage to } \\
\text { organizational assets; 3) results in major financial loss; or 4) } \\
\text { results in severe or catastrophic harm to individuals involving } \\
\text { loss of life or serious life-threatening injuries). }\end{array}$ & $\begin{array}{l}\text { FIPS 199; } \\
\text { CNSSI-4009 }\end{array}$ \\
\hline $\begin{array}{l}\text { ICT Supply } \\
\text { Chain }\end{array}$ & $\begin{array}{l}\text { Linked set of resources and processes between acquirers, } \\
\text { integrators, and suppliers that begins with the design of ICT } \\
\text { products and services and extends through development, } \\
\text { sourcing, manufacturing, handling, and delivery of ICT } \\
\text { products and services to the acquirer. } \\
\text { Note: An ICT supply chain can include vendors, manufacturing } \\
\text { facilities, logistics providers, distribution centers, distributors, } \\
\text { wholesalers, and other organizations involved in the design and } \\
\text { development, manufacturing, processing, handling, and } \\
\text { delivery of the products, or service providers involved in the } \\
\text { operation, management, and delivery of the services. }\end{array}$ & $\begin{array}{l}\text { ISO 28001, } \\
\text { adapted }\end{array}$ \\
\hline
\end{tabular}




\begin{tabular}{|c|c|c|}
\hline $\begin{array}{l}\text { ICT Supply } \\
\text { Chain Risk }\end{array}$ & $\begin{array}{l}\text { Risks that arise from the loss of confidentiality, integrity, or } \\
\text { availability of information or information systems and reflect } \\
\text { the potential adverse impacts to organizational operations } \\
\text { (including mission, functions, image, or reputation), } \\
\text { organizational assets, individuals, other organizations, and the } \\
\text { Nation. }\end{array}$ & $\begin{array}{l}\text { NIST SP } 800- \\
\text { 53 Rev 3: FIPS } \\
\text { 200, adapted }\end{array}$ \\
\hline $\begin{array}{l}\text { ICT Supply } \\
\text { Chain Risk } \\
\text { Management }\end{array}$ & $\begin{array}{l}\text { The process of identifying, assessing, and mitigating the risks } \\
\text { associated with the global and distributed nature of ICT product } \\
\text { and service supply chains. }\end{array}$ & \\
\hline Identity & $\begin{array}{l}\text { The set of attribute values (i.e., characteristics) by which an } \\
\text { entity is recognizable and that, within the scope of an identity } \\
\text { manager's responsibility, is sufficient to distinguish that entity } \\
\text { from any other entity. }\end{array}$ & $\begin{array}{l}\text { CNSSI No. } \\
4009\end{array}$ \\
\hline $\begin{array}{l}\text { Industrial } \\
\text { Security }\end{array}$ & $\begin{array}{l}\text { The portion of internal security that refers to the protection of } \\
\text { industrial installations, resources, utilities, materials, and } \\
\text { classified information essential to protect from loss or damage. }\end{array}$ & $\begin{array}{l}\text { NISPOM, } \\
\text { adapted }\end{array}$ \\
\hline $\begin{array}{l}\text { Information and } \\
\text { Communications } \\
\text { Technologies } \\
\text { (ICT) }\end{array}$ & $\begin{array}{l}\text { Encompasses the capture, storage, retrieval, processing, } \\
\text { display, representation, presentation, organization, } \\
\text { management, security, transfer, and interchange of data and } \\
\text { information. }\end{array}$ & $\begin{array}{l}\text { ANSDIT, } \\
\text { adapted }\end{array}$ \\
\hline $\begin{array}{l}\text { Information } \\
\text { Assurance (IA) }\end{array}$ & $\begin{array}{l}\text { Measures that protect and defend information and information } \\
\text { systems by ensuring their availability, integrity, authentication, } \\
\text { confidentiality, and non-repudiation. These measures include } \\
\text { providing for restoration of information systems by } \\
\text { incorporating protection, detection, and reaction capabilities. }\end{array}$ & $\begin{array}{l}\text { CNSSI No. } \\
4009\end{array}$ \\
\hline $\begin{array}{l}\text { Information } \\
\text { System }\end{array}$ & $\begin{array}{l}\text { A discrete set of information resources organized for the } \\
\text { collection, processing, maintenance, use, sharing, } \\
\text { dissemination, or disposition of information. }\end{array}$ & $\begin{array}{l}44 \text { U.S.C., Sec. } \\
3502\end{array}$ \\
\hline Integrator & $\begin{array}{l}\text { An organization that customizes (e.g., combines, adds, } \\
\text { optimizes) elements, processes, and systems. The integrator } \\
\text { function can be performed by acquirer, integrator, or supplier } \\
\text { organizations. }\end{array}$ & \\
\hline Life cycle & $\begin{array}{l}\text { Evolution of a system, product, service, project, or other } \\
\text { human-made entity from conception through retirement. }\end{array}$ & ISO/IEC 15288 \\
\hline Low Impact & $\begin{array}{l}\text { The loss of confidentiality, integrity, or availability that could } \\
\text { be expected to have a limited adverse effect on organizational } \\
\text { operations, organizational assets, individuals, other } \\
\text { organizations, or the national security interests of the United } \\
\text { States; (i.e., 1) causes a degradation in mission capability to an } \\
\text { extent and duration that the organization is able to perform its } \\
\text { primary functions, but the effectiveness of the functions is } \\
\text { noticeably reduced; 2) results in minor damage to } \\
\text { organizational assets; } 3 \text { ) results in minor financial loss; or } 4 \text { ) } \\
\text { results in minor harm to individuals). }\end{array}$ & CNSSI-4009 \\
\hline Market research & $\begin{array}{l}\text { Collecting and analyzing information about capabilities within } \\
\text { the market to satisfy agency needs. }\end{array}$ & 48 CFR \\
\hline
\end{tabular}




\begin{tabular}{|c|c|c|}
\hline Moderate Impact & $\begin{array}{l}\text { The loss of confidentiality, integrity, or availability that could } \\
\text { be expected to have a serious adverse effect on organizational } \\
\text { operations, organizational assets, individuals, other } \\
\text { organizations, or the national security interests of the United } \\
\text { States; (i.e., 1) causes a significant degradation in mission } \\
\text { capability to an extent and duration that the organization is able } \\
\text { to perform its primary functions, but the effectiveness of the } \\
\text { functions is significantly reduced; 2) results in significant } \\
\text { damage to organizational assets; 3) results in significant } \\
\text { financial loss; or 4) results in significant harm to individuals } \\
\text { that does not involve loss of life or serious life-threatening } \\
\text { injuries). }\end{array}$ & CNSSI-4009 \\
\hline $\begin{array}{l}\text { Modular } \\
\text { Contracting }\end{array}$ & $\begin{array}{l}\text { Under modular contracting, an executive agency's need for a } \\
\text { system is satisfied in successive acquisitions of interoperable } \\
\text { increments. Each increment complies with common or } \\
\text { commercially accepted standards applicable to information } \\
\text { technology so that the increments are compatible with other } \\
\text { increments of information technology composing the system. }\end{array}$ & $\begin{array}{l}\text { U.S. Code Title } \\
41\end{array}$ \\
\hline Procurement & (See “acquisition.”) & 48 CFR \\
\hline Provenance & $\begin{array}{l}\text { The records describing the possession of, and changes } \\
\text { to, components, component processes, information, systems, } \\
\text { organization, and organizational processes. Provenance enables } \\
\text { all changes to the baselines of components, component } \\
\text { processes, information, systems, organizations, and } \\
\text { organizational processes, to be reported to specific actors, } \\
\text { functions, locales, or activities. }\end{array}$ & \\
\hline $\begin{array}{l}\text { Red Team/Blue } \\
\text { Team Approach }\end{array}$ & $\begin{array}{l}\text { A group of people authorized and organized to emulate a } \\
\text { potential adversary's attack or exploitation capabilities against } \\
\text { an enterprise's security posture. The Red Team's objective is to } \\
\text { improve enterprise Information Assurance by demonstrating } \\
\text { the impacts of successful attacks and by demonstrating what } \\
\text { works for the defenders (i.e., the Blue Team) in an operational } \\
\text { environment. } \\
\text { 1. The group responsible for defending an enterprise's use of } \\
\text { information systems by maintaining its security posture against } \\
\text { a group of mock attackers (i.e., the Red Team). Typically the } \\
\text { Blue Team and its supporters must defend against real or } \\
\text { simulated attacks 1) over a significant period of time, 2) in a } \\
\text { representative operational context (e.g., as part of an } \\
\text { operational exercise), and 3) according to rules established and } \\
\text { monitored with the help of a neutral group refereeing the } \\
\text { simulation or exercise (i.e., the White Team). } \\
\text { 2. The term Blue Team is also used for defining a group of } \\
\text { individuals that conduct operational network vulnerability } \\
\text { evaluations and provide mitigation techniques to customers } \\
\text { who have a need for an independent technical review of their } \\
\text { network security posture. The Blue Team identifies security } \\
\text { threats and risks in the operating environment, and in } \\
\text { cooperation with the customer, analyzes the network } \\
\text { environment and its current state of security readiness. Based } \\
\text { on the Blue Team findings and expertise, they provide }\end{array}$ & CNSSI 4009 \\
\hline
\end{tabular}




\begin{tabular}{|c|c|c|}
\hline & $\begin{array}{l}\text { recommendations that integrate into an overall community } \\
\text { security solution to increase the customer's cyber security } \\
\text { readiness posture. Often a Blue Team is employed by itself or } \\
\text { prior to a Red Team employment to ensure that the customer's } \\
\text { networks are as secure as possible before having the Red Team } \\
\text { test the systems. }\end{array}$ & \\
\hline Risk Mitigation & $\begin{array}{l}\text { Prioritizing, evaluating, and implementing the appropriate risk- } \\
\text { reducing controls/countermeasures recommended from the risk } \\
\text { management process. }\end{array}$ & CNSSI-4009 \\
\hline $\begin{array}{l}\text { Secondary } \\
\text { market }\end{array}$ & An unofficial, unauthorized, or unintended distribution channel. & \\
\hline $\begin{array}{l}\text { Sources Sought } \\
\text { Notice }\end{array}$ & $\begin{array}{l}\text { A synopsis posted by a government agency that states they are } \\
\text { seeking possible sources for a project. It is not a solicitation for } \\
\text { work, nor is it a request for proposal. }\end{array}$ & $\begin{array}{l}\text { FAR, Subpart } \\
7.3 \text { and OMB } \\
\text { Circular A-76 } \\
\end{array}$ \\
\hline $\begin{array}{l}\text { Statement of } \\
\text { Work (SOW) }\end{array}$ & $\begin{array}{l}\text { The SOW details what the developer must do in the } \\
\text { performance of the contract. Documentation developed under } \\
\text { the contract, for example, is specified in the SOW. Security } \\
\text { assurance requirements, which detail many aspects of the } \\
\text { processes the developer follows and what evidence must be } \\
\text { provided to assure the organization that the processes have } \\
\text { been conducted correctly and completely, may also be specified } \\
\text { in the SOW. }\end{array}$ & $\begin{array}{l}\text { NIST SP 800- } \\
64\end{array}$ \\
\hline Supplier & $\begin{array}{l}\text { Organization or individual that enters into an agreement with } \\
\text { the acquirer or integrator for the supply of a product or service. } \\
\text { This includes all suppliers in the supply chain. }\end{array}$ & $\begin{array}{l}\text { ISO/IEC } \\
\text { 15288, adapted }\end{array}$ \\
\hline $\begin{array}{l}\text { Supply Chain } \\
\text { Assurance }\end{array}$ & $\begin{array}{l}\text { Confidence that the supply chain will produce and deliver } \\
\text { elements, processes, and information that function as expected. }\end{array}$ & $\begin{array}{l}\text { DoD Key } \\
\text { Practices and } \\
\text { Implementation } \\
\text { Guide, adapted }\end{array}$ \\
\hline System & $\begin{array}{l}\text { A combination of interacting elements organized to achieve one } \\
\text { or more stated purposes. }\end{array}$ & $\begin{array}{l}\text { ISO/IEC } \\
15288: 2008 \\
\end{array}$ \\
\hline $\begin{array}{l}\text { System } \\
\text { Assurance }\end{array}$ & $\begin{array}{l}\text { The justified confidence that the system functions as intended } \\
\text { and is free of exploitable vulnerabilities, either intentionally or } \\
\text { unintentionally designed or inserted as part of the system at any } \\
\text { time during the life cycle. }\end{array}$ & NDIA 2008 \\
\hline $\begin{array}{l}\text { System } \\
\text { Development } \\
\text { Life Cycle } \\
\text { (SDLC) }\end{array}$ & $\begin{array}{l}\text { The scope of activities associated with a system, encompassing } \\
\text { the system's initiation, development and acquisition, } \\
\text { implementation, operation and maintenance, and ultimately its } \\
\text { disposal that instigates another system initiation. }\end{array}$ & $\begin{array}{l}\text { NIST SP 800- } \\
34 ; \text { CNSSI- } \\
4009\end{array}$ \\
\hline System Owner & $\begin{array}{l}\text { Person or organization having responsibility for the } \\
\text { development, procurement, integration, modification, operation } \\
\text { and maintenance, and/or final disposition of an information } \\
\text { system. }\end{array}$ & CNSSI-4009 \\
\hline Threat & $\begin{array}{l}\text { Any circumstance or event with the potential to adversely } \\
\text { impact organizational operations (including mission, functions, } \\
\text { image, or reputation), organizational assets, individuals, other } \\
\text { organizations, or the Nation through an information system via } \\
\text { unauthorized access, destruction, disclosure, modification of } \\
\text { information, and/or denial of service. }\end{array}$ & $\begin{array}{l}\text { NIST SP 800- } \\
53 ; \text { NIST SP } \\
800-53 A ; \text { NIST } \\
\text { SP 800-27; } \\
\text { NIST SP 800- } \\
60 ; \text { NIST SP } \\
800-37 ; \\
\text { CNSSI-4009 } \\
\end{array}$ \\
\hline $\begin{array}{l}\text { Threat } \\
\text { Assessment/ }\end{array}$ & $\begin{array}{l}\text { Process of formally evaluating the degree of threat to an } \\
\text { information system or enterprise and describing the nature of }\end{array}$ & $\begin{array}{l}\text { CNSSI-4009; } \\
\text { SP 800-53A }\end{array}$ \\
\hline
\end{tabular}




\begin{tabular}{|c|c|c|}
\hline Analysis & the threat. & \\
\hline Threat Scenario & $\begin{array}{l}\text { A set of discrete threat events, associated with a specific threat } \\
\text { source or multiple threat sources, partially ordered } \\
\text { in time. }\end{array}$ & $\begin{array}{l}\text { NIST } 800-30 \\
\text { Rev. } 1\end{array}$ \\
\hline Threat Source & $\begin{array}{l}\text { The intent and method targeted at the intentional exploitation of } \\
\text { a vulnerability or a situation and method that may accidentally } \\
\text { exploit a vulnerability. }\end{array}$ & CNSSI-4009 \\
\hline Trust & $\begin{array}{l}\text { The confidence one element has in another, that the second } \\
\text { element will behave as expected. }\end{array}$ & $\begin{array}{l}\text { Software } \\
\text { Assurance in } \\
\text { Acquisition: } \\
\text { Mitigating } \\
\text { Risks to the } \\
\text { Enterprise, } \\
\text { NDU, and } \\
\text { October 22, } \\
\text { 2008. }\end{array}$ \\
\hline Validation & $\begin{array}{l}\text { Confirmation (through the provision of strong, sound, objective } \\
\text { evidence) that requirements for a specific intended use or } \\
\text { application have been fulfilled. }\end{array}$ & ISO 9000 \\
\hline Verification & $\begin{array}{l}\text { Confirmation, through the provision of objective evidence, that } \\
\text { specified requirements have been fulfilled (e.g., an entity’s } \\
\text { requirements have been correctly defined, or an entity’s } \\
\text { attributes have been correctly presented; or a procedure or } \\
\text { function performs as intended and leads to the expected } \\
\text { outcome). }\end{array}$ & $\begin{array}{l}\text { CNSSI-4009, } \\
\text { ISO 9000, } \\
\text { adapted }\end{array}$ \\
\hline $\begin{array}{l}\text { Visibility (also } \\
\text { Transparency) }\end{array}$ & $\begin{array}{l}\text { A property of openness and accountability throughout the } \\
\text { supply chain. }\end{array}$ & $\begin{array}{l}\text { ISO/IEC } \\
\text { 27036-3 Draft, } \\
\text { adapted }\end{array}$ \\
\hline Vulnerability & $\begin{array}{l}\text { Weakness in an information system, system security } \\
\text { procedures, internal controls, or implementation that could be } \\
\text { exploited or triggered by a threat source. }\end{array}$ & $\begin{array}{l}\text { NIST SP 800- } \\
\text { 53; NIST SP } \\
800-53 A ; \text { NIST } \\
\text { SP 800-37; } \\
\text { NIST SP 800- } \\
60 ; \text { NIST SP } \\
800-115 ; \text { FIPS } \\
200 \\
\end{array}$ \\
\hline $\begin{array}{l}\text { Vulnerability } \\
\text { Assessment }\end{array}$ & $\begin{array}{l}\text { Systematic examination of an information system or product to } \\
\text { determine the adequacy of security measures, identify security } \\
\text { deficiencies, provide data from which to predict the } \\
\text { effectiveness of proposed security measures, and confirm the } \\
\text { adequacy of such measures after implementation. }\end{array}$ & $\begin{array}{l}\text { NIST SP 800- } \\
\text { 53A; CNSSI- } \\
4009\end{array}$ \\
\hline
\end{tabular}




\section{APPENDIX B ACRONYMS}

\begin{tabular}{|c|c|}
\hline $\mathrm{AO}$ & Authorizing Official \\
\hline CCR & Central Contractor Registry \\
\hline $\mathrm{CIO}$ & Chief Information Officer \\
\hline $\mathrm{CM}$ & Configuration Management \\
\hline CNCI & Comprehensive National Cybersecurity Initiative \\
\hline CNSS & Committee on National Security Systems \\
\hline CNSSI & Committee on National Security Systems Instruction \\
\hline $\mathrm{CO}$ & Contracting Officer \\
\hline COTS & Commercial off-the-shelf \\
\hline COTR & Contracting Officer’s Technical Representative \\
\hline CRADA & Cooperative Research and Development Agreement \\
\hline CWE & Common Weakness Enumeration \\
\hline DHS & Department of Homeland Security \\
\hline DISA & Defense Information Systems Agency \\
\hline DoD & Department of Defense \\
\hline DUNS & Dun and Bradstreet \\
\hline FAR & Federal Acquisition Regulation \\
\hline FDCC & Federal Desktop Core Configuration \\
\hline FIPS & Federal Information Processing Standards \\
\hline GITWG & Global Information Technology Working Group \\
\hline GOTS & Government off-the-shelf \\
\hline GSA & General Services Administration \\
\hline HAZMAT & Hazardous Materials \\
\hline IA & Information Assurance \\
\hline ICT & Information and Communication Technology \\
\hline
\end{tabular}


NIST IR 7622, Notional Supply Chain Risk Management Practices for Federal Information Systems

\begin{tabular}{|c|c|}
\hline IEC & International Electrotechnical Commission \\
\hline IP & Internet Protocol \\
\hline ISO & International Organization of Standardization \\
\hline IT & Information Technology \\
\hline ITL & Information Technology Laboratory (NIST) \\
\hline MTBF & Mean-time-between-failures \\
\hline NASPO & North American Security Products Organization \\
\hline NDIA & National Defense Industrial Association \\
\hline NIST & National Institute of Standards and Technology \\
\hline NSA & National Security Agency \\
\hline OEM & Original Equipment Manufacturer \\
\hline OMB & Office of Management and Budget \\
\hline OWASP & Open Web Application Security Project \\
\hline$R \& D$ & Research and Development \\
\hline RFI & Request for Information \\
\hline RFP & Request for Proposal \\
\hline RFQ & Request for Quote \\
\hline SCAP & Security Content Automation Protocol \\
\hline SCRM & Supply Chain Risk Management \\
\hline SDLC & System Development Life cycle \\
\hline SISO & Senior Information Security Officer \\
\hline SLA & Service-Level Agreement \\
\hline SOO & Statement of Objectives \\
\hline SOP & Standard Operating Procedure \\
\hline sOW & Statement of Work \\
\hline $\mathrm{T} \& \mathrm{E}$ & Test and Evaluation \\
\hline U.S. & United States (of America) \\
\hline
\end{tabular}


NIST IR 7622, Notional Supply Chain Risk Management Practices for Federal Information Systems

\begin{tabular}{|l|l}
\hline USGCB & United States Government Configuration Baseline
\end{tabular} 


\section{APPENDIX C REFERENCES}

American National Standards Institute/ North American Security Products Organization, ANSI/NASPO-SA-2008.

The Common Criteria Evaluation and Validation Scheme, Home Page 2008, URL: http://www.niap-ccevs.org/cc-scheme/, accessed December 5, 2011.

Department of Homeland Security, Information Technology Sector Baseline Risk Assessment, August 2009.

Software Assurance Community Resources and Information Clearinghouse Sponsored by the Department of Homeland Security Cyber Security Division, URL: http://buildsecurityin.uscert.gov, accessed December 5, 2011.

Department of Treasury, Office of Investment Security, Guidance Concerning the National Security Review Conducted by the Committee on Foreign Investment in the United States. Guidance, 2007, URL http://www.treasury.gov/Pages/Search.aspx?k=12012008.pdf, accessed November 7, 2011.

Committee on National Security Systems (CNSS) Instruction 4009, National Information Assurance (IA) Glossary, Revised April 2010, URL:

http://www.cnss.gov/Assets/pdf/cnssi_4009.pdf, accessed November 7, 2011.

Data and Analysis Center for Software (DACS), Software Development Security: A Risk Management Perspective. DoD Software Tech News, July 2005.

Department of Defense, Defense Information Systems Agency, Information Assurance Support Environment, Security Technical Implementation Guides Index Page, URL: http://iase.disa.mil/stigs/index.html, accessed December 5, 2011.

DHS National Cyber Security Division Security in the Software Lifecycle: Making Software Processes and the Software Produced by Them - More Secure, Section 3.5 and Appendix G: G.5. Draft Version 2.1, August 2006.

Acquisition Central, Sponsored by U.S. General Services Administration, Federal Acquisition Regulation, URL: https://www.acquisition.gov/far/, accessed November 7, 2011.

Global Information Technology Working Group (GITWG) of the Committee on National Security Systems (CNSS), Framework for Lifecycle Risk Mitigation for National Security Systems in the Era of Globalization: A Defense-in-Breadth Approach, CNSS Report CNSS145-06, November 2006.

Goertzel, Karen, et al., Software Security Assurance: A State of the Art Report (SOAR), Information Assurance Technology Analysis Center (IATAC) and Defense Technical Information Center (DTIC), July 2007.

Howard \& Lipner, 2007, chapters 9, 21. The Security Development Lifecycle, Microsoft Press.

Information Assurance Technology Analysis Center (IATAC), Data and Analysis Center for Software (DACS). Software Security Assurance: State-of-the-Art Report, Section 5.2.3.1, "Threat, Attack, and Vulnerability Modeling and Assessment." 
International Organization for Standardization, Systems and Software Engineering - System Life Cycle Processes, 2008, URL: http://www.iso.org/iso/catalogue_detail?csnumber=43562, accessed December 5, 2011.

International Organization for Standardization, Specification for Security management systems for the supply chain, 2007, URL:

http://www.iso.org/iso/iso_catalogue/catalogue_tc/catalogue_detail.htm?csnumber=44641.

International Organization for Standardization, Quality management systems: Requirements, 2008, URL:

http://www.iso.org/iso/iso_catalogue/catalogue_tc/catalogue_detail.htm?csnumber=46486.

Management Pilot Program. February 25, 2010. National Defense Industrial Association (NDIA), Engineering for System Assurance, September 2008, version 1.0, aka NDIA System Assurance Guidebook, http://www.acq.osd.mil/se/docs/SA-Guidebook-v1-Oct2008.pdf, accessed December 5, 2011.

National Defense University (NDU), Software Assurance in Acquisition: Mitigating Risks to the Enterprise, October 2008, URL: https://buildsecurityin.uscert.gov/swa/downloads/SwA_in_Acquisition_102208.pdf, accessed December 5, 2011.

National Institute of Standards and Technology, Federal Information Processing Standards Publication 140-2, Security Requirements for Cryptographic Modules, May 2001.

National Institute of Standards and Technology, Federal Information Processing Standards Publication 199, Standards for Security Categorization of Federal Information and Information Systems, February 2004.

National Institute of Standards and Technology, Federal Information Processing Standards Publication 200, Minimum Security Requirements for Federal Information and Information Systems, March 2006.

National Institute of Standards and Technology, Special Publication 800-30, Revision 1, Guide for Conducting Risk Assessments, September 2012.

National Institute of Standards and Technology, Special Publication 800-37, Revision 1, Guide for Applying the Risk Management Framework to Federal Information Systems: A Security Life Cycle Approach, February 2010.

National Institute of Standards and Technology, Special Publication 800-40, Revision 2, Creating a Patch and Vulnerability Management Program, November 2005.

National Institute of Standards and Technology, Special Publication 800-50, Building an Information Technology Security Awareness and Training Program, October 2003.

National Institute of Standards and Technology, Draft Special Publication 800-53, Revision 4, Recommended Security Controls for Federal Information Systems, February 2012.

National Institute of Standards and Technology, Special Publication 800-61, Revision 2, Computer Security Incident Handling Guide, August 2012.

National Institute of Standards and Technology, Special Publication 800-70, Revision 2, National Checklist Program for IT Products - Guidelines for Checklist Users and Developers, February 2011. 
National Institute of Standards and Technology, Special Publication 800-88, Guidelines for Media Sanitization, September 2006.

National Institute of Standards and Technology, Special Publication 800-100, Information Security Handbook: A Guide for Managers, October 2006.

National Institute of Standards and Technology, Special Publication 800-128, Guide for Security-Focused Configuration Management of Information Systems, August 2011.

Open Trusted Technology Provider Standard (O-TTPS) Mitigating Tainted and Counterfeit Products (now in snapshot form for review. Final expected Quarter 1, 2013.

Open Web Application Security Project (OWASP) Top 10 Project, 2007, URL:

http://www.owasp.org/index.php/Top_10_2007; accessed December 5, 2011.

OSSTMM - Open Source Security Testing Methodology Manual, http://www.isecom.org/osstmm/; accessed December 5, 2011.

A Guide to the Project Management Book of Knowledge, 2004, 3d ed. Washington D.C. Project Management Institute.

SafeCode, Fundamental Practices for Secure Software Development, October 8, 2008, URL, http://www.safecode.org/publications/SAFECode_Dev_Practices1108.pdf, accessed December 5, 2011.

Business for Social Responsibility: Perspectives on Information Management in Sustainable Supply Chains. http://www.bsr.org/reports/BSR_Info-ManagementSupply-Chains1.pdf; accessed September 2, 2011.

O'Connor, Christopher J. Transparency - what does it mean to the supply chain? From www.nexeraconsulting.com/60/File.aspx; accessed September 2, 2011. 


\section{APPENDIX D UMD ICT SUPPLY CHAIN STUDY}
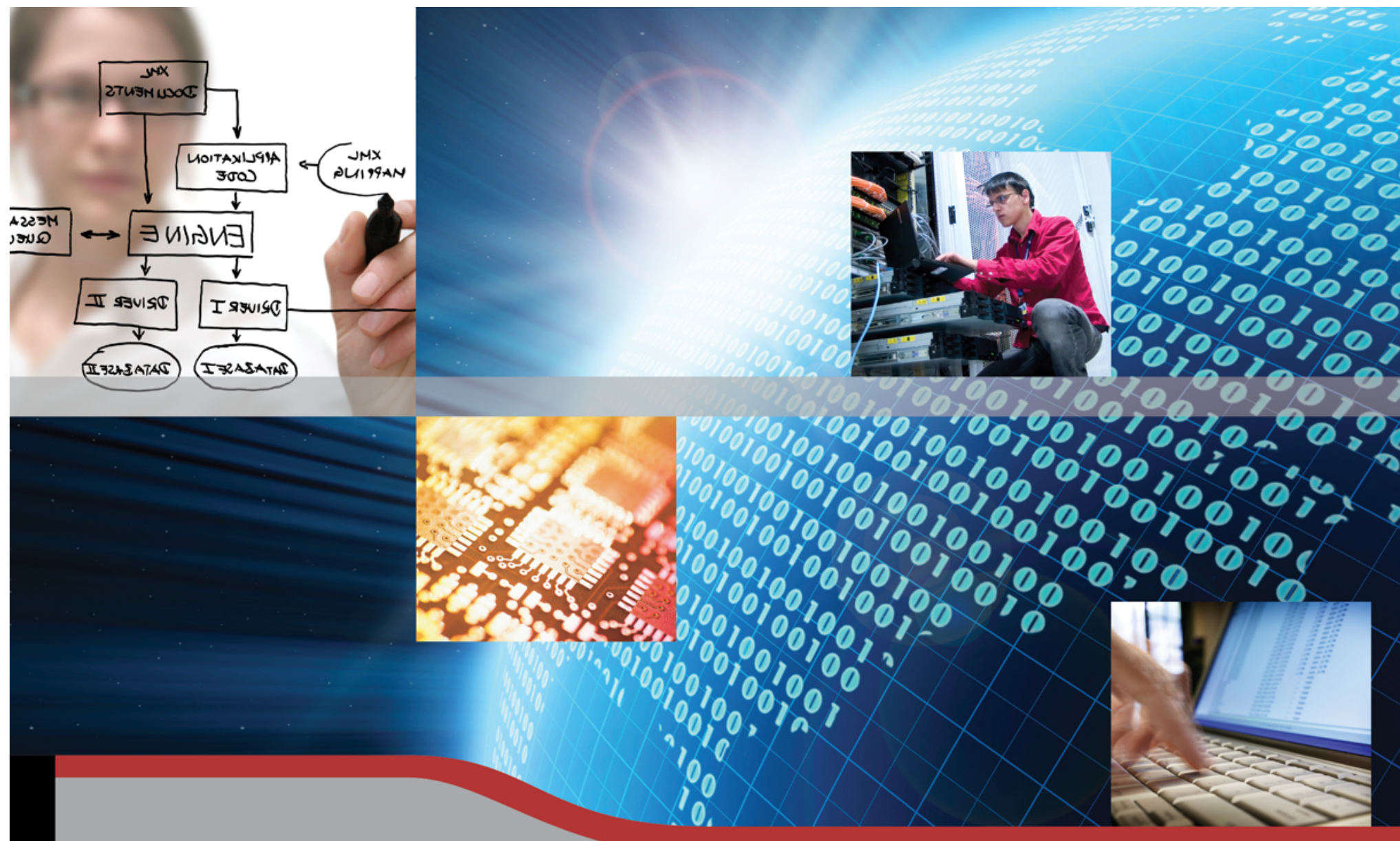

ASSESSING SCRM CAPABILITIES

AND PERSPECTIVES OF

THE IT VENDOR COMMUNITY:

TOWARD A CYBER-SUPPLY CHAIN

CODE OF PRACTICE

EXECUTIVE SUMMARY

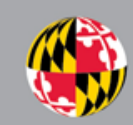

UN IVERSITY OF

\section{ROBERT H.SMITH}




\section{Executive Summary}

\section{Project Concept}

Initiative 11 (Supply Chain Risk Management) of the President's Comprehensive National Cybersecurity Initiative (CNCI) tasked the National Institute of Standards and Technology (NIST) with integrating lessons learned about cyber supply chain practices from various federal and industry initiatives into guidance for the federal enterprise and its industry partners.

NIST's Information Technology Lab awarded the Supply Chain Management Center of the Robert H. Smith School of Business at the University of Maryland in College Park a grant in support of the development of cyber supply chain best practice guidelines by NIST. In October, 2010, the Supply Chain Management Center began work on a project to develop, validate, and pilot test a research tool to assess the cyber-supply chain capabilities of the IT vendor community

This grant was aimed at addressing the fact that, at present, no readily identifiable assessment tool for industry exists that, if used extensively, could form the basis for a body of cyber-supply chain knowledge. Such a body of knowledge should contain data about current/planned corporate risk governance mechanisms, risk management audit/compliance activities, and benchmark practices against which to audit the capability and maturity of an organization.

This lack of a data-driven body of knowledge has been a major deficiency in the emerging discipline of Cyber-Supply Chain Risk Management (SCRM) and has constrained sound decision-making across government and the private sector. It was hoped that data gathered from this project could contribute to the formulation of a straw man SCRM Code of Practice that could advance the discipline and serve as a basis for ongoing dialogue between the public and private sectors.

\section{Project Methodology}

This project developed a tool to assess cyber-supply chain risk management capabilities by consolidating the collective inputs of the set of public and private actors engaged in supporting Initiative 11. The Department of Commerce (NIST and Bureau of Industry and Security, BIS), the Department of Homeland Security (DHS); the Department of Defense (DOD/CIO and DOD/NSA); and the Government Services Administration all provided formal inputs to design the assessment tool.

Representatives from Safe Code and Tech America’s SCRM sub-committee also contributed valuable inputs.

This tool was then distributed to and validated with a sample of vendors of IT systems, software, hardware, and services. Our target participants included: small to mediumsized IT vendors traditionally under-represented in IT surveys; Chief Information Officers/Chief Security Officers nationally and in the Washington DC region; and Directors of Supply Chain. 
There were 131 respondents who completed the survey from beginning to end. This means our survey response rate equaled the 1\% industry benchmark for Third Party IT Surveys (source: IDG List Services). This is especially impressive given the absence of official survey distribution; the length of time it takes to fill in the survey (approximately 30 minutes); the newness of the subject discipline; and the difficulties some companies reported in routing the survey to appropriate person(s) in the organization. An additional 159 respondents completed one or more sections of the survey. In total, 290 surveys were either partially or fully completed.

\section{Key Results}

\section{Respondent Characteristics}

Sample of research respondents reflects the fact that a number of different functional areas within firms are addressing the cyber-supply chain problem. As expected, professionals in IT, Telecom Services, and Information Security represent $63.4 \%$ of the sample, while professionals in Supply Chain Management, Procurement/Acquisition, and Risk Management accounted for an additional 36.6\% of the sample.

Our respondent sample is dominated by small companies with less than $\$ 20$ million in revenues, who represent $71 \%$ of the sample. By contrast, large companies with annual sales greater than $\$ 1$ billion represent $10.3 \%$ of the sample. We believe these results represent one of the first times survey research in the cyber-community has reached beyond Tier 1 product companies and prime vendor/ integrators.

Software was cited as a line of business by $48.6 \%$ of respondents; hardware by $31.4 \%$; telecom/data networking by $24.8 \%$.; and system integration services by $62.4 \%$ of the sample.

We found that 55.4\% of companies with annual sales of less than $\$ 20$ million reported working across four or more IT product/service areas. We interpret this to mean that even very small companies are increasingly focused on the development and deployment of systems across traditional product/service boundaries. It also implies a trend to increasing IT Sector-wide managerial complexity. This complexity invariably leads to higher risk profiles across all classes of firms as broader sets of supply chain assets/resources need to be continuously protected from cyber threats.

About $86.8 \%$ of respondents currently serve and plan to serve the federal government.

\section{Respondent SCRM Practices}

Research results demonstrated that there is significant difference between the extent of use of strategic risk management practices in the IT supply chain and more tactical or field level practices.

On the strategic side of risk management, $47.6 \%$ of the sample never uses a Risk Board or other executive mechanisms to govern enterprise risk; $46.1 \%$ never uses a shared risk registry/ an online database of IT supply chain risks; and 49.4\% never uses an integrated IT supply chain dashboard/control. Even if we take away the requirement of real time supply chain systems, $44.9 \%$ say they never use a supply chain risk management plan. 
The adaption of strategic risk management actions that does occur seems to be the province of big companies: the greater the company revenue, the greater the propensities to always or often use strategic risk measures. Only $17 \%$ of the smallest companies said they always or often use real time dashboards; compared to $50 \%$ of the biggest companies. Only $7 \%$ of smallest companies used on line risk registries always or often, compared to $63.2 \%$ of the biggest companies.

There appears to be a huge gulf between the smallest companies and the biggest companies who appear to have more real time information access and who tend to deploy that information as part of sense and respond cyber supply chain operations. One contributory factor might be that bigger companies are more risk and liabilitysensitive. Additionally, they can invest more in sophisticated threat analysis techniques and in implementing enterprise-wide risk governance programs. On the other hand, more tactical, narrowly focused cyber-SCRM practices are used much more often or always. Indeed, $67.3 \%$ of the sample often or always do personnel security reviews; $57.3 \%$ often or always use perimeter detection systems; and $49.4 \%$ often or always use a standardized process for pre-qualifying suppliers.

These more tactical defense mechanisms are indicative of single enterprise protection mechanisms, which may, in concert with other activities, provide some measure of defense in depth. However, they are not implemented with defense in breadth in mind; and can be perceived to lack the necessary executive management buy-in to influence customers and suppliers.

This deficiency of extended enterprise SCRM was further highlighted by the lack of collaboration among key actors within a supply chain evidenced in our sample:

Companies report little or no collaboration with key suppliers: for example, 51.5\% of companies in the sample provide no access to planning systems for their suppliers. Even the most widely accepted SCRM practice "jointly monitoring current changes, incidents, exceptions and disruptions" was only extensively used by $28.8 \%$ of the sample, less than a third of the respondents

The results seem clear: there is an overall lack of corporate emphasis on strategic defense in breadth and extended enterprise management of supply chain risks. Companies of all sizes tend to focus heavily on field-level technical practices.

\section{Attractiveness Of Code Of Practice Elements}

Finally, we asked respondents to rate the attractiveness of items for potential inclusion into a Code of Practice for IT Vendors that seeks to improve supply chain risk management. Attractiveness was defined as an index score blending both operational effectiveness and feasibility of implementation.

We found a straightforward correlation: the greater the corporate revenue, the greater the corporate support for Code of Practice elements that are strategic in scope, e.g. Risk Boards and Risk Plans. Also, the largest companies are especially interested in obtaining government-designated favored supplier status: $91.7 \%$ of them rated priority 
status as the most effective/highly effective potential Code element as compared to $57.2 \%$ of the smallest companies.

There was across the board support for inclusion of elements that "provide additional contractual resources for SCRM" and "streamline regulations" into a Code of Practice.

On one hand, there is this desire on the part of companies of all sizes for streamlined, less burdensome or obtuse regulations and less government intervention. Yet, on the other hand, we found widespread support for government actions and information to clarify:

- What is the real threat?

- What are priority SCRM practices?

- How can expanded use of those practices by companies tie into to real corporate benefits, such as reduction of liability and overall compliance costs?

Successfully answering the latter question is especially crucial for successful adoption of a Cyber-Supply Chain Code of Practice

\section{Conclusions}

There are a few critical conclusions that can be drawn from our research:

\section{Both Large \& Small Companies Seriously Under-Manage Cyber-SCRM}

Both small and big companies increasingly work across hardware and software development, network management, and systems integration boundaries and have multiple product/service offerings. In other words, companies of all sizes have become complex supply chains with highly dispersed assets and resources.

Given the challenge of escalating cyber supply chain complexity, the current state of corporate SCRM capability seems inadequate for managing systemic risk. The deficiency of cyber supply chain-wide risk governance strategies; the stove piped nature of risk management, cyber security and supply chain functions within corporations of all sizes; and an ongoing industry orientation toward narrowly focused process-models and technical solutions- all present serious impediments to effective SCRM in the current era.

\section{Both Large \& Small Companies Can Be Incentivized To Improve Cyber-}

\section{$\underline{\text { SCRM }}$}

Small companies are highly motivated to get and use government cyber-supply chain risk management practice guidelines. This helps them to win business with the federal acquirer community; as well as to conserve scarce dollars and management time that they would otherwise have to spend themselves on cyber security compliance research. 
Although their cyber security units are not well integrated into or supported by corporate risk management programs, big companies are nevertheless highly sensitive to managing regulatory demands for risk assurance and seeking to limit their own corporate liability. This sensitivity to risk and the search for shielding mechanisms have certainly been major motivating factors in developing Codes of Practice in other non-IT industries, such as the chemical industry (Code of Responsible Care) and the consumer products industry (Supply Chain Operations Reference Model).

Key challenges going forward include identifying and deploying the best incentive strategies available to assure maximum diffusion of and compliance with a core set of cyber-SCRM best practices. Such strategies might include: defining liability limits in cyber-supply chains; encouraging industry risk pooling to free up company-level capital reserves currently held for future liability claims or uninsurable risks; and implementing legislative/regulatory streamlining initiatives that ease industry compliance costs while building assurance levels.

Only by going forward together, can government and industry master the extreme challenges of cyber-SCRM in a global era. 